Teste de Composição de Web Services: Uma Estratégia Baseada em um Modelo de Teste de Programas Paralelos 

SERVIÇO DE PÓS-GRADUAÇÃO DO ICMC-USP

Data de Depósito: 19 de março de 2008

Assinatura:

\title{
Teste de Composição de Web Services: Uma Estratégia Baseada em um Modelo de Teste de Programas Paralelos
}

\author{
André Takeshi Endo
}

Orientador: Prof. Dr. Adenilso da Silva Simão

Dissertação apresentada ao Instituto de Ciências Matemáticas e de Computação - ICMC/USP, como parte dos requisitos para obtenção do título de Mestre em Ciências Ciências de Computação e Matemática Computacional.

USP - São Carlos

Março/2008 

Aos meus pais, Angelina e José e meu irmão Gustavo. 



\section{Agradecimentos}

- A Deus, por me dar oportunidade, capacidade e vontade para realizar este trabalho.

- A toda minha família, em especial, meus pais Angelina e José e meu irmão Gustavo. Palavras não são suficientes para expressar o quanto amo, admiro e tenho orgulho de vocês.

- Ao Prof. Dr. Adenilso da Silva Simão, pela amizade, conhecimento e confiança na orientação deste trabalho.

- Aos amigos do LABES/ICMC, pelo companheirismo e pela hora do café. Mesmo correndo o risco de esquecer alguém, vou "tentar" listá-los a seguir em ordem alfabética: Abe, Alessandra, André Freire, Andrézinho, Camila, Dalcimar, Débora, Edson, Eduardo, Erika, Falcão, Felipe, Gambi, Ivan, Jarbas, KLB, Kika, Jaú, Lúcio, Luíza, Marcão, Marcela, Marcelo, Marllos, Mateus, Matrix, Maycon, Merley, Nardo, Nersô, Otávio, Paula Donegan, Paula Herculano, Resina, Taty, Tiago, Tott, Valdecir, Vanessa, Vânia, Vascão e Viviane. Obrigado a todos!

- Aos professores tanto da graduação quanto do mestrado que contribuíram para minha formação, em especial, os professores Renata, Simone, Paulo, Masiero, Maldonado, Rosely, Guilherme, Turine, Craveiro, Marco Aurélio e Edna.

- Aos funcionários do ICMC, pelo constante auxílio.

- A todos os meus amigos, em especial aos "malacabados", ao seinenkai, aos amigos de CG e aos companheiros de república. Malacabados: Jerinho, Eduardo, Eder, Rufino, Bicão, Baiano, Slash, Rogério, Hugão, Dércio, Eltinho e Angelo. Seinenkai: Japa, Tiaguinho, Goboy, Renato, Bento, Koiti, Paulo Yukio, Bentinho, Mie, Rosi, Massumi, Jun Go, Rato, Santoro, Mateus etc. Amigos de CG: Cersão, Gláucia, Everton, Dotta, Bichano, Marcelo e Joseph. República: Japa, Dotta, Carlão, Júlio, Otávio e Max. Provavelmente esqueci de alguém, mas com certeza todos estão gravados em minhas melhores lembranças.

- A todas as pessoas que contribuíram de alguma forma para a realização deste trabalho.

- À FAPESP e à CAPES, pelo apoio financeiro. 

Eb Services constituem uma tecnologia emergente utilizada para disponibilização de serviços na Web. Devido aos complexos processos de negócio existentes, esses serviços são combinados para que operem seguindo um fluxo de trabalho. Esse processo é chamado de composição de Web Services. Como no processo de desenvolvimento de um software tradicional, a atividade de teste é fundamental no processo de desenvolvimento da composição de Web Services. Neste trabalho é proposta uma estratégia de teste para a composição de Web Services, em que especificações de composições são transformadas para um modelo de teste de programas paralelos baseados em passagem de mensagens. É proposto o conceito de grupos de elementos requeridos para melhorar a cobertura dos critérios. Uma ferramenta de apoio à estratégia de teste foi desenvolvida. Alguns estudos experimentais para avaliar a aplicabilidade da estratégia proposta também são apresentados. Além disso, é proposto um método que utiliza redes de Petri para eliminar sincronizações não-executáveis no envio e recebimento de mensagens. 

Eb Services constitute an emerging technology for deploying services in the Web. Due to the complex business processes, these services are combined to operate, following a workflow. This process is named Web Services Composition. As in the development process of a traditional software, the testing activity is fundamental in the development process of Web Services Composition. This work proposes a test strategy for Web Services Composition, in that composition specifications are transformed into a test model of message-passing parallel programs. The concept of required elements groups is proposed to improve the criteria coverage. A tool that supports the test strategy was developed. Some experimental studies for evaluating the applicability of proposed strategy are also presented. Furthermore, it presents a method that uses Petri Nets to eliminate non-executable synchronizations in the sending and receiving of messages. 

Resumo $\quad$ v

$\begin{array}{lll}\text { Abstract } & \text { vii }\end{array}$

1 Introdução $\quad 1$

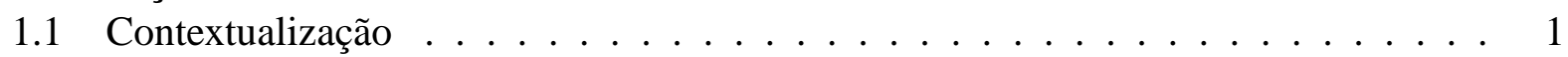

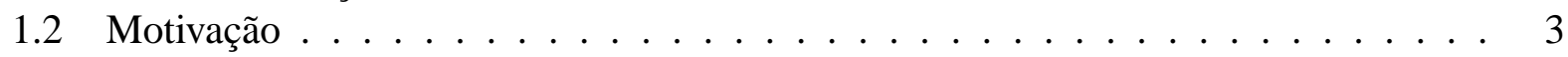

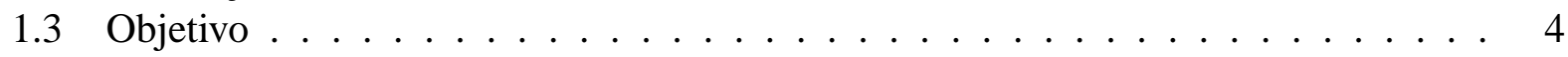

1.4 Organização do Trabalho . . . . . . . . . . . . . . . . . . . . . 4

2 Composição de Web Services $\quad 7$

2.1 Considerações Iniciais . . . . . . . . . . . . . . . . . . . . 7

2.2 Web Services . . . . . . . . . . . . . . . . . . . . . 7

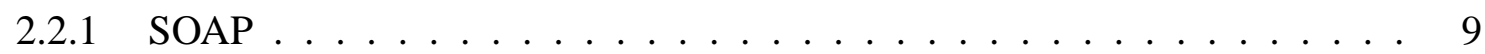

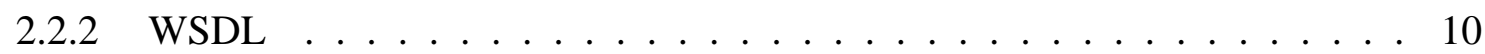

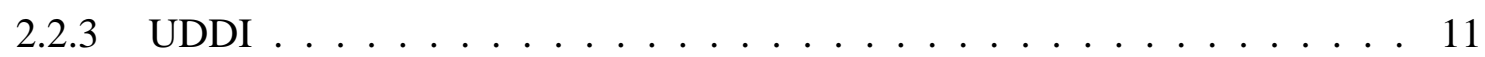

2.3 Composição de Web Services . . . . . . . . . . . . . . . . . . . . . . . . 11

2.3.1 Paradigmas de Composição de Web Services . . . . . . . . . . . . . . . . . 12

2.3.2 Abordagens para Composição de Web Services . . . . . . . . . . . . . . . . . 14

2.4 Exemplo de Uso . . . . . . . . . . . . . . . . . . . . . . . . . . . . . . . . . . . . . . . . . . . . . . . . . . .

2.5 Considerações Finais . . . . . . . . . . . . . . . . . . 23

3 Teste de Software $\quad 25$

3.1 Considerações Iniciais . . . . . . . . . . . . . . . . . . . . 25

3.2 Fundamentos do Teste de Software . . . . . . . . . . . . . . . . . . . . . . . . . . . . .

3.3 Técnicas de Teste Funcional . . . . . . . . . . . . . . . . . . . . . . . . . . . . . . . . . . .

3.4 Técnicas de Teste Estrutural . . . . . . . . . . . . . . . . . . . . . . . . 29

3.5 Técnicas de Teste Baseado em Erros . . . . . . . . . . . . . . . . . . . . 33

3.6 Técnicas de Teste Baseado em Estados . . . . . . . . . . . . . . . . . . . . . 33

3.7 Teste de Programas Paralelos . . . . . . . . . . . . . . . . . . . . 34

3.8 Comparação entre Critérios de Teste . . . . . . . . . . . . . . . . . . . . . . . . . . . . . . 35

3.9 Ferramentas de Teste de Software . . . . . . . . . . . . . . . . . . 36

3.10 Considerações Finais . . . . . . . . . . . . . . . . . . 38 
4 VV\&T para Composição de Web Services $\quad 39$

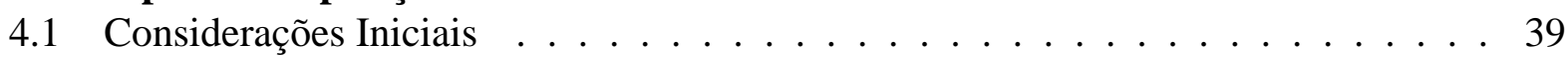

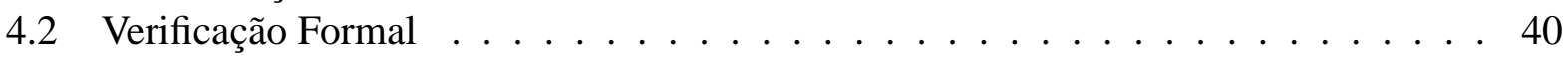

4.2.1 Redes de Petri . . . . . . . . . . . . . . . . . . 40 40

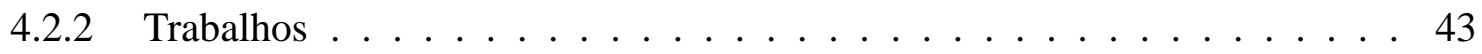

4.3 Técnicas de Teste . . . . . . . . . . . . . . . . . . . 45

4.4 Considerações Finais . . . . . . . . . . . . . . . . . . . . 51

5 Estratégia de Teste para Composição de Web Services 53

5.1 Considerações Iniciais . . . . . . . . . . . . . . . . . . . 53

5.2 Modelo PCFG . . . . . . . . . . . . . . . . . . . . . . 54

5.3 Transformação . . . . . . . . . . . . . . . . . . 57

5.3.1 Exemplo de Aplicação . . . . . . . . . . . . . . . . . . . . . 62

5.3.2 Critérios de Teste de CWS . . . . . . . . . . . . . . . 63

5.4 Grupos de Elementos Requeridos . . . . . . . . . . . . . . . . . . . 65

5.5 Eliminação de Arcos Não-Executáveis Usando Redes de Petri . . . . . . . . . . . 67

5.5.1 Caracterização do Problema . . . . . . . . . . . . . . . . 68

5.5 .2 Método . . . . . . . . . . . . . . . . . . 69

5.6 Ferramenta ValiBPEL-Web . . . . . . . . . . . . . . . 77

5.6 .1 Ferramenta ValiPar . . . . . . . . . . . . . . . . 77

5.6 .2 Projeto da Ferramenta . . . . . . . . . . . . . . . 78

5.6 .3 Aspectos de Implementação . . . . . . . . . . . . . . . . . . . . . . . . . . . . . . . . . . 87

5.6.4 Processo de Teste da Ferramenta . . . . . . . . . . . . . . . . . . . 87

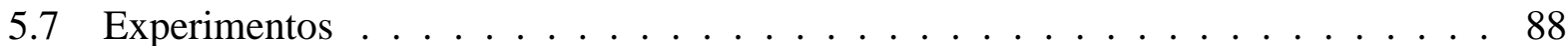

5.7 .1 Exemplos . . . . . . . . . . . . . . . . . 89

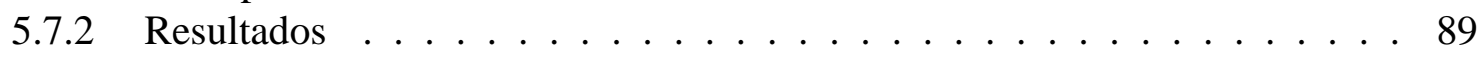

5.8 Considerações Finais . . . . . . . . . . . . . . . . . . . 91

6 Conclusão $\quad 93$

6.1 Contribuições . . . . . . . . . . . . . . . . . . . . 93

6.2 Dificuldades e Limitações . . . . . . . . . . . . . . . . . . . . . . . . . . . . 94 94

6.3 Trabalhos Futuros . . . . . . . . . . . . . . . . . . . . . . 94

$\begin{array}{lll}\text { A Códigos BPEL } & 111\end{array}$ 


\section{Lista de Figuras}

2.1 Arquitetura de WS. . . . . . . . . . . . . . . . . . . . . 9

2.2 Pilha de protocolos WS. . . . . . . . . . . . . . . . . 9

2.3 Orquestração de WSs. . . . . . . . . . . . . . . . . . . . . . . . . 13

2.4 Coreografia de WSs. . . . . . . . . . . . . . . . . . . . . . . . . . . . . . . . . . . . . . . . . .

2.5 Web Service implementado como um processo BPEL. . . . . . . . . . . . . . . 16

2.6 Processo de negócio NiceJourney. . . . . . . . . . . . . . . . . . . . . . . . . . . 19

2.7 NiceJourney modelado na notação gráfica da ferramenta ActiveBPEL Designer. . . 22

3.1 Código do Identifier.c. . . . . . . . . . . . . . . . . . . 30

3.2 Grafo do Identifier.c. . . . . . . . . . . . . . . . . . . . 31

3.3 Grafo Def-Uso do Identifier.c. . . . . . . . . . . . . . . . . . . 32

4.1 Exemplo de uma rede de Petri (Peterson, 1981) . . . . . . . . . . . . . . . . . 42

4.2 Árvore de cobertura para rede de Petri da Figura 4.1 (Simão, 2004). . . . . . . . . . 43

4.3 Modelo de composição e arquitetura de teste (Li et al., 2005) . . . . . . . . . . . . . 46

4.4 arquitetura de teste BPEL (Mayer e Lübke, 2006) . . . . . . . . . . . . . . . . 47

4.5 Group Testing de múltiplos WS compostos (Tsai et al., 2004). . . . . . . . . . . . 48

4.6 Visão geral do método proposto por García-Fanjul et al. (2006). . . . . . . . . . . . 49

4.7 Arquitetura de múltiplos observadores (Benharref et al., 2006) . . . . . . . . . . . . 49

4.8 Fluxo de trabalho do método proposto por Yan et al. (2006). . . . . . . . . . . . . 50

4.9 Processo para o método de geração proposto por Yuan et al. (2006). . . . . . . . . 50

4.10 Taxonomia de defeitos combinada com efeitos observados. . . . . . . . . . . . 51

5.1 PCFG para o programa GCD (Vergilio et al., 2005). . . . . . . . . . . . . 57

5.2 Transformação para as atividades Assign, Throw, Wait, Empty e ReThrow. . . . . . 58

5.3 Transformação para as atividades Sequence e Flow. . . . . . . . . . . . . . . . . 58

5.4 Transformação para a atividade If. . . . . . . . . . . . . . . . . . . . . . 59

5.5 Transformação para as atividades While e ForEach. . . . . . . . . . . . . . . . 59

5.6 Transformação para a atividade RepeatUntil. . . . . . . . . . . . . . . . . . . 60

5.7 Transformação para as atividades Receive e Reply. . . . . . . . . . . . . . . . . . 60

5.8 Transformação para a atividade Invoke. . . . . . . . . . . . . . . . . 61

5.9 Transformação para a atividade Pick. . . . . . . . . . . . . . . . . . 61 . . . . . . . . 63

5.10 Exemplo de aplicação . . . . . . . . . . . . . . . . . . . . 63

5.11 Problema da atividade Pick. . . . . . . . . . . . . . . . 66

5.12 Exemplo de pares não-executáveis. . . . . . . . . . . . . . . . . . . 69

5.13 Exemplo GCD. . . . . . . . . . . . . . . . . . . 72 
5.14 Rede de Petri para o exemplo 1. . . . . . . . . . . . . . . . . 73

5.15 Árvore de cobertura para a rede de Petri da Figura 5.14 . . . . . . . . . . . . . . 74

5.16 Resultados obtidos com a execução do método proposto para o exemplo da Figura

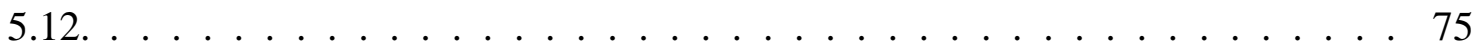

5.17 Resultados obtidos com a execução do método proposto para o exemplo GCD. . . . 76

5.18 Arquitetura da Ferramenta ValiPar (Hausen, 2005) ～. . . . . . . . . . . . . 77

5.19 Diagrama de Classes para os submódulos GraphGen e Instrumentor. . . . . . . . . 79

5.20 Diagrama de Classes para os objetos gerenciados pelo módulo Web Interface. . . . 80

5.21 Tela de autenticação. . . . . . . . . . . . . . . . . . . 81

5.22 Tela de listagem de usuários. . . . . . . . . . . . . . . . . . . 81

5.23 Telas de criação de um projeto. . . . . . . . . . . . . . . . . . . 82

5.24 Tela de listagem de projetos. . . . . . . . . . . . . . . . . . . 83

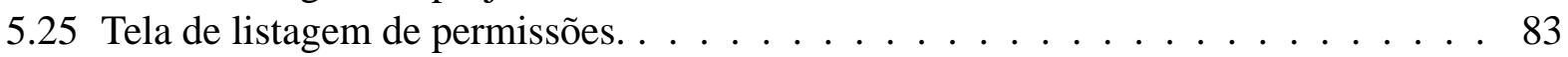

5.26 Tela de abertura de um projeto. . . . . . . . . . . . . . . . . . 84

5.27 Tela de Sessão de Teste. . . . . . . . . . . . . . . . . . . . . . . . . 84

5.28 Tela de visualização dos rastros de execução do caso de teste. . . . . . . . . . . . . 85

5.29 Telas de visualização da cobertura dos critérios em uma determinada sessão de teste. 85

5.30 Telas de visualização da cobertura para um critério específico. . . . . . . . . . . . 86

5.31 Arquitetura da Ferramenta ValiBPEL-Web. . . . . . . . . . . . . . . 88 


\section{Lista de Tabelas}

2.1 atividades da BPEL $\ldots \ldots \ldots \ldots \ldots \ldots \ldots \ldots$

5.1 Tabela das marcações para a árvore de cobertura. . . . . . . . . . . . . . . 74

5.2 Classes do Módulo GraphGen . . . . . . . . . . . . . . . . . . . . . 79

5.3 Classes do Módulo Instrumentator . . . . . . . . . . . . . . . . . . . . 80

5.4 Tabela de Exemplos. . . . . . . . . . . . . . . . . . . . . . . 90

5.5 Tabela de nós e arcos. . . . . . . . . . . . . . . . . . . . . . . . 90

5.6 Comparação do número de elementos do critério todos-arcos-s. . . . . . . . . . . . 90

5.7 Número de Elementos Requeridos para critérios de cobertura. . . . . . . . . . . . 91 

AM - Análise de Mutantes

API - Application Programming Interface

B2B - Business-to-Business

B2C - Business-to-Consumer

BFG - BPEL Flow Graph

BPEL, WS-BPEL - Web Services Business Process Execution Language

BPEL4WS - Business Process Execution Language for Web Services

BPR - Business Process Archive File

COS - Computação Orientada a Serviços

CWS - Composição de Web Services

DAML-S - DARPA Agent Markup Language Services

DOM - Document Object Model

EIAG - Event InterActions Graph

GFC - Grafo de Fluxo de Controle

HTTP - HyperText Transfer Protocol

IEEE - Institute of Electrical and Electronics Engineers

JSP - JavaServer Pages

MEF - Máquina de Estados Finitos

MPI - Message Passing Interface

OASIS - Organization for the Advancement of Structured Information Standards

OO - Orientação a Objetos

OWL - Ontology Web Language

OWL-S - Ontology Web Language for Services

PCFG - Parallel Control Flow Graph

PPFG - Parallel Program Flow Graph

PVM - Parallel Virtual Machine

RPC - Remote Procedure Call

SOA - Service Oriented Architecture

SOAP - Simple Object Access Protocol

UDDI - Universal, Discovery, Description and Integration

VV\&T - Verificação, Validação e Teste

W3C - World Wide Web Consortium

WS - Web Service

WS-BPEL - Web Services Business Process Execution Language

WS-CDL - Web Services Choreography Description Language 
WSCI - Web Service Choreography Interface

WSDL - Web Services Description Language

WSGT - Web Services Group Testing

XCFG - Extended Control Flow Graph

XML - eXtensible Markup Language 


\section{CAPÍTULO \\ 1 \\ Introdução}

\subsection{Contextualização}

A Arquitetura Orientada a Serviço (Service-Oriented Architecture - SOA) representa um modelo arquitetural em que as funcionalidades são decompostas em unidades distintas (serviços), com o objetivo de alcançar baixo grau de acoplamento entre os serviços. Esses serviços podem ser distribuídos pela rede e podem ser combinados ou reusados para criar aplicações de negócios (Newcomer, 2002; Newcomer e Lomow, 2004). A Computação Orientada a Serviços (COS) (Papazoglou e Georgakopoulos, 2003) é um paradigma que utiliza serviços para o desenvolvimento de aplicações. A COS objetiva fornecer bases para construir software pela montagem independente de serviços (Bucchiarone et al., 2007).

A incompatibilidade com sistemas legados, o alto custo e complexidade na integração de sistemas heterogêneos e a necessidade de existir interoperabilidade entre sistemas sempre foram desafios presentes na computação (Offutt e Xu, 2004). Tentando resolver esses problemas, empresas como Microsoft, HP, IBM, Sun Microsystem, entre outras, vêm trabalhando para o desenvolvimento de uma tecnologia denominada Web Services (WSs) (W3C, 2002), que segue o modelo da SOA. WSs são aplicações com baixo grau de acoplamento que são disponibilizados como serviços, e que podem facilmente ser consumidos por outras aplicações por meio da Internet. WSs representam a aplicação na Web do paradigma COS (Papazoglou e Georgakopoulos, 2003). Com a utilização de WSs, aplicações em diferentes plataformas e implementadas em linguagens diversas comunicam-se entre si por meio de protocolos padrões da Web, tais como Simple Object Access Protocol (SOAP), Web Services Description Language (WSDL) e Universal, Discovery, Description and Integration (UDDI). 
Para resolver problemas mais complexos, vários WSs podem ser combinados de maneira colaborativa, seguindo um fluxo de trabalho, para a criação de um novo WS. Esse processo é denominado Composição de Web Services (CWS) e pode ser realizado de duas formas (Peltz, 2003; Juric, 2005): Orquestração e Coreografia. A orquestração possui um coordenador central que tem o controle sobre os WSs envolvidos na composição. Já na coreografia, cada WS possui o conhecimento de como se comportar na composição. Dentre as linguagens utilizadas para especificar CWS, a WS-BPEL (Web Services Business Process Execution Language) (Jordan et al., 2007), ou simplesmente BPEL, se destaca por sua adoção pela indústria e por fornecer mecanismos para definição e execução de uma composição.

O desenvolvimento de uma CWS, tal como ocorre com o desenvolvimento de software em geral, deve ser conduzido de forma rigorosa e sistemática, buscando atender a padrões de qualidade tanto do ponto de vista do usuário quanto do ponto de vista do desenvolvedor. Ao longo do processo de desenvolvimento de software, diversas atividades, coletivamente chamadas de atividades de Verificação, Validação e Teste (VV\&T), são conduzidas para a garantia da qualidade. Dentre essas atividades, a atividade de teste é de grande importância como recurso para identificar falhas em atender aos requisitos do sistema. De um modo geral, a atividade de teste é um processo de executar um programa com a intenção de encontrar erros (Myers et al., 2004). Por ser uma das atividades mais onerosas do desenvolvimento de software, estudos teóricos e empíricos da comunidade de teste vêm sendo conduzidos, buscando identificar formas eficazes e eficientes de se aplicar os recursos disponíveis.

Além de apresentar características comuns ao software tradicional, a CWS possui natureza distribuída e comportamento assíncrono (García-Fanjul et al., 2006). Isso torna o teste de CWS mais complexo. Características como distribuição, sincronização e concorrência precisam ser consideradas durante a atividade de teste. Trabalhos para o teste de unidade em CWS especificadas em BPEL vêm sendo desenvolvidos pela academia (Li et al., 2005; Mayer e Lübke, 2006; Yan et al., 2006). Na CWS também pode ser aplicado o teste de sistema, considerando fatores como recuperação de falhas, segurança, estresse e desempenho.

Este trabalho de mestrado está inserido no contexto de teste de integração, que busca encontrar erros relacionados às interfaces das unidades. Nessa perspectiva é preciso que o desenvolvedor da composição tenha acesso à implementação dos WSs participantes. A CWS troca mensagens com os WSs de forma semelhante ao paradigma de programação paralela baseada em passagem de mensagens. Um programa paralelo consiste em um conjunto de threads cooperativas que podem executar em paralelo. Para executar um objetivo em comum, essas threads se comunicam pelo acesso a variáveis compartilhadas e/ou troca de mensagens. Programas paralelos apresentam algumas características que tornam a atividade de teste mais complexa, como não-determinismo, concorrência, sincronização, aspectos de comunicação, entre outros (Vergilio et al., 2005). Assim, a CWS pode ser vista como a interação entre vários WSs que acontecem pela troca de mensagens entre os participantes da composição. Logo, a aplicação de técnicas de teste para programas paralelos no contexto de CWS é válida. Os trabalhos de Yang et al. (1998); Vergilio et al. (2005) 
propõem extensões para o Grafo de Fluxo de Controle (GFC) (Rapps e Weyuker, 1985), de forma que aspectos de programas paralelos sejam representados pelos modelos. No trabalho de Vergilio et al. (2005) são propostos o modelo Parallel Control Flow Graph (PCFG) e critérios de teste para programas paralelos baseados em troca de mensagens. Nesse tipo de programa, o surgimento de sincronizações não-executáveis no envio e recebimento de mensagens é um problema que dificulta a realização sistemática dos testes.

\subsection{Motivação}

Atualmente, muitas aplicações são desenvolvidas utilizando WSs, sendo esses vitais para o funcionamento correto dessas novas aplicações. Testar WSs com eficiência e eficácia tem se tornado um importante fator para o sucesso da aplicação dessa tecnologia no desenvolvimento de software (Mei e Zhang, 2005). WSs não podem ser testados como um software tradicional, porque apresentam algumas particularidades. Os WSs não possuem uma interface de usuário e são aplicações distribuídas que podem apresentar diversos comportamentos durante sua execução (Offutt e $\mathrm{Xu}, 2004)$. Essas características incentivam estudos mais detalhados em como realizar testes de WSs.

O teste de CWS é uma área pouco explorada e com poucas ferramentas de apoio. No contexto deste trabalho, poucos estudos foram encontrados sobre teste de CWS. Segundo Bucchiarone et al. (2007), enquanto muito esforço vem sendo gasto em especificação de WSs e de CWS, somente recentemente estudos sobre VV\&T para WSs e CWS vêm sendo desenvolvidos. Pode-se concluir que poucos trabalhos tratam o teste de CWS como objeto central de estudo. Isso motiva pesquisar detalhadamente o teste de CWS e investigar mecanismos de teste que sejam aplicáveis/adaptáveis para a CWS.

Este trabalho de mestrado contribui para o desenvolvimento do teste de CWS. Na CWS, há um maior foco em verificação por model checking, com poucos trabalhos que utilizam conceitos tradicionais da área de teste de software, tais como critérios de teste, análise de adequação, cobertura e geração baseada em modelos. Por exemplo, segundo Tsai et al. (2002b), teste de WSs é equivalente a um teste de caixa-preta, onde as especificações estão disponíveis, mas o projeto e o código não. Além disso, segundo Li et al. (2005), o teste para CWS pode ser visto como um teste de caixa-branca. Dessa forma, uma grande quantidade de técnicas e critérios de teste para software tradicional pode ser investigada no contexto da CWS.

WSs apresentam características únicas que aumentam a complexidade na realização dos testes (Canfora e Di Penta, 2006). Muitas abordagens de teste consolidadas também podem ser aplicadas no contexto de WSs. Entretanto, a natureza dinâmica e adaptativa de WSs faz com que muitas técnicas não possam ser aplicadas diretamente (Canfora e Di Penta, 2006). Segundo Bucchiarone et al. (2007), embora técnicas e metodologias de teste existentes possam ser reutilizadas, a disciplina de teste de CWS ainda está imatura, possuindo diversos aspectos que precisam ser tratados. 
Vale ressaltar o interesse constante por parte da academia que vem realizando inúmeros encontros sobre pesquisa com SOA e WSs com destaque para as conferências IEEE International Conference on Web Services (ICWS) ${ }^{1}$, IEEE International Conference on Services Computing $(\mathrm{SCC})^{2}$, International Conference On Service Oriented Computing (ICSOC) ${ }^{3}$ e IEEE International Workshop on Service-Oriented System Engineering (SOSE) ${ }^{4}$. Revistas sobre o assunto são também publicadas como a IEEE Transactions on Services Computing ${ }^{5}$ e a International Journal of Web Services Research (JWSR) ${ }^{6}$. Pretende-se enviar resultados deste trabalho para alguma dessas conferências ou revistas.

\subsection{Objetivo}

O objetivo deste trabalho é propor uma estratégia que aplica um modelo de teste de programas paralelos para o teste de Composição de Web Services representada em BPEL. A finalidade dessa aplicação é fornecer mecanismos para analisar a cobertura dos testes. É realizada uma transformação de composições especificadas em BPEL para o modelo de teste. Ao realizar a transformação, os critérios de teste do modelo de teste são instanciados para o teste de CWS. Alguns experimentos foram realizados para avaliar a aplicabilidade da estratégia. Um conceito, chamado grupo de elementos requeridos, também é proposto para melhorar a cobertura dos critérios de teste.

Como apoio à estratégia proposta, uma ferramenta Web foi definida e implementada para automatizar o processo de teste. Por fim, é proposto um método que utiliza redes de Petri para eliminar sincronizações não-executáveis no envio e recebimento de mensagens.

\subsection{Organização do Trabalho}

Esta dissertação está organizada da seguinte maneira. No Capítulo 2 são apresentados conceitos sobre Web Services e Composição de Web Services. São apresentados os paradigmas para Composição de Web Services e suas abordagens. Um exemplo que ilustra a Composição de Web Services também é apresentado. No Capítulo 3 é apresentado o teste de software. São abordados os fundamentos, técnicas, critérios, comparação de critérios e ferramentas presentes no teste de software. No Capítulo 4 são apresentados os principais trabalhos que aplicam técnicas de Verificação, Validação e Teste para a Composição de Web Services. No Capítulo 5, a estratégia de teste para CWS proposta neste trabalho é apresentada. O conceito de grupos de elementos requeridos, utilizado para melhorar a cobertura de critérios, é apresentado. É apresentado um método para eliminar sincronizações não-executáveis em um modelo de teste para programas paralelos baseados

\footnotetext{
${ }^{1}$ http://conferences.computer.org/icws

${ }^{2} \mathrm{http}: / /$ conferences.computer.org/scc

${ }^{3} \mathrm{http}: / /$ www.icsoc.org/

${ }^{4}$ http://sose2008.ncu.edu.tw

${ }^{5}$ http://www.computer.org/tsc

${ }^{6} \mathrm{http} / / / \mathrm{www}$.servicescomputing.org/jwsr/
} 
em passagem de mensagens. Uma ferramenta de apoio à estratégia proposta também é apresentada nesse capítulo. Resultados de um estudo experimental que aplicou a estratégia de teste em alguns exemplos são apresentados. Por fim, no Capítulo 6, as conclusões deste trabalho são apresentadas, destacando as principais contribuições, dificuldades e limitações encontradas e sugestões de trabalhos futuros. 



풀

\section{Composição de Web Services}

\subsection{Considerações Iniciais}

Neste capítulo são apresentados conceitos sobre Web Services e Composição de Web Services. Este capítulo faz parte do embasamento teórico necessário para o desenvolvimento deste trabalho de mestrado.

O capítulo está organizado da seguinte forma. Na Seção 2.2, os conceitos de Web Services são explicados, descrevendo duas visões da arquitetura de um WS. Os três padrões principais utilizados na tecnologia WSs são apresentados: SOAP, WSDL e UDDI. Na Seção 2.3, a Composição de Web Services é definida, considerando seus paradigmas (orquestração e coreografia) e principais abordagens (WS-BPEL, OWL-S, WSCI e WS-CDL). Dentre as abordagens estudadas, a linguagem WS-BPEL será descrita mais detalhadamente. Na Seção 2.4, um exemplo de uso é apresentado para ilustrar a aplicação da CWS.

\subsection{Web Services}

A COS é um paradigma da computação que utiliza os serviços como elementos fundamentais para o desenvolvimento de aplicações (Papazoglou e Georgakopoulos, 2003). Web Services representam a aplicação da COS na Web. WSs são aplicações com baixo grau de acoplamento que são fornecidos como serviços, e que podem ser facilmente utilizados por outras aplicações usando a Internet como meio de comunicação. Com a utilização de WSs, aplicações de diferentes plataformas e implementadas em linguagens diversas comunicam-se entre si por meio de protocolos padrões da Web. 
Segundo Kreger (2001), o que a Web foi para as interações entre aplicação-usuário (B2C), a tecnologia WSs é para interações entre aplicação-aplicação (B2B). WSs permitem que companhias reduzam custos de $e$-bussiness, disponibilizem soluções mais rápidas e criem novas oportunidades. Isso está sendo alcançado porque WSs são construídos baseados em tecnologias como HTTP, XML, SOAP, WSDL e UDDI. Além disso, WSs permitem que empresas desenvolvam funções que podem ser utilizadas sob demanda ou utilizadas em conjunto para prover um serviço de negócio (Chen et al., 2003). WSs estão emergindo para prover uma infra-estrutura sistemática e extensível para interações aplicação-aplicação, construída sobre protocolos Web já existentes e baseada em padrões XML abertos (Curbera et al., 2002).

A arquitetura de um WS é baseada na interação entre três papéis (Figura 2.1) (Gottschalk et al., 2002; Kreger, 2001; Roy e Ramanujan, 2001):

Provedor de Serviço (Service Provider): responsável pela criação de um WS. Para que todo o potencial de um WS seja alcançado, é tarefa do provedor de serviço descrever de forma padronizada cada serviço criado e publicá-lo em registros centralizados e públicos. Essas tarefas garantem que um WS possa ser compreendido e encontrado, por meio de mecanismos de busca, por qualquer um que deseje utilizá-lo;

Requerente de Serviço (Service Requester): representa a entidade que vai utilizar um WS criado por um provedor de serviço. É importante ressaltar que um requerente de serviço é capaz de obter as informações necessárias para a utilização de um serviço, a partir da descrição realizada pelo provedor. Essas informações podem ser obtidas por meio de uma consulta a um registro de serviços; e

Registro de Serviços (Service Registry): a entidade com a qual tanto o provedor de serviço quanto o requerente de serviço interagem. Os provedores de serviços publicam seus serviços nesse repositório para que os requerentes consigam encontrá-los e utilizá-los. O registro de serviço é essencialmente um repositório baseado em XML.

A arquitetura de um WS também pode ser vista como uma pilha de protocolos Web (Figura 2.2). Essa pilha possui quatro camadas principais (Cerami, 2002):

Transporte de Serviço (Service Transport): camada responsável por transportar as mensagens entre as aplicações;

Troca de Mensagem XML (XML Messaging): camada responsável por codificar mensagens em um formato XML comum;

Descrição de Serviço (Service Description): camada responsável por descrever a interface pública de um WS específico; e

Descoberta de Serviço (Service Discovery): camada responsável por centralizar os serviços em um registro comum e fornecer funcionalidades de publicação e busca. 


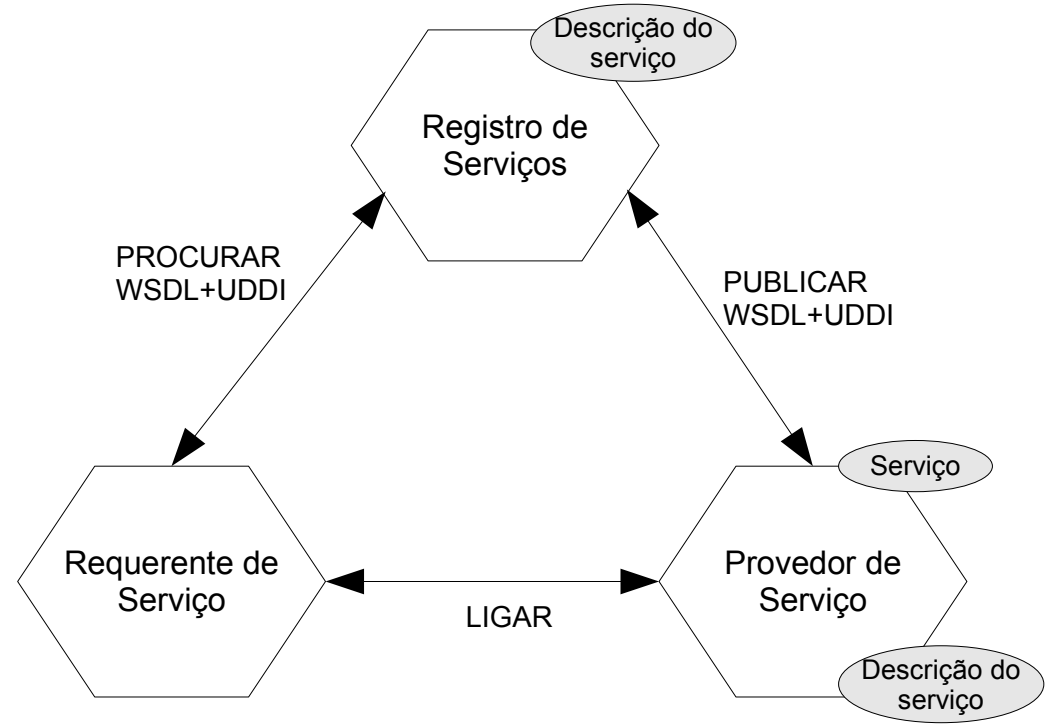

Figura 2.1: Arquitetura de WS.

\begin{tabular}{|lc|}
\hline Descoberta & UDDI \\
\hline \hline Descrição & WSDL \\
\hline \hline Troca de Mensagem XML & XML-RPC, SOAP, XML \\
\hline Transporte & HTTP, SMTP, FTP, BEEP \\
\hline
\end{tabular}

Figura 2.2: Pilha de protocolos WS.

Os padrões utilizados pela tecnologia WS são baseados na linguagem XML (W3C, 2003). Esse fato torna a tecnologia WS independente de linguagem e plataforma permitindo interoperabilidade por meio de serviços atuando sob a Internet. Isso significa que as aplicações que utilizam WSs podem se comunicar mesmo sendo executadas em diferentes plataformas e implementadas em diferentes linguagens de programação. WSs são essencialmente baseados em três padrões principais: SOAP, WSDL e UDDI, descritos a seguir.

\subsubsection{SOAP}

Simple Object Access Protocol (SOAP) (SOAP, 2003) é um protocolo do W3C ${ }^{1}$ para a troca de informações estruturadas em um ambiente descentralizado e/ou distribuído que permite comunicação entre aplicações de forma simples e completamente independente da linguagem de programação e plataforma. Ele é definido utilizando XML. Na tecnologia WS, SOAP é utilizado para

\footnotetext{
${ }^{1}$ http: //www.w3c.org
} 
definir a estrutura das mensagens trocadas entre seus atores. Um pacote SOAP é composto pelas seguintes partes (Newcomer, 2002):

Envelope: define o início e o fim das mensagens, quem poderá tratá-las e se o tratamento é obrigatório ou opcional;

Cabeçalho: contém atributos opcionais das mensagens;

Corpo: contém os dados em XML incluídos na mensagem que está sendo enviada;

Anexo: consiste de um ou mais documentos anexados à mensagem;

RPC: define como o modelo RPC (Remote Procedure Call) interage com o SOAP, com o objetivo de invocar procedimentos em um sistema remoto; e

Codificação: define como representar os dados a serem transmitidos nas mensagens.

\subsubsection{WSDL}

Web Service Description Language (WSDL) (W3C, 2001) é um padrão da W3C em formato XML que pode ser utilizado para descrever a interface de um WS. A descrição inclui detalhes como definição de tipos de dados, operações suportadas pelo WS, formato das mensagens de entrada e saída, entre outros. WSDL descreve três componentes básicos dos WSs (Newcomer, 2002; Curbera et al., 2002):

Tipos de dados: para atingir o nível de abstração requerido em WSDL, é preciso que o documento WSDL inclua um container abstrato para o armazenamento das definições dos tipos de dados utilizados dentro do WS. WSDL provê um mecanismo de separação para especificar a linguagem em que os tipos de dados estão definidos.

Operações: cada operação WSDL descreve uma interface abstrata para o comportamento ou ação oferecida por um WS. Dentro de cada operação WSDL podem ser especificados parâmetros de entrada e saída, além de correlacioná-los com os tipos de dados definidos dentro do documento WSDL.

Protocolos de Ligação: a WSDL descreve os protocolos das camadas inferiores (Mensagem e Transporte, considerando as camadas dos WSs). WSDL permite que protocolos das camadas que estão abaixo dele sejam especificados. Essa flexibilidade do WSDL permite que desenvolvedores ou outro software que estejam utilizando as descrições WSDL possam prover diferentes protocolos de ligação concretos para as operações abstratas definidas em WSDL. 


\subsubsection{UDDI}

Universal, Discovery, Description and Integration (UDDI) (OASIS, 2005) é um padrão da OASIS $^{2}$ que define um conjunto de serviços para apoio à descrição e descoberta de negócios, organizações e outros provedores de serviços. Ao utilizar um registro UDDI, um requerente de serviço pode encontrar um serviço desejado. Além de descrever os WSs, ou seja, especificar quais são as interfaces utilizadas, as ferramentas, e os tipos de valores que um WS possui, UDDI permite também que sejam descritas as finalidades desses WSs. A capacidade de descrição da tecnologia UDDI se dá pela utilização de palavras-chave e pequenas tags de descrição, possibilitando que se informe a todos, exatamente o que o WS oferece. Dessa forma, UDDI torna-se uma poderosa ferramenta para os consumidores que estão à procura de provedores de serviços que melhor atendam a suas necessidades (Newcomer, 2002; Cerami, 2002).

\subsection{Composição de Web Services}

Para modelar processos de negócios complexos, vários Web Services podem ser utilizados para executar conjuntamente uma tarefa específica. A isso se dá o nome de Composição de Web Services. Nesse modelo, os WSs podem ser combinados e estruturados seguindo um fluxo de trabalho (workflow). O resultado da CWS pode ser chamado de Web Service Composto.

Segundo Kazhamiakin et al. (2006), CWS é uma das idéias mais promissoras relacionadas a WSs. Novas funcionalidades podem ser definidas e implementadas pela combinação e interação de WSs existentes. Diferentes padrões e linguagens têm sido propostos para desenvolver CWS.

Desenvolvedores e usuários podem resolver problemas complexos pela combinação de WSs disponíveis e requisitando-os de forma que o problema seja resolvido de acordo com os requisitos desejados. CWS acelera o desenvolvimento de aplicações, melhora o reúso de serviços e o consumo de serviços complexos (Milanovic e Malek, 2004).

Segundo Milanovic e Malek (2004), os requisitos para CWS diferem dos requisitos do desenvolvimento baseado em componentes. No lugar de acesso aos documentos ou código, desenvolvedores e usuários de aplicações WSs precisam acessar somente descrições funcionais em documentos WSDL. WSs executam em diferentes containers, separados por firewalls e outras barreiras de confiança (trust barriers). Milanovic e Malek (2004) propõem os seguintes requisitos que um mecanismo de composição deve satisfazer:

Conectividade (connectivity): toda abordagem para composição deve garantir conectividade. Se essa conectividade for confiável, poderá ser determinado quais WSs são compostos e qual a razão das mensagens de entrada e saída.

\footnotetext{
${ }^{2}$ http: //www.oasis-open.org
} 


\section{Propriedades de qualidade-de-serviço não-funcional (nonfunctional Quality-of-Service (QoS)}

properties): WSs são baseados em troca de mensagens, logo desenvolvedores devem objetivar propriedades de QoS não-funcionais, como timeliness, segurança e dependability.

Corretude (correctness): A corretude da composição requer verificação das propriedades do WS composto, como segurança, dependability, consistência de dados ou satisfação de restrições de negócios.

Escalabilidade (scalability): Por lidar com transações de negócio complicadas, é provável que envolva vários WSs em um complexo encadeamento de invocações. Portanto, frameworks de composição devem escalar com o número de WSs compostos.

Outro assunto em pesquisa é a composição automática, que promete desenvolvimento rápido de aplicações, reúso seguro (safer reuse) e facilidade para o usuário interagir com conjuntos de serviços complexos (Milanovic e Malek, 2004). Com a composição automática, o usuário final ou desenvolvedor da aplicação especifica um objetivo de negócio expressado em uma linguagem de descrição ou notação matemática e uma engine de composição "inteligente" seleciona os serviços adequados e fornece a composição transparentemente para o usuário. Outra questão discutida por Milanovic e Malek (2004) é a escalabilidade no desenvolvimento de CWS. Em um cenário real, usuários finais vão querer interagir com muitos WSs e aplicações invocarão centenas de WSs, tornando-se uma das questões críticas para CWS.

\subsubsection{Paradigmas de Composição de Web Services}

Em determinadas situações, desenvolver WSs e expor suas funcionalidades não é suficiente. É necessária também uma forma de compor essas funcionalidades em uma ordem certa, ou seja, definir processos de negócio que usarão as funcionalidades expostas. Obviamente, prefere-se uma maneira relativamente simples e direta para definir esses processos, particularmente porque é conhecido que processos de negócio mudam freqüentemente, portanto modificá-los facilmente é necessário. Uma das formas de definir esses processos é utilizando CWS. Segundo Juric (2005), a CWS pode acontecer de duas formas: Orquestração e Coreografia.

$\mathrm{Na}$ orquestração, um coordenador central possui o controle sobre os WSs envolvidos e coordena a execução das diferentes operações desses WSs, conforme os requisitos pré-estabelecidos da orquestração. Os WSs envolvidos não sabem (e não precisam saber) que estão envolvidos dentro da composição, nem que são partes de um processo de negócio de alto nível. Somente o coordenador central da orquestração possui esse conhecimento, então a orquestração é centralizada com definições explícitas das operações e com a ordem da invocação dos WSs (Juric, 2005). Na orquestração, um processo de negócio interage com WSs internos e/ou externos por meio de mensagens, além de incluir a lógica de negócio e a ordem de execução das tarefas. A orquestração sempre representa o controle na perspectiva de apenas uma das partes envolvidas na composição, 
o coordenador central (Peltz, 2003). A orquestração de WSs pode ser representada graficamente pela Figura 2.3.

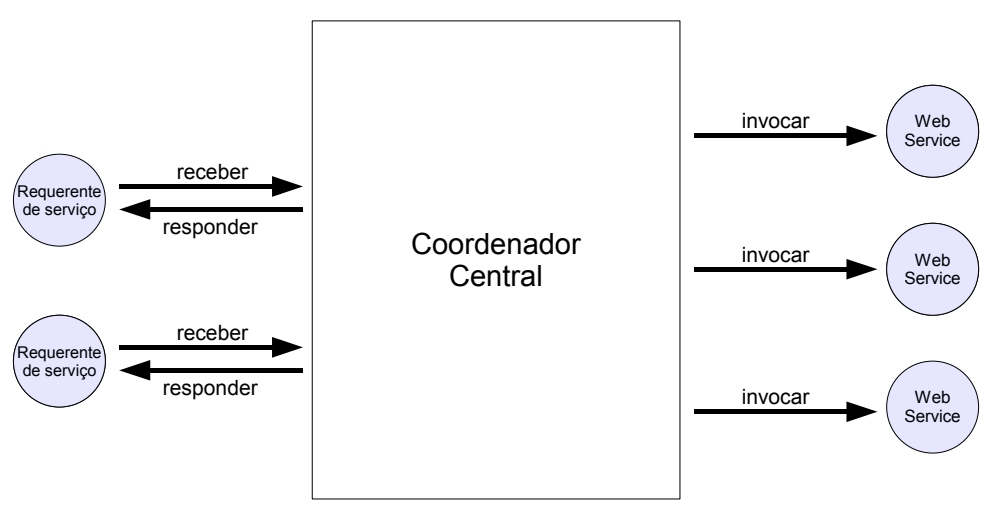

Figura 2.3: Orquestração de WSs.

Por outro lado, a coreografia não conta com um coordenador central. Cada WS envolvido na coreografia conhece exatamente quando executar suas operações e com quem interagir, ou seja, cada WS possui um protocolo. A coreografia é um esforço colaborativo focado na troca de mensagens. Todos os participantes da coreografia necessitam estarem cientes do processo de negócio, operações a executar, mensagens que serão trocadas e o momento (timing) da troca de mensagens. Segundo Peltz (2003), a coreografia é mais colaborativa e permite que cada parte envolvida descreva sua parte na interação. A coreografia rastreia a sequiência de mensagens entre as múltiplas partes e fontes, diferentemente de um processo de negócio específico em que uma simples parte possui o conhecimento da composição. A coreografia de WSs pode ser representada graficamente pela Figura 2.4.

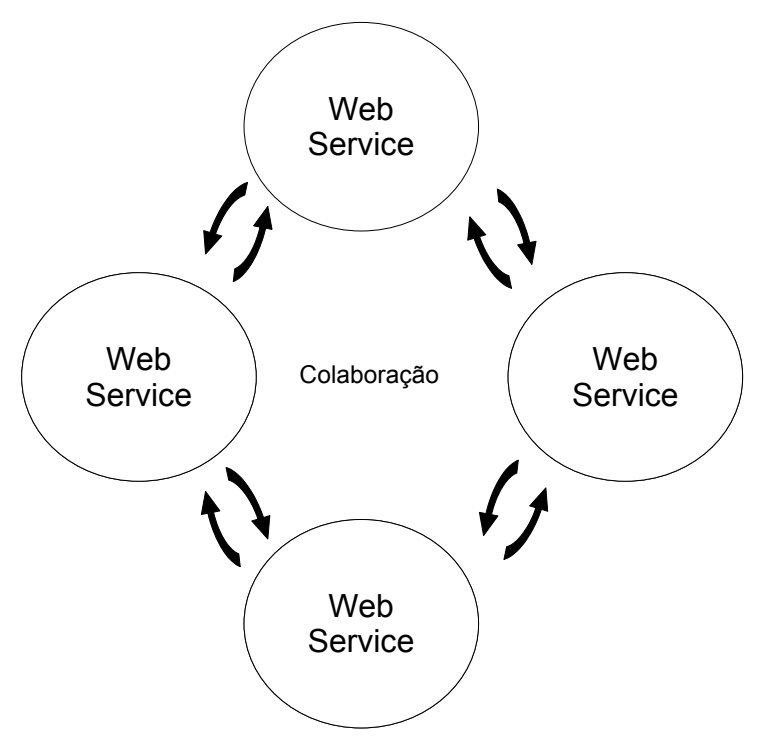

Figura 2.4: Coreografia de WSs. 


\subsubsection{Abordagens para Composição de Web Services}

Apesar de alguns padrões para CWS serem mais utilizados que outros, nenhum deles é unanimidade. Para orquestração, existem a WS-BPEL (mais utilizada pela indústria) e a OWL-S (comunidade acadêmica e pesquisadores da Web semântica). Para coreografia, existem os padrões da W3C, como WSCI e WS-CDL. Procurando propor modelos alternativos ou melhorias a modelos existentes, pesquisadores propuseram a utilização de modelos formais para CWS como Redes de Petri (Hamadi e Benatallah, 2003), Redes de Petri Coloridas (Yang et al., 2006), Statecharts (Zeng et al., 2003) e Máquinas de Estados (Betin-Can e Bultan, 2005; Foster et al., 2005b).

Ontology Web Language for Services (OWL-S) é uma ontologia para WSs baseada na OWL (Ontology Web Language) (McGuinness e van Harmelen, 2004), a qual fornece aos provedores de serviço uma linguagem de marcação para descrever propriedades e capacidades de seus WSs sem ambigüidade e em uma forma interpretável pelo computador. OWL-S facilita a automação de tarefas, incluindo descoberta, execução, composição e interoperação de serviços. É importante ressaltar que uma especificação OWL-S não é um programa para ser executado, e sim uma especificação de como um cliente deve interagir com um WS.

Web Service Choreography Interface (WSCI) (Arkin et al., 2002) é uma linguagem de descrição de interface baseada em XML que descreve o fluxo de mensagens trocadas entre WSs participantes em uma interação coreografada com outros WSs. WSCI descreve a interface dinâmica do WS participante em uma troca de mensagens com o objetivo de reusar as operações definidas na interface estática. WSCI trabalha em conjunto com o WSDL ou outras linguagens de definição de WSs semelhantes. Basicamente, o objetivo do WSCI é descrever o comportamento observável de um WS, fornecendo uma interface orientada a fluxo de mensagem. Essa descrição habilita desenvolvedores e ferramentas a descrever e compor uma visão global da dinâmica da troca de mensagens pelo entendimento das interações com o WS (Arkin et al., 2002).

Web Services Choreography Description Language (WS-CDL) (Kavantzas et al., 2005) é uma linguagem baseada em XML que descreve colaborações par-a-par de participantes pela definição de uma visão global de seu comportamento observável comum e complementar; em que a troca de mensagens ordenadas resulta na realização de um objetivo de negócio comum. A especificação WS-CDL está focada na composição de colaborações interoperáveis entre algum tipo de participante sem ligação com a plataforma de suporte ou modelo de programação usado para implementação do ambiente de hospedagem. Uma descrição de coreografia é um contrato com múltiplos participantes que descreve essa composição de uma perspectiva global. WS-CDL é o meio pelo qual esse contrato técnico é descrito (Kavantzas et al., 2005). O modelo conceitual do WS-CDL é baseado no $\pi$-calculus (Milner, 1999): cada WS participante, cujo comportamento é descrito por meio de um sistema de transição de estados finitos e sequencial, interage com outros e compartilha recursos por canais pré-definidos. WS-CDL fornece construções para comunicação, escolhas, concorrência e iterações, tendo semânticas formais claras baseadas em construções análogas ao 
$\pi$-calculus. Além disso, graças ao modelo conceitual formal, é possível verificar formalmente propriedades como livelock ou deadlock (Berardi, 2005).

A linguagem BPEL será descrita detalhadamente porque está diretamente relacionada a este trabalho. As composições de WSs consideradas neste trabalho foram descritas utilizando BPEL. A BPEL foi escolhida por sua adoção pela indústria e por ser uma linguagem executável que possibilita a realização de testes.

WS-BPEL Inicialmente, a linguagem Business Process Execution Language for Web Services (BPEL4WS) (Andrews et al., 2003), desenvolvida pela BEA, IBM, Microsoft, SAP e Siebel, foi uma linguagem XML que suportava CWS orientado a processos. A continuidade da BPEL4WS ficou sob responsabilidade da OASIS com o nome de Web Services Business Process Execution Language (WS-BPEL) (Jordan et al., 2007), cuja versão 2.0 foi disponibilizada em dezembro de 2005 e última versão revisada em abril de 2007. A descrição dessa seção será baseada nessa última versão.

A BPEL é uma linguagem XML, baseada em orquestração, para definição de CWS. Composições em BPEL interagem com WSs para realizarem uma determinada tarefa. Na linguagem BPEL, o resultado de uma CWS é chamado de processo, os WSs participantes são chamados de parceiros (partners) e a troca de mensagens ou a transformação de resultado intermediário é chamada de atividade (activity). Portanto, um processo é um conjunto de atividades que interagem com WSs (Milanovic e Malek, 2004). Um processo BPEL também é um WS, logo pode ser invocado por outra composição e precisa de um arquivo WSDL que descreva sua interface.

Além disso, a BPEL fornece construções baseadas em XML para descrever a lógica de controle necessária para coordenar os WSs participantes em um fluxo de processo (Peltz, 2003). Na linguagem BPEL, os processos, ou processos de negócios, podem ser descritos de duas formas (Jordan et al., 2007):

Processos de negócios abstratos: também chamados de protocolos de negócio, especificam a troca de mensagens públicas entre as partes envolvidas no protocolo. Usam descrições de processos que especificam o comportamento da troca de mensagens, mutuamente visível a cada uma das partes envolvidas no protocolo, sem revelar seu comportamento interno. Protocolos de negócio não são executáveis e não expõem os detalhes internos do fluxo de processo (Peltz, 2003; Jordan et al., 2007). Processos abstratos podem ser comparados a uma API: descrevem o que o processo pode fazer e suas entradas e saídas, mas não descrevem como o processo é executado. São mais utilizados para descrever um processo de negócio para uma outra parte que quer usá-lo.

Processos de negócios executáveis: modelam o comportamento dos participantes em uma interação de negócio específica, essencialmente modelando o fluxo de trabalho interno. Nesse caso, uma engine de orquestração pode executar essa especificação BPEL, coordenando as 
atividades e tratando de erros que eventualmente ocorram (Peltz, 2003). Na Figura 2.5 é ilustrada a visão de um processo BPEL executável. Os processos executáveis contêm todos os passos de execução que representam uma unidade de trabalho coesa. Este trabalho de mestrado é baseado nesse tipo de processo, logo processos BPEL se referem a processos de negócios executáveis.

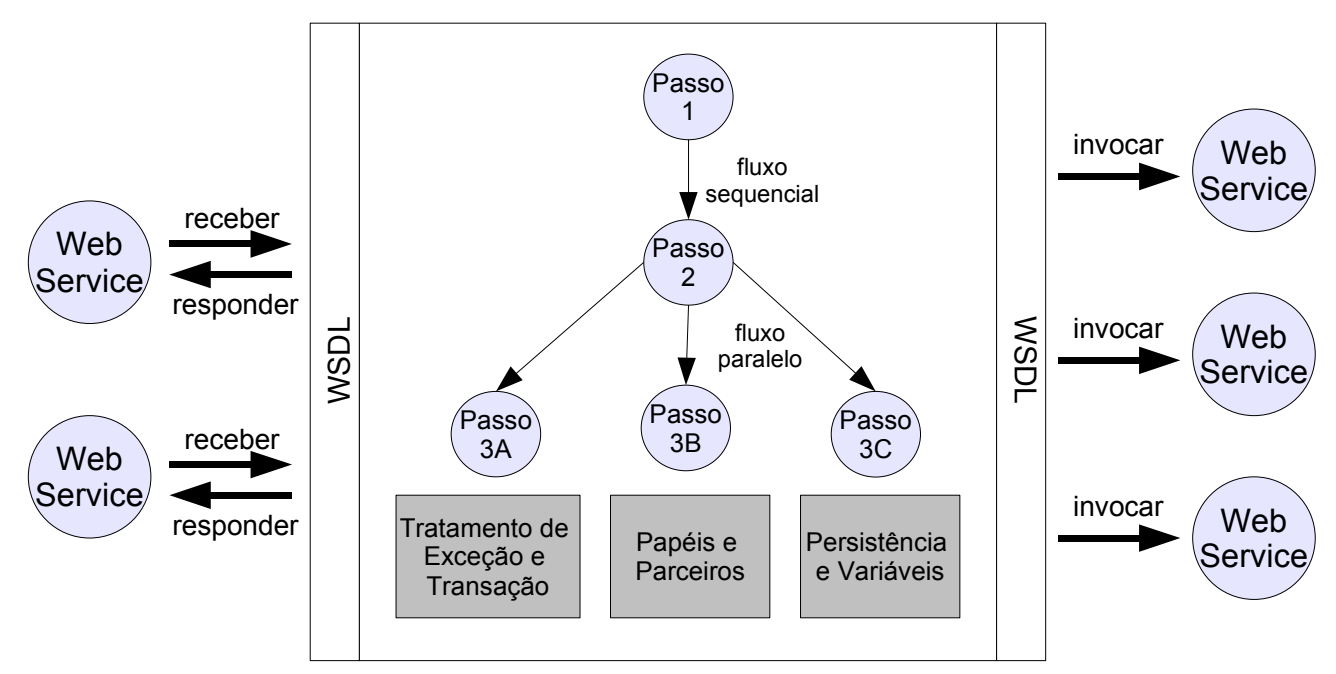

Figura 2.5: Web Service implementado como um processo BPEL.

Em geral, para definir um processo executável são necessários: um arquivo-fonte BPEL que descreve as atividades que serão realizadas pelo processo; um arquivo WSDL que descreve a interface do processo (caracterizando o processo como um WS); e um arquivo descritivo opcional que contém a localização física dos parceiros (Milanovic e Malek, 2004).

A especificação WS-BPEL possui atividades básicas e estruturadas. Uma atividade básica é uma instrução que não interfere no fluxo de execução e executa uma operação simples, como invocar um WS ou fazer tratamento de dados. Uma atividade estruturada gerencia o fluxo do processo, especificando a ordem de execução, como por exemplo, laços, execução seqüencial, execução em paralelo e desvios condicionais. Na Tabela 2.1 são apresentadas as atividades da BPEL separadas em atividades básicas e estruturadas.

Um processo BPEL descreve um fluxo de interações entre processos e WSs que acontecem por meio de troca de mensagens. Cada interação descreve qual papel o processo e os WSs desempenham e quais dados podem ser manipulados. Essa interação é definida por uma construção chamada PartnerLink. A BPEL possui as atividades receive, reply, invoke e pick para troca de mensagens com os WSs participantes da composição. Essas atividades estão relacionadas com uma PartnerLink e uma determinada operação definida em um arquivo WSDL, que pode ser executada. A operação relacionada a essas atividades pode ser síncrona ou assíncrona. Uma operação síncrona (request-response) é caracterizada como uma operação com dados de entrada e saída. Já uma operação assíncrona (one-way) é caracterizada apenas com dados de entrada. 
Tabela 2.1: atividades da BPEL

\begin{tabular}{|c|l|}
\hline \multicolumn{2}{|c|}{ Atividades Básicas } \\
\hline Invoke & invoca um WS. \\
\hline Reply & envia uma mensagem de resposta a um cliente. \\
\hline Receive & recebe uma mensagem de um cliente. \\
\hline Assign & comando de atribuição. \\
\hline Throw & usado para sinalizar explicitamente um defeito interno. \\
\hline Wait & especifica um tempo de espera. \\
\hline Empty & uma atividade que não tem nenhum efeito. \\
\hline Rethrow & utilizado para relançar um defeito que foi capturado. \\
\hline \multicolumn{2}{|c|}{ Atividades Estruturadas } \\
\hline Sequence & atividades dentro do sequence são executadas sequencialmente. \\
\hline If & fornece estrutura para desvio condicional. \\
\hline While & fornece estrutura para execução iterativa (laços). \\
\hline RepeatUntil & $\begin{array}{l}\text { fornece estrutura para execução iterativa (é executado } \\
\text { ao menos uma vez). }\end{array}$ \\
\hline Pick & $\begin{array}{l}\text { permite associar ações a determinados eventos (recebimento de } \\
\text { mensagens, condições temporais). }\end{array}$ \\
\hline Flow & atividades dentro do flow são executadas em paralelo. \\
\hline ForEach & fornece estrutura para execução iterativa contada. \\
\hline
\end{tabular}

A atividade receive recebe uma mensagem. Quando está ligada a uma operação síncrona possui uma respectiva atividade reply que envia uma mensagem com os dados de saída. A atividade invoke pode chamar uma operação síncrona ou assíncrona de um WS. Quando a atividade invoke síncrona é executada, essa fica bloqueada esperando o envio da mensagem de resposta. Já a invoke assíncrona envia uma mensagem e o processo BPEL continua, sem bloqueio, seu fluxo de execução. A atividade pick possui uma série de eventos em que um único evento pode ocorrer. Esses eventos podem ser do tipo onMessage, que caracteriza o recebimento de uma mensagem como um receive, ou onAlarm, que é um evento relacionado a um período de tempo. A atividade invoke de um processo BPEL pode ser relacionada a uma atividade receive em um outro processo por meio das informações de seus PartnerLinks e da operação. O mesmo acontece para as demais atividades para troca de mensagem.

Processos BPEL podem ser executados em engines (ambiente que permite a execução da BPEL) como a BPEL4J (BPWS4J, 2004) e a ActiveBPEL (ActiveBPEL, 2006). Na BPEL4J, para cada processo disponibilizado, a engine necessita de um documento BPEL que descreve o processo e de documentos WSDL referentes aos WSs que poderão ser invocados durante sua execução. Em seguida, gera um documento WSDL que descreve a interface que o processo irá apresentar ao cliente. Com essas informações, o processo é disponibilizado como um WS. A engine ActiveBPEL é uma implementação de código aberto para BPEL escrita em Java. Seu funcionamento é semelhantemente à BPEL4J, lendo definições de processos BPEL (e outras entradas como arquivos WSDL) e criando representações de processos BPEL. Quando uma mensagem chega, uma atividade ini- 
cial é disparada, a engine cria uma nova instância do processo que começa a executar. A engine monitora a persistência, filas de mensagens, alarmes e muitos outros detalhes da execução.

Estando um processo BPEL disponibilizado em uma engine, esse pode receber mensagens. Assim que um processo BPEL recebe uma requisição, uma instância do processo é criada. No BPEL, as atividades que possibilitam a criação de uma instância de processo são chamadas de atividades iniciadoras e encontram-se no início do fluxo de execução do processo. Uma atividade iniciadora cria uma nova instância de um processo BPEL. Deve existir uma dependência de controle entre uma atividade iniciadora e as demais atividades, ou seja, a atividade iniciadora deve ser executada antes das demais atividades. Uma atividade iniciadora pode ser receive ou pick. Cada processo BPEL deve conter no mínimo uma atividade iniciadora. Em uma atividade iniciadora pick, todos os seus eventos devem ser do tipo onMessage. Para manter uma identidade sobre as instâncias de processos, correlation sets podem ser utilizados.

O correlation set é um conjunto de propriedades compartilhada pelas mensagens. A proposta do correlation set é agir como um identificador da conversação. Ele mantém juntas todas as mensagens pretendidas para a mesma conversação. Os correlation sets são associados a atividades para troca de mensagens.

A linguagem BPEL possui outras construções como variáveis, links, escopos e tratadores (Jordan et al., 2007). Uma variável identifica um dado específico trocado em um fluxo de mensagem. Quando um processo BPEL recebe uma mensagem, essa é atribuída a uma variável apropriada para que subseqüentes requisições possam acessar o dado (Peltz, 2003). Variáveis são utilizadas para receber, enviar e manipular dados que são trocados dentro do processo BPEL. Em um processo BPEL, as variáveis podem ser de três tipos (Jordan et al., 2007):

- WSDL message type: esse tipo de variável usa um message type definido em arquivo WSDL que é referenciado no processo BPEL por meio de um namespace. Esse tipo de variável é usado geralmente para envio e recebimento de mensagens.

- XML schema type: variáveis do tipo simples ou complexos que são definidos por um arquivo XML schema referenciado por um namespace no processo.

- XML schema element: usam um elemento definido em XML schema.

Um link é uma estrutura que conecta duas atividades e controles para ordenar a execução de duas atividades dentro de uma atividade flow. Um link pode incluir uma condição, além de controlar quando, ou se, uma atividade executa. Os links podem ser utilizados como alternativa para atividades estruturadas como Sequence ou If.

Escopos (scopes) fornecem um contexto que influencia somente a execução das atividades dentro deles. Possui suas próprias variáveis, parceiros, entre outros. Requer a existência de pelo menos uma atividade, todas as outras estruturas são opcionais. Suas variáveis, parceiros etc são 
visíveis somente dentro do próprio escopo. Os escopos são utilizados principalmente pelos tratadores (handlers). Compensation Handlers fornecem mecanismos de recuperação a um possível erro gerado. Fault Handlers fornecem estruturas que permitem capturar e tratar erros. Cada escopo ou processo pode ter um conjunto de Event Handlers. Esses tratadores de eventos podem ocorrer concorrentemente com o escopo e serem invocados quando um evento acontecer. Por fim, os Termination Handlers fornecem um comportamento explícito para a finalização de um escopo.

\subsection{Exemplo de Uso}

Nesta seção é apresentado um exemplo de uso chamado NiceJourney que é um processo de negócio para reservar viagem (retirado de Keen et al. (2004)). Esse exemplo é apresentado para ilustrar a CWS, usando a linguagem BPEL.

NiceJourney é uma agência de viagens especializada em reservar viagens que necessitem de reservas de vôo e hotel. NiceJourney usa parceiros externos para fazer as reservas e consultar dados de seus clientes. O processo de negócio de reserva de viagem é apresentado na Figura 2.6 em um diagrama swimlane (Larman, 2007), que é uma figura que representa a seqüência de tarefas e decisões no processo. As linhas pontilhadas indicam que um passo pode ser ou não executado, dependendo da condição definida. O fluxo de processo mostrado na Figura 2.6 indica que:

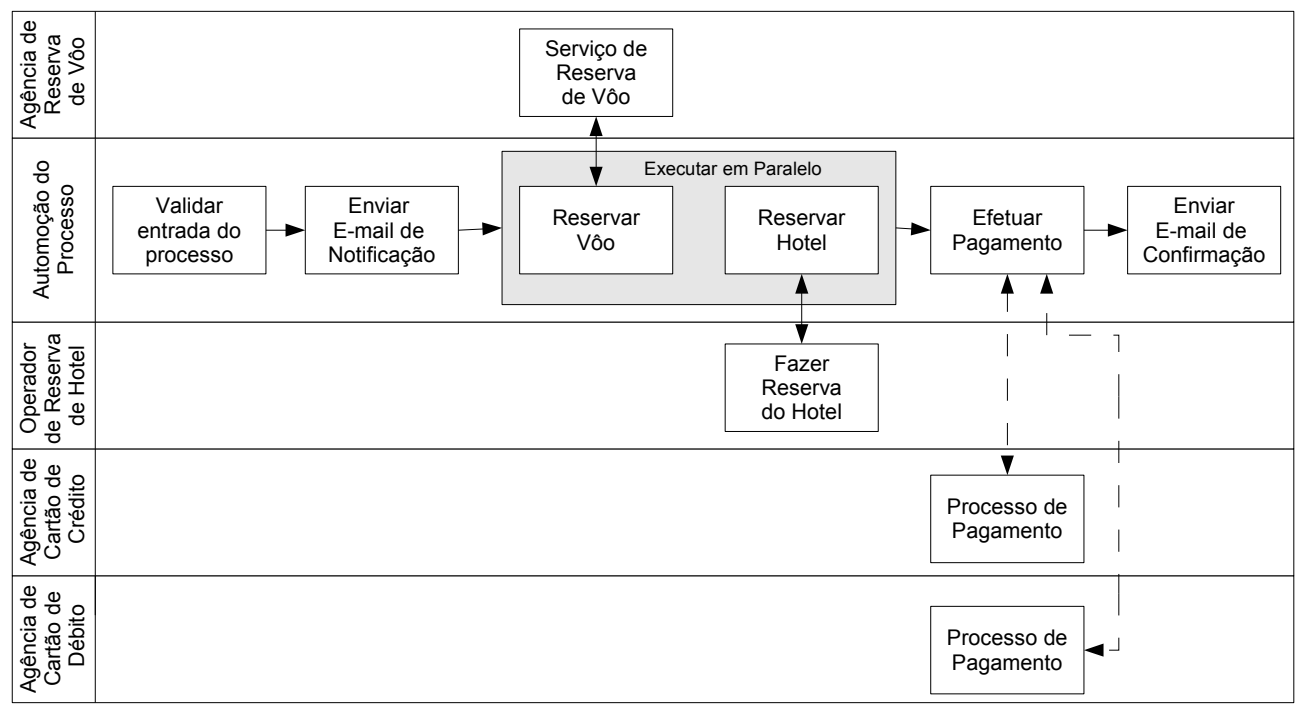

Figura 2.6: Processo de negócio NiceJourney.

1. Um processo iniciador (uma aplicação cliente) começa o processo de negócio, fornecendo dados de entrada (como destino e datas da viagem) que serão usados para fazer a reserva da viagem. Esses dados são validados antes que o processo de reserva continue.

2. Uma notificação é enviada ao processo iniciador na forma de uma mensagem de e-mail. Essa notificação diz ao processo iniciador que a requisição está sendo processada. Esse passo é necessário porque o processo pode levar um tempo significativo para ser completado. 
3. Os dois componentes de reserva são executados em paralelo: reserva de vôo e reserva de hotel:

- O componente reserva de vôo usa um parceiro externo da agência de reservas de vôo para reservar o vôo.

- O componente reserva de hotel usa um parceiro operador de reserva de hotel para manualmente fazer a reserva do hotel.

4. Assim que as duas tarefas de reserva se completam, o cliente efetua o pagamento usando ou a agência de cartão de crédito ou a agência de cartão de débito.

5. Por fim, o processo envia outro e-mail para o processo iniciador informando que a reserva foi completada e fornece um código de identificação da reserva.

Após os conceitos de CWS apresentados, ficou demonstrado que a reserva de viagem é um exemplo de CWS, no caso realizado como uma orquestração. WSs para fazer reserva de vôo, reserva de hotel e validação de dados são combinados de forma que um novo WS seja criado, a reserva de viagem. O problema foi modelado na ferramenta ActiveBPEL Designer, que gera especificações BPEL para a engine ActiveBPEL, e pode ser visto na Figura 2.7. O código BPEL gerado pela ferramenta pode ser visto no Apêndice A.

A seguir será dada uma breve explicação de cada atividade na Figura 2.7:

- Sequence. Dentro dela, todas as atividades ocorrem sequencialmente.

- Receive. Essa atividade inicia a execução do processo BPEL, caracterizando o recebimento de uma mensagem do cliente.

- Assign1. Essa atividade inicia as variáveis usadas nos invokes em seguida.

- Invoke_valid_entrada. Essa atividade invoca o WS que valida os dados de entrada do cliente.

- Invoke_email_reconhecimento. Essa atividade invoca o WS que envia o e-mail de reconhecimento ao cliente.

- Flow. Dentro dela, as atividades ocorrem em paralelo.

- Invoke_res_voo. Essa atividade invoca o WS que reserva o vôo.

- Invoke_res_hotel. Essa atividade invoca o WS que reserva o hotel.

- Assign2. Essa atividade inicia as variáveis usadas nos Invokes de pagamento.

- Switch_pagamento. Dentro dela, é decidido qual o tipo de pagamento será realizado.

- Invoke_credito. Essa atividade invoca o WS que efetua o pagamento em cartão de crédito. 
- Invoke_debito. Essa atividade invoca o WS que efetua o pagamento em cartão de débito.

- Assign3. Essa atividade inicia as variáveis usadas no Invoke que envia o e-mail de confirmação e no Reply.

- Invoke_email_confirmacao. Essa atividade invoca o WS que envia o e-mail de confirmação ao cliente.

- Reply. Essa atividade finaliza a execução do processo BPEL, caracterizando o envio de uma mensagem de resposta ao cliente. 


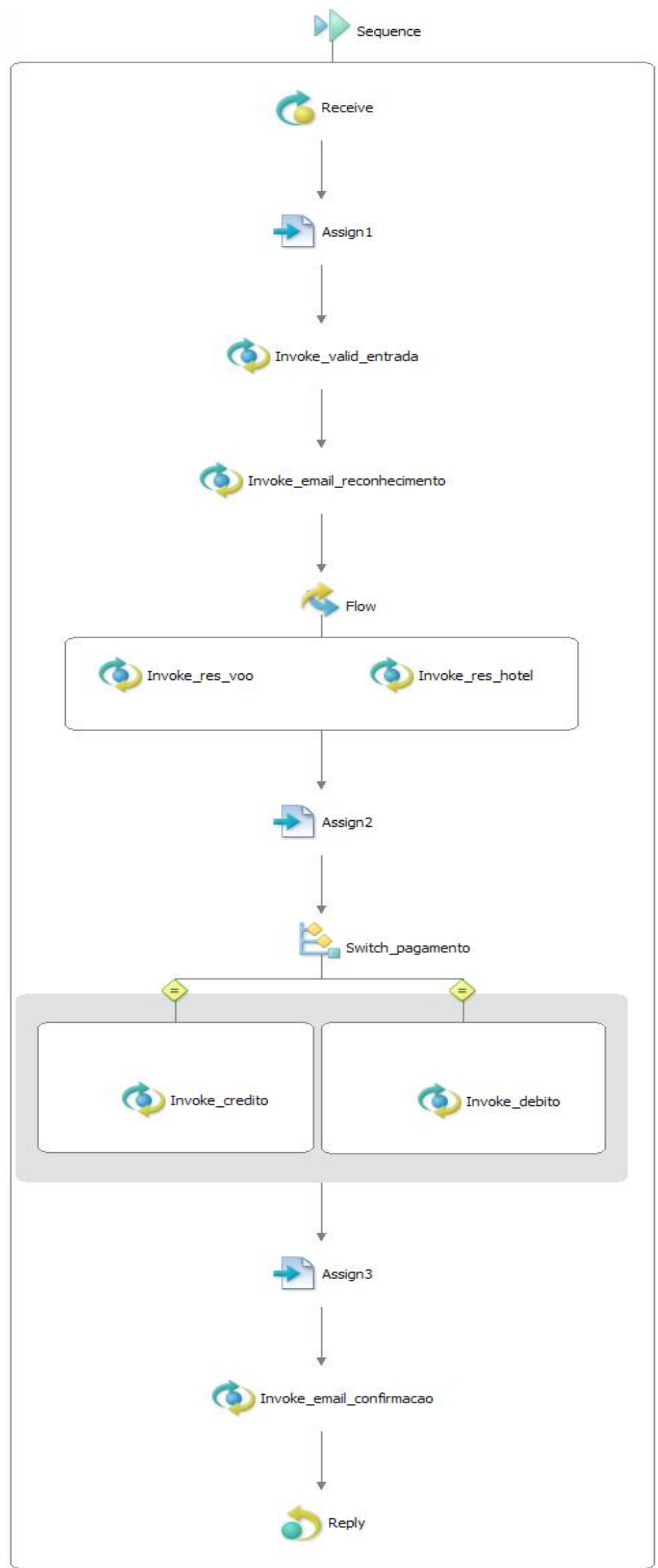

Figura 2.7: NiceJourney modelado na notação gráfica da ferramenta ActiveBPEL Designer. 


\subsection{Considerações Finais}

Neste capítulo foram abordados conceitos sobre Web Services e sua arquitetura. Os padrões SOAP, WSDL e UDDI usados pelos WSs foram descritos. Em seguida, apresentaram-se a Composição de Web Services, seus paradigmas e abordagens para realizar a CWS como a BPEL, OWL-S, WSCI e WS-CDL. A linguagem BPEL foi descrita em mais detalhes. Foi apresentado também o exemplo de reserva de viagem modelado usando a ferramenta ActiveBPEL.

Foram vistas várias abordagens para a CWS, sendo que nenhuma das abordagens apresentadas é amplamente aceita. Até o momento, grande parte dos trabalhos utiliza a linguagem BPEL para representar a composição. Executar testes em CWS é necessário para que essa tenha qualidade. Assim, no próximo capítulo é apresentada uma revisão bibliográfica sobre Teste de Software. 



\section{3}

\section{Teste de Software}

\subsection{Considerações Iniciais}

Neste capítulo, os principais conceitos referentes ao teste de software são apresentados. São considerados fundamentos, técnicas, critérios, comparação entre critérios e ferramentas da atividade de teste de software. Este capítulo fornece embasamento teórico necessário para os trabalhos relacionados apresentados no Capítulo 4 e para o trabalho de mestrado desenvolvido.

O capítulo está organizado da seguinte forma. Na Seção 3.2, os principais conceitos sobre teste de software são apresentados. Na Seção 3.3, são apresentados critérios de teste funcional. Na Seção 3.4, é discutido o teste estrutural, com ênfase nos critérios baseados em fluxo de controle e fluxo de dados. Na Seção 3.5, são mostradas técnicas baseadas em erros. Na Seção 3.6, são apresentadas técnicas de teste baseado em estados. Na Seção 3.7 são apresentados os principais trabalhos no teste de programas paralelos, visto que aspectos de execução paralela estão presentes na Composição de Web Services. Na Seção 3.8, são apresentadas formas de comparação entre os critérios de teste. Na Seção 3.9 é discutida a necessidade de automatização dos testes, bem como iniciativas acadêmicas e industriais para o desenvolvimento de ferramentas.

\subsection{Fundamentos do Teste de Software}

O processo de desenvolvimento de software envolve uma série de atividades nas quais, apesar das técnicas, métodos e ferramentas empregados, erros no produto ainda podem ocorrer. Atividades agregadas sob o nome de Garantia de Qualidade de Software têm sido introduzidas ao longo 
de todo o processo de desenvolvimento. Entre elas, podem-se citar as atividades de Verificação, Validação e Teste (VV\&T), com o objetivo de minimizar a ocorrência de erros e riscos associados. Atividades de verificação permitem ao desenvolvedor identificar se o desenvolvimento de software está sendo feito da maneira correta. As atividades de validação possibilitam avaliar a adequação do software produzido em relação aos requisitos do cliente. A atividade de teste é um processo em que um programa é executado com a intenção de encontrar erros. Teste é um elemento crítico de garantia de qualidade de software e representa a revisão final da especificação, projeto e código (Myers et al., 2004; Pressman, 2005). Dentre essas atividades, a atividade de teste é uma das mais utilizadas, constituindo-se em um dos elementos para fornecer evidências da confiabilidade do software em complemento a outras atividades, como por exemplo, o uso de revisões e de técnicas formais e rigorosas de especificação e de verificação (Maldonado, 1991).

No contexto do teste de software, o padrão IEEE 610.12 (IEEE, 1990) diferencia os seguintes termos: defeito (fault) - passo, processo ou definição de dados incorreta (instrução ou comando incorreto); engano (mistake) - ação humana que produz um resultado incorreto (uma ação incorreta tomada pelo programador); falha (failure) - produção de uma saída incorreta em relação à especificação; e erro (error) - diferença entre o valor obtido e o valor esperado, ou seja, um estado intermediário incorreto ou resultado inesperado na execução do programa constitui um erro.

A atividade de teste de software pode ser dividida em quatro etapas (Maldonado, 1991):

Planejamento de Testes: nessa etapa, é criado um plano de teste que é uma parte essencial para o gerenciamento do processo de teste. Segundo Myers et al. (2004), um plano de teste deve possuir: objetivos; critérios de finalização que julgam quando uma fase dos testes foi completada; cronogramas; distribuição de responsabilidades; padrões para casos de teste; identificações das ferramentas; tempo de uso de computadores para realizar os testes; configuração de hardware; estratégia de integração; rastreamento do progresso; procedimentos para depuração (localizar e corrigir erros); e um planejamento para o teste de regressão (reexecução de algum subconjunto dos testes que já foram conduzidos, para garantir que mudanças não tenham inseridos novos erros (Leung e White, 1989)).

Projeto dos Casos de Teste: nessa etapa são utilizadas as técnicas apresentadas neste capítulo. Como o teste não garante inexistência de erros, a criação de casos de teste efetivos é muito importante (Myers et al., 2004). Os casos de teste são especificações das entradas para o teste e da saída esperada do sistema, e mais uma declaração do que está sendo testado (Sommerville, 2003). Myers et al. (2004) recomendam que casos de teste sejam desenvolvidos usando técnicas de teste funcional e complementados com técnicas de teste estrutural.

Execução do Teste: nessa etapa, são aplicados os procedimentos especificados no plano de teste.

Coleta e avaliação dos resultados dos testes: nessa etapa, os resultados dos testes realizados são registrados, organizados e apresentados na forma de relatórios. Os resultados obtidos são comparados com os resultados esperados. Os resultados esperados são obtidos por meio de 
um oráculo, que é o testador ou outro mecanismo, que decide se os valores de saída são corretos.

Os testes são aplicados em três fases: teste de unidade, teste de integração e teste de sistema.

Teste de unidade: concentra-se na menor unidade do projeto de software implementada no códigofonte. Essa unidade pode ser chamada de componente ou módulo do software, que pode ser uma função no paradigma procedimental. No paradigma da Orientação a Objetos (OO), a unidade pode ser um método (Vincenzi, 2004) ou uma classe (Perry e Kaiser, 1990; Binder, 1999). O teste de unidade limita-se a lógica interna e estruturas de dados dentro dos limites da unidade.

Teste de integração: acontece em paralelo com a fase de integração do software, conduzindo testes para descobrir erros associados às interfaces. Segundo Sommerville (2003), as estratégias de teste top-down e bottom-up refletem abordagens diferentes de integração do sistema. Na integração top-down, os componentes de alto nível de um sistema são integrados e testados antes que seus projetos e sua implementação tenham sido completados. Na integração bottom-up, os componentes de nível inferior são integrados e testados antes que os componentes de nível superior tenham sido desenvolvidos.

Teste de sistema: visa a exercitar o sistema como um todo por meio de vários tipos de teste como teste de recuperação, segurança, estresse e desempenho (Pressman, 2005). O teste de recuperação força a falha do sistema de várias formas, verificando se a recuperação é executada corretamente. O teste de segurança verifica os mecanismos de proteção do sistema, na qual o testador tenta invadir o sistema. O teste de estresse verifica o comportamento do sistema com uma alta demanda de recursos em quantidade, freqüência ou volume. O teste de desempenho é projetado para testar o desempenho do software em tempo de execução.

Durante a atividade de teste, é necessário saber se o teste efetuado é realmente de boa qualidade. Um critério de teste define quais propriedades ou requisitos que precisam ser testados para avaliar a qualidade dos testes (Zhu et al., 1997). Dados um programa $P$ que está sendo testado, um conjunto $T$ de casos de teste (que contém um subconjuntos das entradas de $P$ ) e um critério de teste $C$, diz-se que o conjunto de casos de teste $T$ é $C$-adequado para o teste de $P$ se $T$ satisfazer os requisitos de teste estabelecidos pelo critério $C$. Os critérios podem ser classificados em diferentes técnicas, em função da informação utilizada para derivar os requisitos de teste. São elas: a funcional, a estrutural, a baseada em erros e a baseada em estados. Na técnica funcional (ou caixa-preta), os critérios e requisitos de teste são constituídos a partir da especificação do software; na técnica estrutural (ou caixa-branca), os casos de teste são derivados essencialmente a partir das características internas da implementação em teste; e, na técnica baseada em erros, os critérios e os requisitos são oriundos do conhecimento sobre erros típicos no processo de desenvolvimento (Maldonado et al., 2004). A técnica baseada em estados deriva os casos de teste por meio de uma máquina de estados finitos que modela o software que está sendo testado. 


\subsection{Técnicas de Teste Funcional}

O teste funcional, também conhecido como teste caixa-preta, é uma técnica em que o testador considera o programa como uma caixa-preta. O testador não possui conhecimento sobre o comportamento interno e estrutura do programa (Myers et al., 2004). Para a geração dos casos de teste são consideradas apenas as funcionalidades do software, baseando-se na especificação. A seguir, são apresentados os principais critérios dessa técnica.

Teste Exaustivo: utiliza todos os possíveis valores de entrada como casos de teste. Em geral, a realização desse critério é impossível devido à grande quantidade de possíveis entradas.

Particionamento em Classes de Equivalência: divide o domínio de entrada do programa em um número finito de classes de equivalência, por meio das quais são derivados os casos de teste. A divisão é feita em classes de equivalência válidas e inválidas, que respectivamente, agrupam entradas válidas e inválidas. A justificativa para isso é que testar um valor representativo de cada classe é equivalente a testar qualquer outro valor dentro dessa mesma classe.

Análise de Valor Limite: pode ser considerado complementar ao critério Particionamento em Classes de Equivalência, dando maior ênfase aos limites associados às condições de entrada. Os casos de teste são selecionados nas fronteiras das classes, pois há evidências de que nesses pontos acontece o maior número de erros (Pressman, 2005). O mesmo é feito para o domínio de saída, que é particionado em classes e são necessários casos de teste que produzam resultados nos limites dessas classes (Myers et al., 2004).

Grafo Causa-Efeito: explora uma fraqueza dos critérios anteriores que não exploram combinações das condições de entrada (Myers et al., 2004). O critério grafo causa-efeito estabelece requisitos de teste baseado nas possíveis condições de entrada. Primeiramente, são levantadas as possíveis condições de entrada (causas) e as possíveis ações (efeitos) do programa. Em seguida, é construído um grafo relacionando as causas e efeitos levantados. Esse grafo é convertido em uma tabela de decisão por meio da qual são derivados os casos de teste.

Método de Partição-Categoria (Ostrand e Balcer, 1988): instrui a criação de casos de teste funcionais pela decomposição de especificações funcionais em especificações de teste para as principais funções do software. São desenvolvidas categorias, que são definidas como as principais características do domínio de entrada da função sobre teste. Em seguida, cada categoria é particionada em classes de equivalência chamadas escolhas (choice). No trabalho de Offutt e Irvine (1995), esse método é aplicado em programas OO para demonstrar que técnicas de teste existentes podem ser efetivas em teste de programas OO.

Teste Funcional Sistemático (Systematic Functional Testing) (Linkman et al., 2003): é uma variante mais forte do critério Particionamento em Classes de Equivalência, seguindo um 
conjunto bem definido de guidelines. Assim que o particionamento ocorre, o teste funcional sistemático exige no mínimo dois casos de teste de cada partição. O critério possui uma série de guidelines para construção dos casos de teste, relacionados a casos especiais, valores ilegais, arrays, valores reais, entre outros.

\subsection{Técnicas de Teste Estrutural}

O teste estrutural, também chamado de teste caixa-branca, é uma técnica em que o testador deriva os casos de teste por meio da lógica interna do programa (Myers et al., 2004). Em geral, a maioria dos critérios dessa técnica utiliza uma representação de programa conhecida com grafo de fluxo de controle ou grafo de programa. Um programa $P$ pode ser decomposto em um conjunto de blocos disjuntos de comandos tal que a execução do primeiro comando de um bloco acarreta a execução de todos os outros comandos desse bloco. Todos os comandos de um bloco, possivelmente com exceção do primeiro, têm um único predecessor e exatamente um único sucessor, exceto possivelmente o último comando.

A representação de um programa $P$ como um grafo de fluxo de controle consiste em estabelecer uma correspondência entre nós e blocos e em indicar possíveis fluxos de controle entre blocos por meio dos arcos. Portanto, um grafo de fluxo de controle (GFC) é um grafo direcionado, com um único nó de entrada e um único nó de saída, no qual cada vértice representa um bloco indivisível de comandos e cada aresta representa um possível desvio de um bloco para outro. O nó de entrada não possui nenhum arco incidente e o nó de saída não possui nenhum arco divergente. A partir do grafo de programa, podem ser escolhidos os componentes que devem ser executados, caracterizando assim as técnicas de teste estrutural. O código do exemplo apresentado aparece na Figura 3.1, e o grafo de fluxo de controle para a função main do programa Identifier é apresentado na Figura 3.2 (exemplo retirado de Maldonado et al. (2004)). O programa Identifier determina se um identificador é válido ou não.

Seja um grafo de fluxo de controle $G=(N, E)$ onde $N$ representa o conjunto de nós e $E$ o conjunto de arcos. Um caminho é uma seqüência finita de nós $\left(n_{1}, n_{2}, \ldots, n_{k}\right), k \geq 2$, tal que existe um arco $\left(n_{i}, n_{i+1}\right) \in E$, para $i=1,2, \ldots, k-1$. Um caminho é simples se todos os nós que compõem esse caminho, exceto possivelmente o primeiro e o último, são distintos; se todos os nós são distintos diz-se que esse caminho é um caminho livre de laço. Um caminho completo é um caminho onde o primeiro nó é o nó de entrada e o último nó é o nó de saída do grafo. Em relação ao programa Identifier, $(2,3,4,5,6,7)$ é um caminho simples e livre de laços e o caminho $(1,2,3,4,5,7,4,8,9,11)$ é um caminho completo. Um caminho é não-executável quando não existe um dado de entrada que leve à execução desse caminho. Observe que o caminho $(6,7,4,5,7,4,8,9)$ é não-executável, porque a variável valid_id recebe o valor zero no nó 6 , logo não tem como o nó 9 ser executado. Qualquer caminho completo que o inclua é também não-executável. 


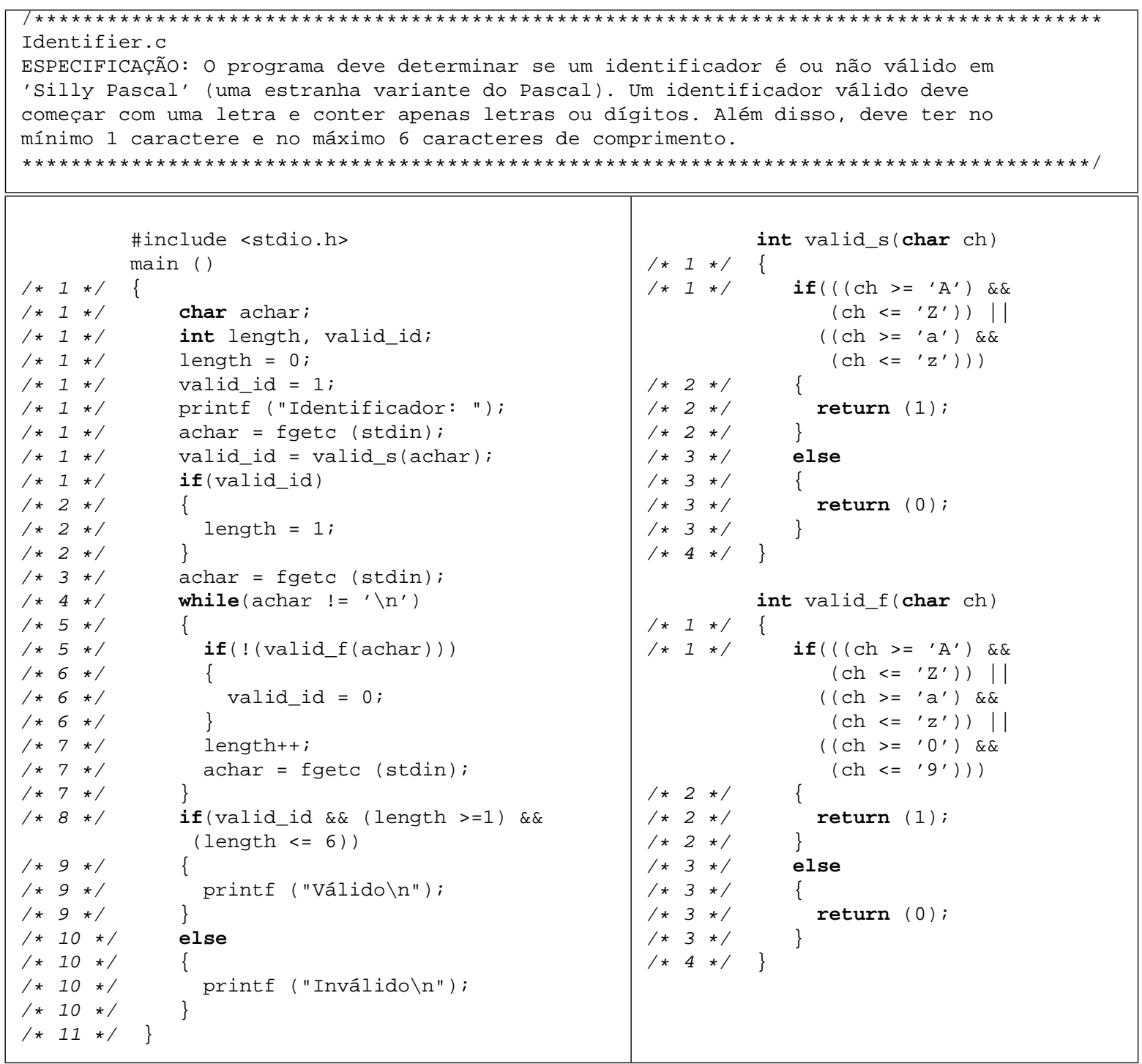

Figura 3.1: Código do Identifier.c.

Os critérios que consideram somente características do controle da execução, baseando-se principalmente no GFC, são chamados de critérios baseados no fluxo de controle. Os critérios mais conhecidos dessa classe são todos-nós, todos-arcos e todos-caminhos.

Todos-Nós: esse critério exige que os casos de teste executem ao menos uma vez cada vértice do GFC, ou seja, cada comando do programa seja executado ao menos uma vez.

Todos-Arcos: esse critério requer que os casos de teste executem ao menos uma vez cada aresta do GFC, ou seja, cada desvio de fluxo de controle do programa.

Todos-Caminhos: esse critério requer que todos os caminhos possíveis sejam executados no GFC.

Nos critérios baseados na complexidade, os requisitos de teste são derivados usando-se informações sobre a complexidade do programa. Um dos critérios dessa classe é o critério de McCabe 


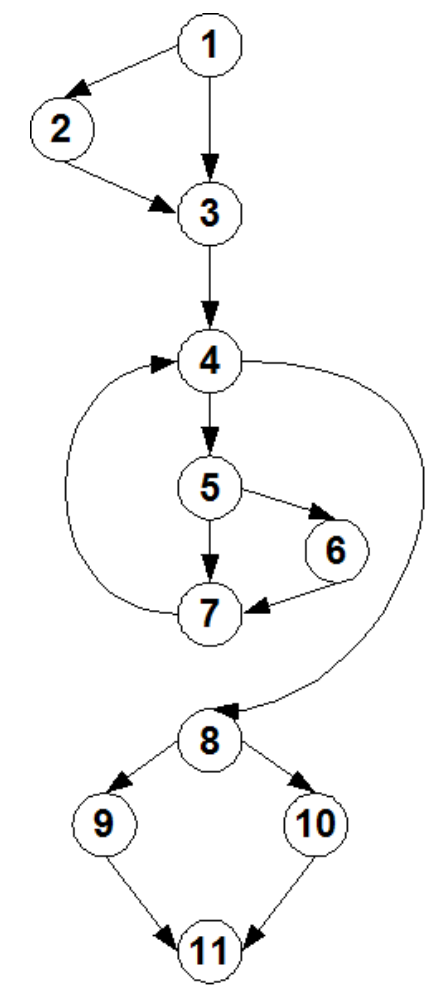

Figura 3.2: Grafo do Identifier.c.

que usa a complexidade ciclomática para derivar os requisitos de teste. A complexidade ciclomática define o número de caminhos independentes em um conjunto básico do programa e fornece um limite superior para o número de testes que deve ser conduzido para garantir que todas as instruções sejam executadas ao menos uma vez (Pressman, 2005).

Os critérios baseados no fluxo de dados utilizam informações do fluxo de dados para determinar os requisitos de teste. Esses critérios exploram definições de variáveis e referências e seus respectivos usos no programa. Uma motivação para a criação desses critérios é que, mesmo para programas pequenos, o teste baseado somente no fluxo de controle pode não ser eficaz para revelar erros simples e triviais. Segundo Rapps e Weyuker (1985), esses critérios têm origem na intuição de que, assim como não se deve considerar suficientemente testado um programa se todos seus comandos não foram exercitados, não se deve considerar suficientemente testado um programa se todos os resultados computacionais não tiverem sido usados ao menos uma vez. Exemplos de critérios baseados em fluxo de dados são os critérios de Rapps e Weyuker (1985) e os critérios Potenciais-Usos (Maldonado, 1991).

No trabalho de Rapps e Weyuker (1985) é proposto o Grafo Def-Uso (Def-Use Graph) que consiste em uma extensão do GFC. Nele são adicionadas informações a respeito do fluxo de dados do programa, caracterizando associações entre pontos do programa onde é atribuído um valor a uma variável (definição de variável) e pontos onde esse valor é utilizado (referência ou uso de variável). Os requisitos de teste são determinados com base em tais associações. Na Figura 3.3 é ilustrado o Grafo-Def-Uso do programa Identifier. Conforme o modelo de fluxo de dados definido por Rapps e Weyuker (1985), uma definição de variável ocorre quando um valor 
é armazenado em uma posição de memória. Em geral, em um programa, uma ocorrência de variável é uma definição se ela está: i) no lado esquerdo de um comando de atribuição; ii) em um comando de entrada; ou iii) em chamadas de procedimentos como parâmetro de saída. Ocorre o uso de uma variável quando seu valor é utilizado computacionalmente, como por exemplo, em uma operação aritmética ou em um desvio condicional. Dois tipos de usos são distinguidos: c-uso e p-uso. O c-uso afeta diretamente uma computação sendo realizada ou permite que o resultado de uma definição anterior possa ser observado; e o $p$-uso afeta diretamente o fluxo de controle do programa.

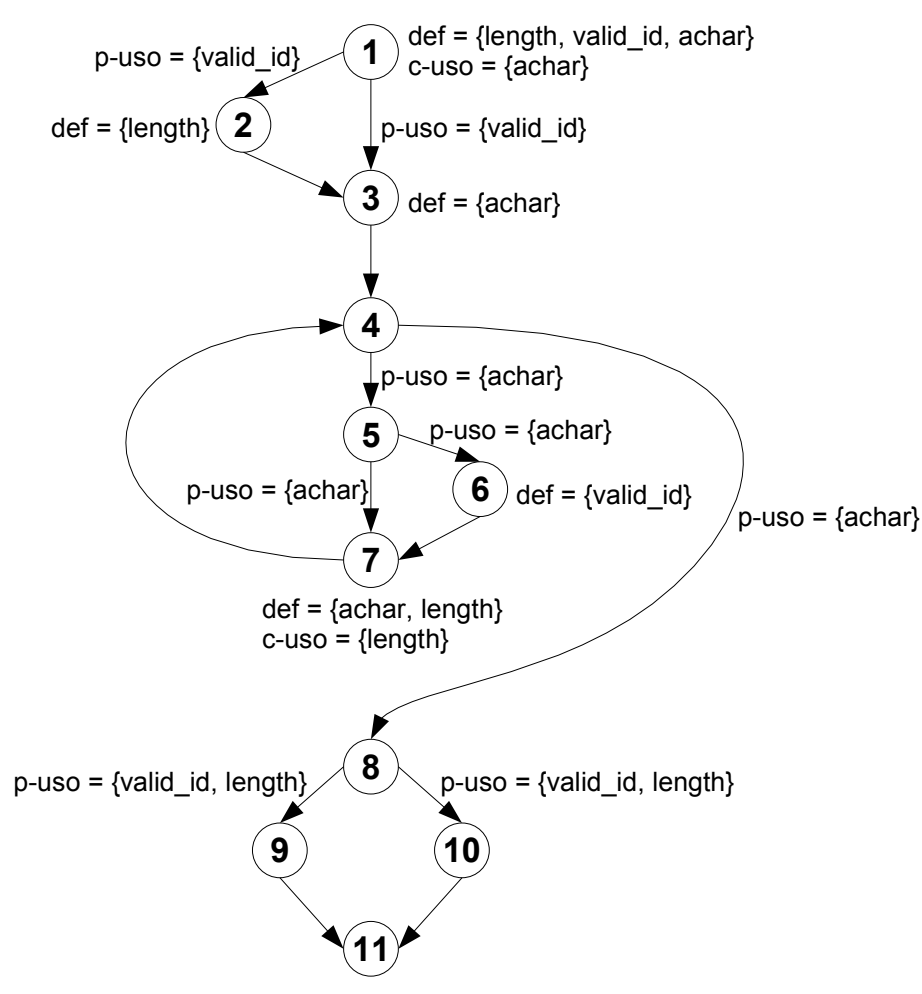

Figura 3.3: Grafo Def-Uso do Identifier.c.

Os critérios mais conhecidos propostos por Rapps e Weyuker (1985) são:

Todas-Definições (all-defs): requer que cada definição de variável seja exercitada pelo menos uma vez, por $p$-uso ou c-uso.

Todos-Usos (all-uses): requer que todas as associações entre uma definição de variável e seus subseqüentes usos sejam exercitadas pelos casos de teste, através de um caminho livre de definição, ou seja, um caminho onde a variável em questão não é redefinida.

Todos-Du-Caminhos (all-du-paths): requer que todos os caminhos livres de definição para toda associação entre uma definição de variável e seus subseqüentes usos sejam exercitados pelos casos de teste.

Os critérios Potenciais-Usos (Maldonado, 1991) introduzem um conceito novo denominado potencial-uso, em que elementos requeridos são caracterizados independentemente da ocorrência 
explícita de uma referência - um uso - a uma determinada definição; se um uso dessa definição pode existir, ou seja, existir um caminho livre de definição até um certo nó ou arco - um potencialuso - a potencial-associação entre a definição e o potencial-uso é caracterizada e requerida. O principal critério dessa família é o Todos-Potenciais-Usos que requer que toda associação entre uma definição de variável e um nó ou arco possível de ser alcançado por um caminho livre de definição seja exercitado ao menos uma vez.

\subsection{Técnicas de Teste Baseado em Erros}

O teste baseado em erros utiliza o conhecimento sobre erros mais comuns no processo de desenvolvimento de software para derivar os requisitos de teste. Dois exemplos de técnicas de teste baseadas em erros são Semeadura de Erros (Error Seeding) e Análise de Mutantes (Mutation Analisys).

A técnica Semeadura de Erros insere uma quantidade conhecida de erros no programa. Após a execução dos testes, por meio do total de erros encontrados verificam-se quais são naturais e quais são artificiais. Usando estimativas de probabilidade, o número de erros naturais ainda existentes no programa pode ser estimado (Budd, 1981; Ramamoorthy e Bastani, 1982). Entretanto, sua precisão depende de como os erros são introduzidos, geralmente de forma manual e não sistemática (Zhu et al., 1997). Outro problema é que os erros artificiais podem não ser representativos dos erros reais.

A Análise de Mutantes (AM) (DeMillo, 1978) é um critério de teste que avalia a adequação de um conjunto de casos de teste em revelar erros específicos. Para isso, utiliza-se um conjunto de operadores de mutação, os quais geram programas semelhantes ao programa que está sendo testado, mas com algum defeito. Esses programas gerados são chamados de mutantes. Os mutantes são executados com os casos de teste e os resultados são comparados com o original. O nível de confiança da adequação dos casos de teste é medido pelo escore de mutação, que relaciona o número de mutantes mortos (mutantes que apresentaram resultados diferentes do programa original) com o número de mutantes gerados. Foi demonstrada a eficácia do critério AM para detectar defeitos (Souza, 1996; Wong et al., 1995) e sua utilização para a geração de conjuntos de casos de teste adequados por construção (DeMillo e Offutt, 1991; Simão e Maldonado, 2000). O critério AM vem sendo aplicado em outros contextos como Redes de Petri (Simão, 2000), Redes de Petri Coloridas (Simão, 2004), Statecharts (Sugeta, 1999), Máquinas de Estados Finitos (Fabbri et al., 1995), especificações WSDL (Siblini e Mansour, 2005) e Programação orientada a aspectos (Ferrari et al., 2008; Masiero et al., 2006).

\subsection{Técnicas de Teste Baseado em Estados}

Os critérios de teste dessa técnica visam a modelar o comportamento do sistema ou unidade a ser testada como uma Máquina de Estados Finitos (MEF). Segundo Vincenzi (2004), com base na 
MEF derivada, métodos de geração de seqüências de teste podem ser utilizados de modo a avaliar se o comportamento esperado da MEF é obtido.

Para modelos descritos por meio de MEFs, no caso geral, os dados de entrada de um caso de teste podem ser descritos como uma seqüência de ações que levam a uma seqüência de estados e a saída esperada do caso de teste pode ser descrita como as saídas esperadas para cada transição e um estado final. Os critérios de teste baseados em MEFs devem definir conjuntos de elementos requeridos do modelo, tais como estados e transições, que devem ser executados durante a execução do teste (Fantinato, 2002). Considerando que estados são nós e transições são arcos, uma MEF pode ser considerada essencialmente um grafo. Dessa forma, alguns critérios podem ser definidos (Offutt et al., 2003): Todos-estados - todos os estados dentro da MEF devem ser exercitados; Todas-transições - todas as transições dentro da MEF devem ser exercitadas; e Todas-combinações - todas as combinações de transições dentro da MEF devem ser executadas, dependendo do tamanho da MEF esse critério pode ser inviável.

Segundo Pressman (2005), o diagrama de estados é usado para representar o comportamento dinâmico de uma classe. Esse diagrama pode ser utilizado para derivar sequiências de testes que exercitará o comportamento dinâmico da classe (e as classes que colaboram com a classe sobre teste). Técnicas de teste baseado em estados vêm sendo muito utilizadas no contexto de teste de software OO (Binder, 1996, 1999; Pressman, 2005).

\subsection{Teste de Programas Paralelos}

A utilização de Web Services e Composição de Web Services insere algumas características que devem ser consideradas, como sincronização, distribuição e concorrência. Dessa forma, ao investigar mecanismos de teste para CWS, o teste de programas paralelos deve ser estudado. Um programa paralelo consiste em um conjunto de threads cooperativas que podem executar em paralelo. Para executar um objetivo em comum, essas threads se comunicam pelo acesso a variáveis compartilhadas e/ou troca de mensagens. Programas paralelos apresentam algumas características que tornam a atividade de teste mais complexa, como não-determinismo, concorrência, sincronização, aspectos de comunicação, entre outros (Wong et al., 2005; Vergilio et al., 2005).

Em Katayama et al. (1998), é proposto o modelo Event InterActions Graph (EIAG) para representar o comportamento de programas concorrentes. O modelo consiste de grafos de evento (event graphs) e interações (Interactions). Um grafo de evento é um grafo de fluxo de controle de uma unidade de programa em um programa concorrente. As interações representam sincronizações entre os grafos de eventos. Em seguida, é definido Copath (cooperated path) que basicamente é um conjunto que representa o fluxo de execução de um programa concorrente. Esse modelo é utilizado para geração de casos de teste (Katayama et al., 1998, 1999).

No trabalho de Yang et al. (1998), é descrita a geração de casos de teste de acordo com o critério Todos-Du-Caminhos (All Du-Paths) para teste de programas paralelos por memória compartilhada. 
O modelo utilizado nesse trabalho considera múltiplas threads que podem ser executadas simultaneamente, e a comunicação é feita por variáveis compartilhadas. Esse modelo é chamado Parallel Program Flow Graph (PPFG), ou grafo de fluxo de programa paralelo. Tem como principal diferença para o GFC a criação de três tipos de arcos: arcos de fluxo de controle intra-thread, arcos de sincronização e arcos de criação de thread. Em Yang e Pollock (2003), um framework para teste de programas paralelos baseado no modelo PPFG é apresentado. O framework é baseado principalmente no critério de teste todos-usos. Além disso, resultados teóricos e empíricos são apresentados em relação à cobertura do critério todos-usos para programas paralelos.

Seguindo a mesma linha, o trabalho de Vergilio et al. (2005) propõe o modelo Parallel Control Flow Graph (PCFG), baseado no modelo PPFG, e propõe uma família de critérios para teste de programas paralelos em ambientes de troca de mensagens. Um exemplo de uso do modelo para um programa em PVM também é apresentado. O modelo PCFG foi utilizado como uma das bases para realização deste trabalho de mestrado.

Considerando o teste de programas concorrentes, a geração de casos de teste também é pesquisada. O trabalho de Wong et al. (2005) propõe quatro métodos diferentes para efetivamente gerar conjuntos menores de seqüências de teste para cobertura de nós no grafo de alcançabilidade (reachability graph).

\subsection{Comparação entre Critérios de Teste}

As vantagens e desvantagens de critérios de teste de software podem ser avaliadas por meio de estudos teóricos e empíricos. Os estudos teóricos têm sido apoiados principalmente na relação de inclusão e no estudo da complexidade dos critérios (Rapps e Weyuker, 1985; Ntafos, 1988; Weyuker, 1984). A relação de inclusão estabelece uma ordem parcial entre os critérios, caracterizando uma hierarquia entre eles. Diz-se que um critério $C_{1}$ inclui um critério $C_{2}$ se, para qualquer programa $P$ e qualquer conjunto de casos de teste $T_{1}$ que é $C_{1}$-adequado, então $T_{1}$ for também $C_{2}$ adequado e existir um programa $P$ e um conjunto $T_{2}$ que é $C_{2}$-adequado que não seja $C_{1}$-adequado. A complexidade é definida como o número máximo de casos de teste requeridos por um critério, no pior caso. No caso dos critérios baseados em fluxo de dados, esses têm complexidade exponencial, o que motiva a condução de estudos empíricos para determinar o custo de aplicação desses critérios do ponto de vista prático (Maldonado et al., 2004).

Os trabalhos de Frankl e Weyuker (1993); Zhu (1996) abordaram do ponto de vista teórico a questão de eficácia de critérios de teste, e definiram outras relações, que captam a capacidade de revelar erros dos critérios de teste. Segundo Frankl e Weyuker (1993), o fato de um critério $C_{1}$ incluir um critério $C_{2}$ não garante que $C_{1}$ é melhor em revelar erros do que $C_{2}$. Zhu (1996) contesta os resultados de Frankl e Weyuker (1993), argumentando que esses resultados são válidos apenas em um cenário em que os casos de teste são construídos com base no critério utilizado. Considerando um segundo cenário, em que os casos de teste são construídos sem o conhecimento do 
critério, mostrou-se que a relação de inclusão implica também em maior capacidade em descobrir erros (Zhu, 1996).

Do ponto de vista de estudos empíricos, três características costumam ser avaliadas: custo, eficácia e strength (ou dificuldade de satisfação) (Mathur, 1991; Mathur e Wong, 1994; Offutt et al., 1996; Weyuker et al., 1991; Wong e Mathur, 1995; Weyuker, 1990). O custo reflete o esforço necessário para que o critério seja utilizado; em geral é medido pelo número de casos de teste necessários para satisfazer o critério. A eficácia refere-se à capacidade que um critério possui de detectar a presença de erros. O strength refere-se à probabilidade de satisfazer-se um critério tendo sido satisfeito um outro critério (Mathur e Wong, 1994).

Estudos empíricos podem ser utilizados para verificar a aplicabilidade de técnicas de teste. Weyuker (1990) realizou um estudo empírico para investigar os custos da aplicação de critérios baseados em fluxo de dados, com dois objetivos principais: determinar a aplicabilidade desses critérios e fornecer uma previsão ao usuário de quantos casos de teste são necessários para satisfazer um determinado critério. Estudos empíricos também podem ser usados para comparar critérios de teste. Mathur e Wong (1994) compararam a adequação de conjuntos de casos de testes em relação aos critérios AM e Todos-Usos. Os resultados obtidos demonstraram que é mais difícil satisfazer o critério AM do que o critério Todos-Usos. Os resultados demonstraram também que na prática o critério AM inclui o critério Todos-Usos. Já Souza (1996) realizou um estudo comparativo entre os critérios AM e Todos-Potenciais-Usos. Os resultados alcançados mostraram que o custo de aplicação do critério AM é maior do que o critério Todos-Potenciais-Usos. Em relação ao strength, os dois critérios são incomparáveis mesmo do ponto de vista empírico.

\subsection{Ferramentas de Teste de Software}

Segundo Sommerville (2003), os testes constituem uma fase dispendiosa e trabalhosa do processo de software. Atualmente, ferramentas oferecem muitos recursos e seu uso reduz significativamente o custo do processo de testes. Em geral, a atividade de teste envolve a manipulação de grande quantidade de dados, sendo, dessa forma, propensa a erros, se conduzida manualmente. Assim, a disponibilidade de ferramentas é essencial para aumentar a produtividade e melhorar a qualidade dos resultados obtidos.

Diversos esforços da comunidade científica nessa direção podem ser observados para apoio às técnicas descritas neste capítulo. Para o teste funcional, encontram-se as ferramentas ConCat (Martins e Toyota, 1999) que auxilia a construção de classes auto-testáveis e J-FuT (Rocha et al., 2005) que utiliza Programação Orientada a Aspectos para auxiliar o teste funcional de programas Java.

Para apoio ao teste estrutural existem diversas ferramentas produzidas pela comunidade científica. ASSET (Frankl e Weyuker, 1985) é uma das primeiras ferramentas de apoio aos critérios baseados em fluxo de dados para a linguagem Pascal. TACTIC (Ostrand e Weyuker, 1996) é outra 
ferramenta de apoio aos critérios baseados em fluxo de dados para a linguagem C. $\chi$ Suds (Agrawal et al., 1998) é um conjunto de ferramentas de apoio ao teste, análise e depuração de programas. Uma das ferramentas do $\chi$ Suds é a ATAC (Horgan e London, 1991) que apóia a aplicação de critérios de teste estrutural em programas escritos em C e C++. A POKE-TOOL (Chaim, 1991) apóia a aplicação dos critérios Potenciais-Usos e outros critérios estruturais em programas escritos em C. A POKE-TOOL trabalha de forma integrada com a ferramenta ViewGraph (Vilela et al., 1997) que possibilita a visualização do GFC. A ferramenta JaBUTi (Vincenzi et al., 2003; Vincenzi, 2004) é um ambiente para o teste de programas e componentes Java. Um extensão dessa ferramenta é a JaBUTi/AJ (Lemos, 2005), usada para o teste de unidade de programas Orientado a Aspectos. A ferramenta ValiPar (Souza et al., 2005) implementa critérios específicos para programas paralelos em ambiente de troca de mensagens, fornecendo auxílio à seleção e avaliação de dados de teste. A ferramenta implementa um conjunto de critérios de teste estrutural estabelecidos por Vergilio et al. (2005). Alguns módulos da ValiPar foram reutilizados na implementação da ferramenta apresentada neste trabalho.

Para o teste baseado em erros, existe uma família de ferramentas chamadas Proteum. Essas ferramentas dão apoio à aplicação do critério AM. A Proteum (Delamaro, 1993) apóia a utilização do critério AM em programas escritos na linguagem C. A Proteum/IM (Delamaro e Maldonado, 1996), apóia a aplicação do critério Mutação de Interface (Delamaro, 1997). Usando o critério AM em nível de especificação, existem as ferramentas Proteum-RS/FSM (Fabbri, 1996), Proteum-RS/ST (Sugeta, 1999) e Proteum-RS/PN (Simão et al., 2000) que apóiam a validação de especificações baseadas em MEFs, Statecharts e Redes de Petri, respectivamente. Existe ainda a ferramenta Mothra (DeMillo, 1980; DeMillo et al., 1988), que é uma ferramenta de apoio ao critério AM para o teste de programas na linguagem FORTRAN-77.

Para o teste baseado em estados, a ferramenta ATeste (Pinto, 1998) apóia o teste baseado em estados para programas escritos em Smalltalk. A ferramenta KTest (Silveira, 2001) fornece apoio às atividades de teste de programas em Java, dando suporte ao teste baseado em estados.

Por parte da indústria, pode-se observar o esforço alocado pela Telcordia (USA), em cooperação com o SERC/Purdue University (USA), para o desenvolvimento das ferramentas xATAC (que apóia a aplicação de critérios baseados na análise de fluxo de controle e de dados) e xRegress (que reduz o custo do teste de regressão). Essas ferramentas foram inicialmente iniciativas acadêmicas, sendo a xATAC a continuidade da ferramenta ATAC (Horgan e London, 1991). A Hewlett-Packard (HP $)^{1}$, empresa de tecnologia de opera em mais de 170 países, possui um produto denominado HP Quality Center ${ }^{2}$, que fornece um conjunto de ferramentas para garantia de qualidade de software. $\mathrm{O}$ produto inclui as ferramentas HP TestDirector (requisitos, planejamento de testes, gerenciamento de defeitos, etc), HP QuickTest Professional (teste funcional e de regressão), HP WinRunner (teste funcional e regressão), HP Business Process Testing (suporte a construção e execução de testes sem conhecimento de programação) e HP Service Test (teste de WS). A ferramenta HP Service

\footnotetext{
${ }^{1} \mathrm{http} / / /$ www.hp.com/

${ }^{2}$ https://h10078.www1.hp.com/cda/hpms/display/main/hpms_content.jsp?zn=bto\&cp=1-11-127-24_4000_100_
} 
Test possibilita a automatização do teste de regressão funcional, teste de performance e simula clientes de vários ambientes para testar a interoperabilidade do WS. A Parasoft Corporation ${ }^{3}$ fornece soluções para identificação e prevenção automática de erros, contando com as ferramentas JTest (teste para aplicações Java), C++ Test (teste de programas C++), Insure++ (detecção de erros de memória para $\mathrm{C}$ e $\mathrm{C}++$ ) e SOATest (teste de WS). A ferramenta SOATest fornece um fluxo de trabalho completo para o teste de WS, incluindo verificação de interoperabilidade, teste de performance, métricas de QoS e interface intuitiva para controle dos testes. A IBM Rational Software ${ }^{4}$, uma das maiores provedoras de metodologia e ferramentas para desenvolvimento de software, também fornece inúmeras ferramentas de teste como Clear Quest (acompanhamento de defeitos), TestManager (gestão de testes), Robot (automatização de scripts de testes), TeamTest (teste de performance) e XDE Tester (teste funcional).

\subsection{Considerações Finais}

Neste capítulo foi apresentada uma visão geral sobre teste de software. Os principais fundamentos de teste de software foram apresentados. Foram apresentados os critérios de teste das técnicas funcional, estrutural, baseada em erros e baseada em estados. Os principais trabalhos sobre teste de programas paralelos foram mostrados. Formas e motivações para comparação entre critérios de teste também foram descritas. Por fim, foram discutidas iniciativas acadêmicas e industriais para a construção de ferramentas de teste.

Percebe-se que a atividade de teste possui inúmeras técnicas que foram aplicadas tanto em software tradicional, como em especificações formais e programas paralelos. Nesse contexto, atividades de VV\&T podem ser aplicadas para a CWS. No próximo capítulo, são apresentados os principais trabalhos relacionados a este trabalho. Esses trabalhos utilizam técnicas de VV\&T para melhorar a qualidade da CWS.

\footnotetext{
${ }^{3}$ http://www.parasoft.com/jsp/home.jsp

${ }^{4}$ www.ibm.com/software/rational
} 
CAPÍTULO

\section{4}

\section{Verificação, Validação e Teste para Composição de Web Services}

\subsection{Considerações Iniciais}

Neste capítulo são apresentados os trabalhos relacionados à aplicação de VV\&T para a CWS. Este capítulo relata os trabalhos que se relacionam a este trabalho, dando uma visão geral do que vem sendo realizado pela comunidade científica.

Assim como no desenvolvimento de software tradicional, atividades de VV\&T também são fundamentais para que o desenvolvimento da CWS tenha qualidade. CWS adiciona novas características que devem ser verificadas, tais como distribuição, concorrência, sincronização e particularidades das tecnologias envolvidas. Nesse contexto, García-Fanjul et al. (2006) classificam as pesquisas em VV\&T aplicadas à CWS em duas categorias: abordagens de verificação formal e técnicas de teste.

O capítulo está organizado da seguinte forma. Na Seção 4.2 são apresentados os trabalhos que tratam da verificação formal para CWS. Conceitos de redes de Petri também são apresentados, já que redes de Petri são utilizadas neste trabalho para eliminar sincronizações não-executáveis. Na Seção 4.3 são apresentados os trabalhos que aplicam técnicas de teste para CWS. 


\subsection{Verificação Formal}

O objetivo das abordagens baseadas em verificação formal é decidir se certas propriedades estão presentes na composição em estudo (García-Fanjul et al., 2006), sendo model checking a principal técnica utilizada. Model Checking ou verificação de modelos verifica automaticamente a validade de propriedades relacionadas ao comportamento do software, principalmente sistemas reativos, que são sistemas que reagem constantemente a estímulos do ambiente externo. Model checking verifica essas propriedades através da enumeração exaustiva de todos os estados alcançáveis. Em geral, a validação das propriedades acontece em três passos (Vasconcelos, 2003):

1. Especificar quais são as propriedades que o sistema deveria ter para que seja considerado correto. Por exemplo, pode-se querer que o sistema nunca entre em deadlock, ou ainda, que ele sempre alcance um determinado estado.

2. Construir o modelo formal do sistema, que deve capturar todas as propriedades essenciais do sistema, para verificar sua correção. Contudo, o modelo também deverá possuir abstrações de detalhes do sistema de tal forma que não afetem a correção das propriedades a serem verificadas. Essas abstrações são feitas para manter o modelo em um tamanho em que a execução do verificador seja aplicável. Por exemplo, em protocolos de comunicações se está, em geral, interessado em testar propriedade de quando uma mensagem é recebida e não do conteúdo dela. Portanto, na construção do modelo formal para um protocolo de comunicação deve-se abstrair o conteúdo da mensagem, representando apenas o recebimento.

3. Executar o verificador de modelos (model checker) para validar as propriedades especificadas do sistema. Nesse passo, já se têm as propriedades e o modelo. Assim, aplica-se o verificador e consegue-se verificar se o modelo do sistema possui ou não as propriedades desejadas. Caso não satisfaça alguma propriedade, é então gerado um contra-exemplo mostrando o motivo da não verificação da propriedade.

Outras técnicas formais são aplicadas para verificação de CWS, como álgebras de processo e redes de Petri. Por ser utilizada neste trabalho como modelo intermediário na eliminação de sincronizações não-executáveis e estar relacionada com alguns trabalhos, conceitos de redes de Petri são apresentados na Seção 4.2.1. Na Seção 4.2.2, trabalhos que aplicam verificação formal para CWS são apresentados.

\subsubsection{Redes de Petri}

Rede de Petri é uma especificação formal utilizada para modelar sistemas reativos. A rede de Petri foi criada inicialmente por Carl A. Petri em 1969 e é utilizada para modelar sistemas com interação de sistemas síncronos e concorrentes (Simão, 2004). Inúmeras classes de redes de Petri foram criadas, dentre elas, as redes de Petri Lugar/Transição (Murata, 1989), Coloridas 
(Jensen, 1997), redes Predicado/Transição (Genrich, 1987), Temporais (Kumar e Harous, 1994), entre outras. Nesta seção, as redes de Petri Lugar/Transição são explicadas em mais detalhes.

Uma rede de Petri é um tipo particular de grafo direcionado, junto com um estado inicial chamado de marcação inicial. O grafo de uma rede de Petri é direcionado, com pesos e bipartido, consistindo de dois tipos de nós chamados lugar e transição. Os arcos ligam um lugar a uma transição ou uma transição a um lugar. Na representação gráfica, lugares são círculos e transições são caixas. Arcos são nomeados com seus pesos, que são inteiros positivos. Uma marcação atribui a cada lugar um inteiro não-negativo. Graficamente, é colocado um ponto nos lugares. Esse ponto é chamado de token. Uma marcação é denotada por $M$, que é um vetor de tamanho $m$, sendo que $m$ é o total de lugares. O $p$-ésimo componente de $M$ é denotado por $M(p)$, que é o número de tokens no lugar $p$. Uma transição $t$ possui um certo número de lugares de entrada, que são os lugares $l$ conectados a $t$ por um arco de $l$ para $t$. Uma transição também possui lugares de saída, que são os lugares $l$ conectados a $t$ por um arco de $t$ para $l$.

A seguir será dada uma definição formal de uma rede de Petri Lugar/Transição. Uma rede de Petri é uma 5-tupla $P N=\left(P, T, F, W, M_{0}\right)$, onde (Murata, 1989):

- $P=\left\{p_{1}, p_{2}, \ldots, p_{m}\right\}$ é um conjunto finito de lugares,

- $T=\left\{t_{1}, t_{2}, \ldots, t_{n}\right\}$ é um conjunto finito de transições,

- $F \subseteq(P \times T) \cup(T \times P)$ é um conjunto de arcos,

- $W: F \mapsto 1,2,3, \ldots$ é uma função de pesos,

- $M_{0}: P \mapsto 0,1,2,3, \ldots$ é a marcação inicial,

- $P \cap T=\emptyset$ e $P \cup T=\emptyset$.

Uma rede de Petri $N$ sem uma marcação inicial definida é denotada por $N=(P, T, F, W)$. Uma rede de Petri com uma dada marcação inicial é denotada por $\left(N, M_{0}\right)$. Um estado ou marcação em uma rede de Petri é mudado de acordo com a seguinte regra de transição:

1. Uma transição $t$ é habilitada se cada lugar de entrada $p$ de $t$ é marcada com no mínimo $w(p, t)$ tokens, onde $w(p, t)$ é o peso do arco de $p$ para $t$.

2. Uma transição habilitada pode ou não ser disparada, dependendo se o evento acontece ou não.

3. O disparo de uma transição $t$ remove $w(p, t)$ tokens de cada lugar de entrada $p$ de $t$, e adiciona $w(t, p)$ tokens para cada lugar de saída $p$ de $t$, onde $w(t, p)$ é o peso do arco de $t$ para $p$. 
O exemplo de uma rede de Petri pode ser visto na Figura 4.1. Essa rede apresenta o conjunto de lugares $P=\left\{P_{1}, P_{2}, P_{3}, P_{4}\right\}$, o conjunto de transições $T=\left\{T_{1}, T_{2}, T_{3}\right\}$ e a marcação inicial $M_{0}=\langle 1,0,1,0\rangle$. Os arcos que não apresentam pesos possuem peso igual a um. Percebe-se que a única transição que pode ser disparada é a $T_{3}$. O disparo da transição $T_{3}$ resultaria na marcação $M=\langle 1,0,0,1\rangle$.

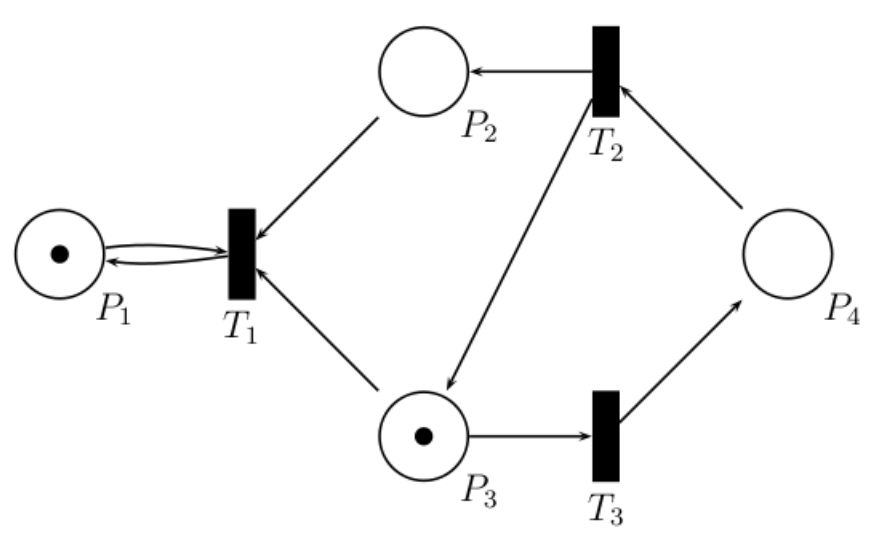

Figura 4.1: Exemplo de uma rede de Petri (Peterson, 1981).

Dada uma rede de Petri $\left(N, M_{0}\right)$, por meio da marcação inicial $M_{0}$ é possível obter novas marcações para cada uma das transições habilitadas. Para cada nova marcação, é novamente possível obter mais marcações. Esse processo resulta em uma árvore representando as marcações alcançáveis. Os nós da árvore representam as marcações, cuja raiz é a marcação $M_{0}$ e cada arco representa a transição habilitada que transformou uma marcação em outra. Entretanto, essa árvore pode crescer infinitamente. Para manter a árvore em um tamanho finito, introduziu-se o símbolo $\omega$, que pode ser interpretado como infinito. Possui as propriedades que, dado um inteiro $n, \omega>n, \omega \pm n=\omega$ e $\omega \geq \omega$. Essa árvore possui um tamanho finito e é chamada de árvore de cobertura (coverability tree). Ela é construída pelo algoritmo a seguir (Murata, 1989).

1. Atribua a marcação inicial $M_{0}$ como a raiz da árvore e nomei-a como "nova".

2. Enquanto existirem marcações "novas", faça:

(a) Selecione uma nova marcação $M$.

(b) Se $M$ é igual a uma marcação no caminho da raiz para $M$, então nomeie $M$ como "velha" e vá para a próxima marcação.

(c) Se nenhuma transição está habilitada em $M$, nomeie $M$ como "dead-end".

(d) Enquanto existir transições habilitadas em $M$, para cada transição $t$ habilitada em $M$ faça:

i. Obtenha a marcação $M^{\prime}$ que resulta do disparo de $t$ em $M$. 
ii. No caminho da raiz até $M$, se existir uma marcação $M^{\prime \prime}$, dado que $M^{\prime}(p) \geq M^{\prime \prime}(p)$ para cada lugar $p$ e $M^{\prime} \neq M^{\prime \prime}$. Isso quer dizer que $M^{\prime}$ é coberto, então troque $M^{\prime}(p)$ por $\omega$ para cada $p$, dado que $M^{\prime}(p)>M^{\prime \prime}(p)$.

iii. Insira $M^{\prime}$ como nó e adicione um arco nomeado $t$ de $M$ para $M^{\prime}$ e nomeie $M^{\prime}$ como "nova".

Na Figura 4.2, é demonstrada a árvore de cobertura para o exemplo apresentado na Figura 4.1, gerada utilizando o algoritmo apresentado.

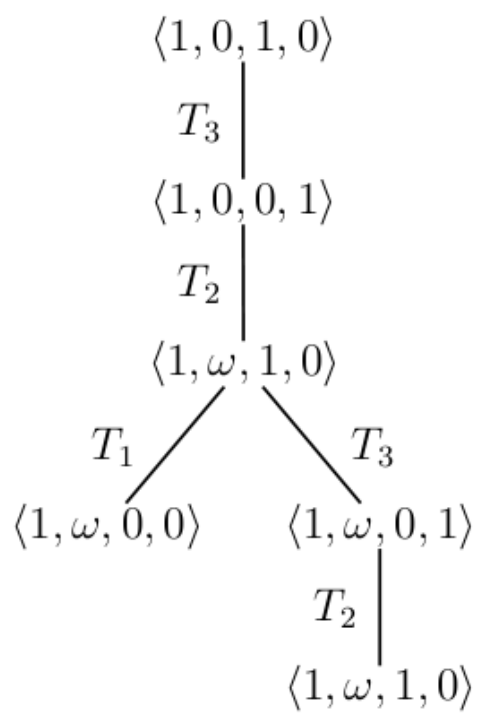

Figura 4.2: Árvore de cobertura para rede de Petri da Figura 4.1 (Simão, 2004).

\subsubsection{Trabalhos}

O trabalho de Fu et al. (2004) traduz especificações BPEL4WS para uma linguagem intermediária e depois para a PROMELA ${ }^{1}$, que é usada como entrada para model checker SPIN (Holzmann, 2003). É usado o conceito proposto de sincronizabilidade para que WSs compostos com filas de entradas ilimitadas possam ser verificados completamente. Um WS composto é sincronizável se seu conjunto de conversação continua igual, mesmo quando uma comunicação assíncrona é substituída por uma comunicação síncrona. Em uma abordagem semelhante, Huang et al. (2005b) especificam a composição em OWL-S e as propriedades em PDDL (Planning Domain Definition Language). Em seguida, geram uma linguagem de especificação semelhante a $\mathrm{C}$ e incluem nessa linguagem as propriedades que se deseja verificar. Por fim, utilizam essa linguagem como entrada para o model checker BLAST (Henzinger et al., 2002). Com o BLAST, são gerados casos de teste positivos (casos de teste em que as propriedades não são violadas) e negativos (casos de teste em

${ }^{1}$ PROMELA (Process Meta Language) é uma linguagem que permite a criação dinâmica de processos concorrentes. Pode ser analisada pelo model checker SPIN. 
que as propriedades são violadas). Em outro trabalho, Huang et al. (2005a) propõem uma nova técnica, chamada proof slicing, para melhorar o processo de model checking, também especificada em OWL-S. A técnica proof slicing quebra provas em fatias de prova (proof slices) que podem ser mais seletivamente reutilizadas. É utilizada para reduzir as chamadas a provas de teorema que diminuem a performance dos model checkers.

Em Foster et al. (2003), composições são modeladas em UML usando diagramas de seqüência e BPEL4WS, e transformadas na notação FSP (Finite State Processes) ${ }^{2}$ para verificação. Esse trabalho possui duas extensões: na primeira, as propriedades a serem verificadas estão ligadas à compatibilidade (Foster et al., 2004); e na segunda, o modelo é estendido para modelar e analisar o comportamento da coreografia (WS-CDL) de interações entre composições de WSs em BPEL4WS (Foster et al., 2006). A ferramenta LTSA-Eclipse ${ }^{3}$ (Foster et al., 2005a), que foi implementada como um plug-in para o Eclipse ${ }^{4}$, oferece apoio ao método proposto. Um estudo de caso também foi desenvolvido para aplicar o método em um sistema da polícia do Reino Unido (Foster et al., 2005b).

O trabalho de Betin-Can et al. (2005) propõe um padrão de projeto denominado Peer Controller que facilita verificação da composição. Esse padrão propõe que, associada a cada peer (WS envolvido na composição) exista uma interface que descreve a interação com os demais peers, além de permitir a geração automática de BPEL4WS. Em Betin-Can e Bultan (2005), esse padrão de projeto é integrado ao modelo de máquina de estado hierárquica - Hierarchical State Machine (HSM) - para realização de model checking.

Outras técnicas formais são aplicadas para verificação de CWS. Ferrara (2004) utiliza a álgebra de processo LOTOS para projetar e verificar CWS, além de fornecer mapeamentos para a tradução de LOTOS para BPEL4WS e para a tradução de BPEL4WS para LOTOS. Deutsch et al. (2006) utilizam dois formalismos para verificar CWS que interagem por troca de mensagens assíncronas: Lógica de Primeira-Ordem Temporal Linear e Protocolos de Conversação. Kazhamiakin et al. (2006) propõem um modelo paramétrico para descrever CWS, permitindo capturar uma hierarquia dos modelos de comunicação, tanto síncrona como assíncrona. Fu et al. (2006) propõem o modelo Service-Oriented Software Architecture Model (SO-SAM), que facilita a verificação e monitoração da CWS e é uma extensão do modelo SAM para aplicações WS. SO-SAM descreve cada WS como um componente e a CWS como conectores entre os componentes, representada por uma rede de Petri. Redes de Petri é outro formalismo que vem sendo utilizado para modelar e facilitar a verificação de CWS. Um dos primeiros trabalhos é o de Narayanan e McIlraith (2002), que codificam especificações de CWS em DAML-S, antecessora da OWL-S, em redes de Petri para simulação, verificação e composição. Modelos estendidos de redes de Petri também são utilizados. Nos trabalhos de Yang et al. (2005b,a, 2006), composições em BPEL4WS são transformadas em redes de Petri coloridas e composições em WSCI são transformadas em redes de Petri coloridas

\footnotetext{
${ }^{2}$ FSP é uma notação textual para descrever concisamente programas concorrentes (Foster et al., 2003).

${ }^{3}$ http://www.doc.ic.ac.uk/ltsa/

${ }^{4}$ http://www.eclipse.org/
} 
hierárquicas. Já o trabalho de Dong et al. (2006), utiliza redes de Petri de alto nível (High-level Petri Net) para modelar e verificar composições BPEL.

\subsection{Técnicas de Teste}

Estudos vêm sendo realizados pela comunidade de teste para propor técnicas e ferramentas de apoio ao teste de WSs. Em Tsai et al. (2002b), extensões ao tradicional formato dos documentos WSDL são propostas para facilitar a execução de testes, como a inclusão de dependências entre entrada e saída e sequiências de invocação. Já Siblini e Mansour (2005) propõem a utilização da técnica análise de mutantes, aplicando operadores de mutação em documentos WSDL, de modo a produzir mutantes que podem demonstrar erros no WS. Em trabalho semelhante, Offutt e Xu (2004) utilizam a técnica perturbação de dados (data perturbation) para gerar casos de teste. A perturbação de dados consiste em modificar uma mensagem de requisição e enviá-la novamente ao WS e analisar a mensagem de resposta em relação ao comportamento correto. No trabalho de Cruz Filho (2007), é proposta uma abordagem de perturbação de dados dirigida por padrões que é aplicada para testar WSs. Uma ferramenta de apoio à nova abordagem também foi implementada (Cruz Filho e Vergilio, 2007). Em Mei e Zhang (2005), um framework para testes de WSs é proposto, facilitando a geração de dados de teste e a execução do teste. A arquitetura da ferramenta que implementa o framework proposto também é demonstrada. Outros trabalhos também propõem frameworks para teste de WSs, como o Coyote (Tsai et al., 2002a) que apóia a especificação e execução dos testes e o framework de Bertolino e Polini (2005) que estende o registro UDDI para validar o comportamento do WS antes de ser registrado. PLASTIC (Providing Lightweight \& Adaptable Service Technology for pervasive Information \& Communication) é um projeto que visa a fornecer uma plataforma para projeto e implementação de serviços móveis (Eikerling et al., 2007). Com o intuito de disponibilizar um conjunto de ferramentas para a validação de serviços, o projeto PLASTIC desenvolveu um pacote de ferramentas denominado PLASTIC Work Package $(\mathrm{WP} 4)^{5}$. Esse pacote é direcionado para a validação de serviços dinâmicos, adaptáveis e móveis, baseando-se em propriedades funcionais e não-funcionais.

Segundo Li et al. (2005), os testes para composições de WSs geralmente não possuem apoio de ferramentas e são executados manualmente. Composições especificadas em BPEL4WS são complexas e interagem com outros WSs que também devem ser testados. No teste de unidade caixa-branca, em que o processo BPEL4WS é considerado a unidade sobre teste, o teste sistemático de sua lógica interna pode fornecer valioso feedback e garantir a qualidade (Li et al., 2005; Mayer e Lübke, 2006).

No trabalho de Li et al. (2005) é proposto um framework para teste de unidade de processos BPEL4WS, incluindo um modelo de composição, uma arquitetura de teste, um esquema de geren-

\footnotetext{
${ }^{5}$ http://plastic.isti.cnr.it/wiki/doku.php/tools
} 
ciamento de ciclo de vida e um esboço do projeto de teste. Li et al. (2005) dividem o framework proposto em quatro partes:

Modelo de composição de processo BPEL - nesse modelo, o processo BPEL sobre teste é chamado de PUT (Process Under Test), e os processos parceiros são chamados de PP (Partner Process). Na Figura 4.3(a) é mostrada a estrutura estática de uma composição.

Arquitetura de teste - nessa arquitetura, no teste de unidade é necessário simular os parceiros do PUT, como mostrado na Figura 4.3(b). Os processos de teste (TP) simulam os parceiros, e o processo de controle (CP) controla os TPs.

Gerenciamento do ciclo de vida - essa parte lida com a inicialização e finalização dos TPs e CT, introduzindo uma interface com o usuário para que o gerenciamento do ciclo de vida seja realizado pelo testador.

Definição do processo de teste - essa parte discute como um TP implementa o comportamento do PP correspondente, e também como o TP implementa mecanismos para detectar tipos de erros pré-definidos, usando modelos de erros de implementações de processos BPEL. Um exemplo seria a perspectiva de entrada e saída, em que erros podem ser classificados em três tipos: conteúdo da mensagem de saída incorreta, ausência de produção de saída e produção de saída inesperada.

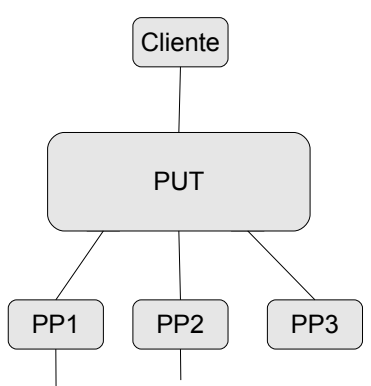

(a)

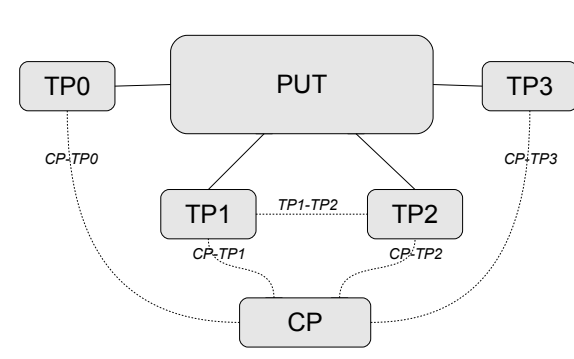

(b)

Figura 4.3: Modelo de composição e arquitetura de teste (Li et al., 2005).

Em um trabalho semelhante, Mayer e Lübke (2006) propõem uma abordagem baseada em camadas para a criação de frameworks de teste de unidade para processos BPEL. A arquitetura proposta, que pode ser vista na Figura 4.4, apresenta as seguintes camadas:

Especificação de teste: essa camada está interessada em como os dados de teste e comportamento são formulados. Da perspectiva do testador, a informação que trafega entre os processos pode ser diferenciada em dado de entrada e dado de saída. Dado de entrada é o dado enviado pelo PUT, que deve ter sua corretude analisada. Dado de saída é o dado de teste devolvido para o PUT. A especificação de teste deve fornecer uma forma de validar a corretude dos dados de entrada bem como criar os dados de saída. 
Organização do teste: um caso de teste pode consistir de múltiplos arquivos e/ou entradas no banco de dados. A organização do teste deve fornecer uma forma de integrar todos os diferentes artefatos em um caso de teste completo. Existem duas abordagens básicas para a organização do teste que são (i) lógica de conjunto de teste integrada e (ii) especificação do conjunto de teste separado. A primeira integra a organização com a especificação de teste. Já a segunda permite separar artefatos da organização de teste.

Execução do teste: para ser testado, como qualquer programa, um processo BPEL deve ser executado. Os testes podem acontecer de duas formas: teste simulado e teste tempo-real. No teste simulado, o processo é disponibilizado em uma engine que fornece uma API para depuração, sendo a execução controlada pelo framework. Dessa forma, as chamadas aos WSs são interceptadas e tratadas localmente. No teste tempo-real, o processo BPEL é disponibilizado em uma engine e invocado usando chamadas a WSs. Todos os parceiros precisam ser trocados por mocks, que são implementações substitutas para emular ou instrumentar outro código, em geral, utilizado para testes.

Resultados do teste: após a execução, os resultados e estatísticas são apresentadas ao usuário. Algumas métricas podem ser utilizadas, como, por exemplo, cobertura de código. Para a cobertura de código são apresentadas algumas soluções como APIs e a utilização dos mocks para logar informações necessárias das atividades realizadas.

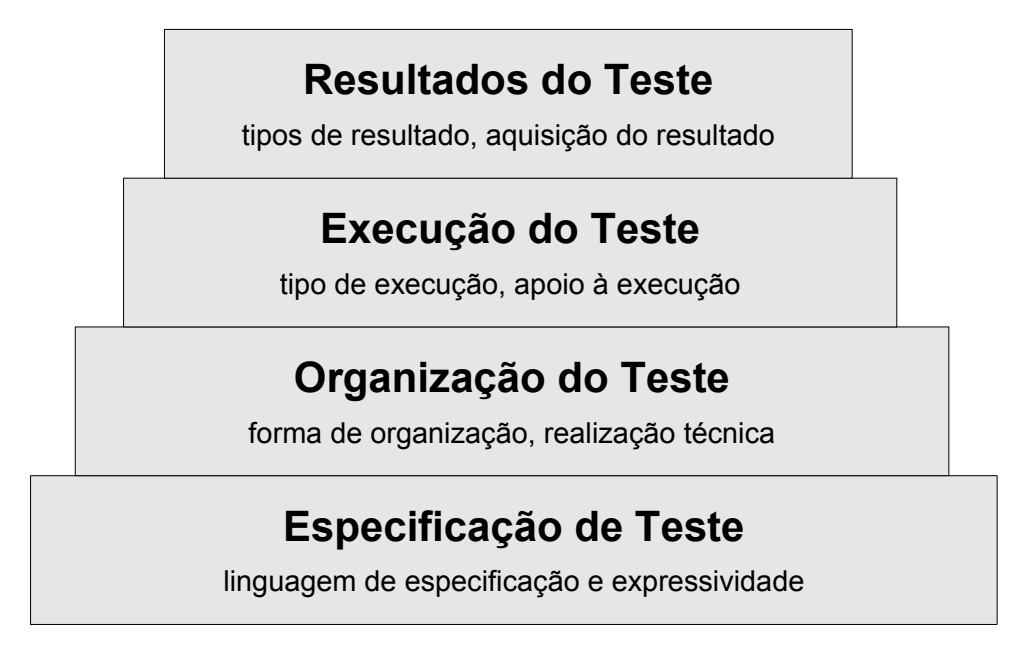

Figura 4.4: arquitetura de teste BPEL (Mayer e Lübke, 2006).

No trabalho de Tsai et al. (2004), uma nova técnica de teste denominada Web Services Group Testing (WSGT) é proposta e aplicada no teste de integração da CWS. A técnica WSGT basicamente agrupa WSs com funcionalidades equivalentes em conjuntos e envia as entradas para todos os WSs compostos (combinação de conjuntos de WS). O serviço de votação é uma aplicação que coleta as saídas dos WSs compostos e sincroniza com as entradas. Com esses dados, o serviço de votação calcula pesos que são utilizados para classificar a confiabilidade dos WSs, efetividade dos 
scripts de teste e estabelecer um oráculo para cada caso de teste. Uma visão da técnica explicada pode ser vista na Figura 4.5.

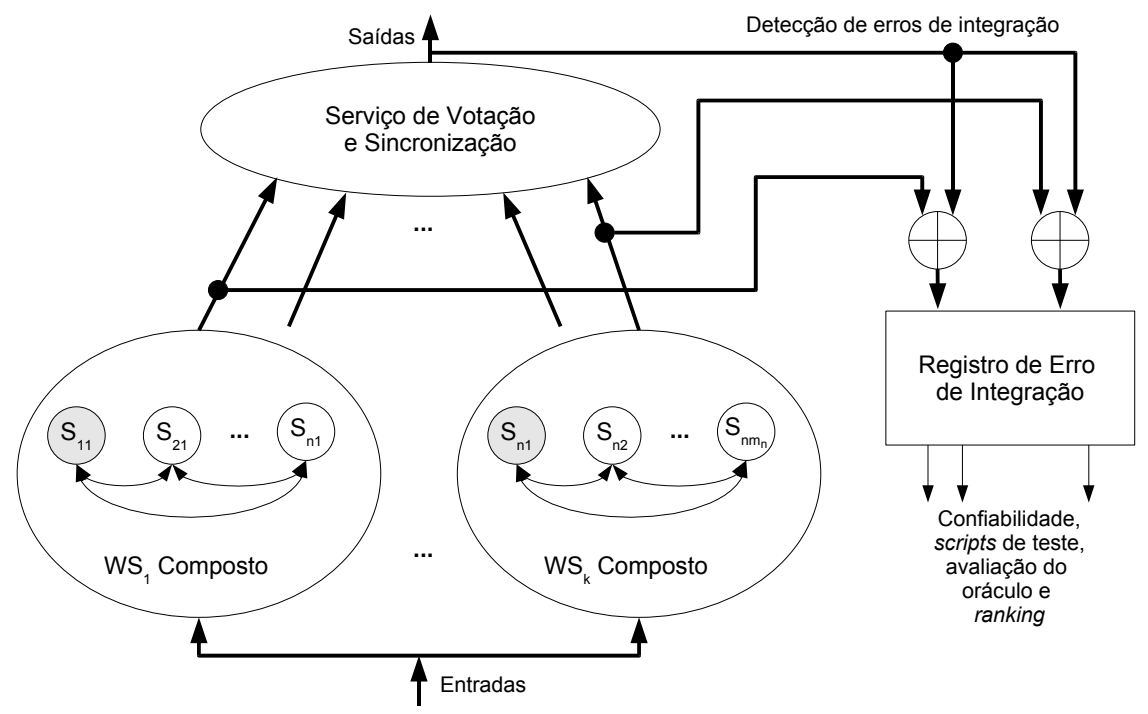

Figura 4.5: Group Testing de múltiplos WS compostos (Tsai et al., 2004).

O trabalho de García-Fanjul et al. (2006) está relacionado à geração de conjuntos de casos de teste utilizando o model checker SPIN, além de definir um procedimento sistemático para selecionar casos de teste. O método proposto é dividido em quatro passos (Figura 4.6):

\section{Transformar BPEL4WS em PROMELA.}

2. Aplicar um critério de adequação, de acordo com os requisitos de teste estabelecidos.

3. Executar o model checker e obter um contra-exemplo.

4. Especificação dos casos de teste, em que uma análise é realizada no contra-exemplo para extrair informações relevantes.

Benharref et al. (2006) propõem uma arquitetura com múltiplos observadores para detectar e localizar defeitos em WSs compostos. A arquitetura geral é ilustrada na Figura 4.7, em que um observador global e observadores locais cooperam para coletar e gerenciar os defeitos que são emitidas pelo WS composto. Nesse trabalho é utilizado o conceito de teste passivo ou observação passiva, que é baseada na coleta e análise de traces.

No trabalho de Pautasso (2005), técnicas de refatoração de código e teste são aplicadas dentro da linguagem de composição visual JOpera (JOpera, 2004), com maior ênfase em refatoração. Em relação aos testes, o ambiente JOpera facilita o teste dos WSs participantes da composição, além de permitir a realização de testes de regressão, gravando informações sobre o estado completo da execução de uma composição e permitindo comparações com outras execuções.

Os trabalhos de Yan et al. (2006) e Yuan et al. (2006) estão focados em geração de casos de teste em nível de unidade. Yan et al. (2006) propõem um novo método para gerar casos de 


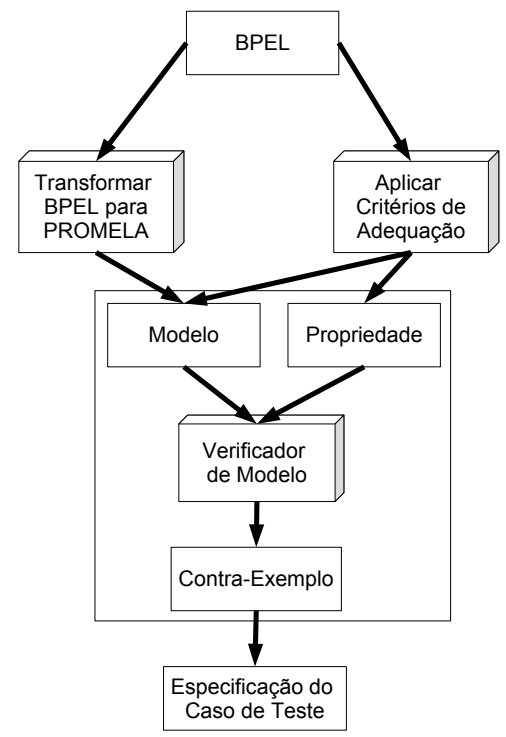

Figura 4.6: Visão geral do método proposto por García-Fanjul et al. (2006).

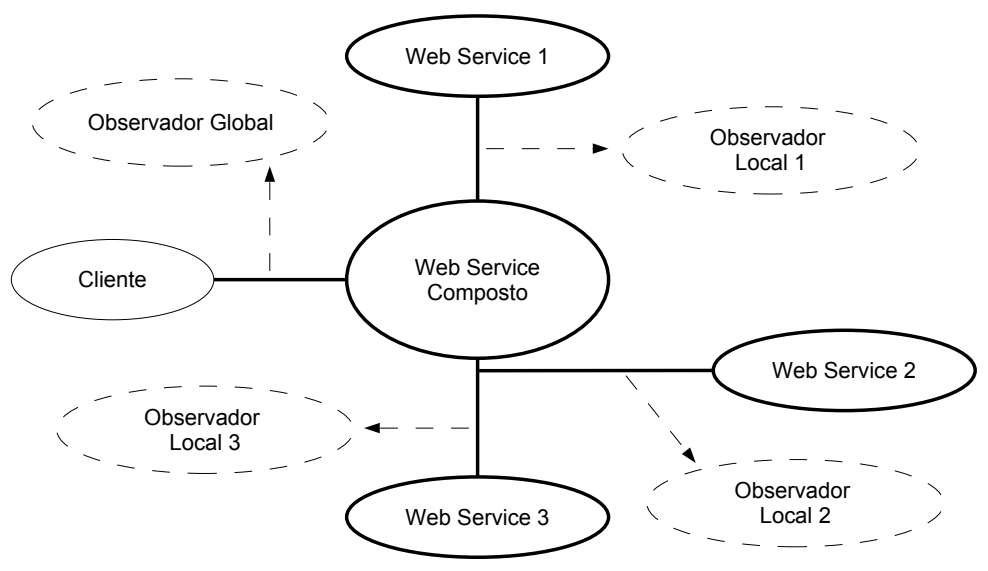

Figura 4.7: Arquitetura de múltiplos observadores (Benharref et al., 2006).

teste para programas BPEL. Inicialmente, o método transforma programas BPEL em um Extended Control Flow Graph (XCFG), e gera todos os caminhos sequenciais do XCFG. Esses caminhos são combinados em caminhos de teste concorrentes. Por fim, o resolvedor de restrições BoNuS é usado para resolver as restrições desses caminhos e gerar casos de teste executáveis. Alguns métodos para reduzir o número de casos de teste gerados são apresentados. O fluxo de trabalho de método proposto pode ser visto na Figura 4.8. Os resultados experimentais foram realizados baseado em apenas um exemplo.

No trabalho de Yuan et al. (2006), os processos BPEL são tratados como um tipo de programa concorrente, em que características especiais devem ser tratadas de forma especial. Yuan et al. (2006) também propõem uma extensão ao GFC chamado BPEL Flow Graph (BFG), para representar graficamente um programa BPEL, utilizando para isso tipos especiais de nós e arcos. O método utilizado para gerar os casos de teste contém quatro passos, como mostrado na Figura 4.9. 


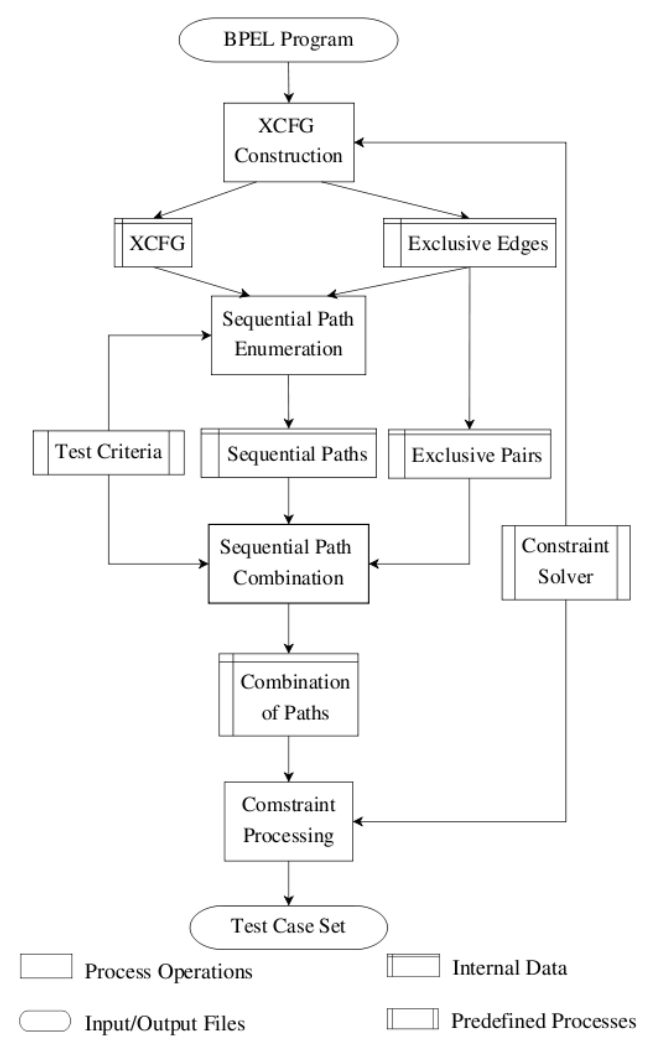

Figura 4.8: Fluxo de trabalho do método proposto por Yan et al. (2006).

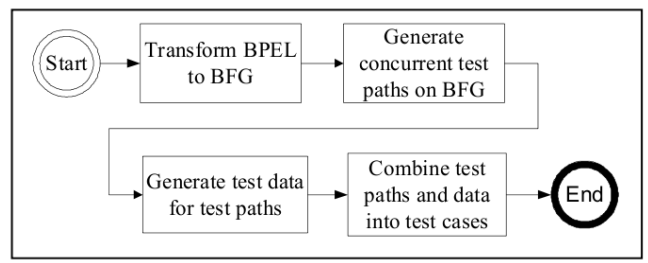

Figura 4.9: Processo para o método de geração proposto por Yuan et al. (2006).

O primeiro passo transforma o programa BPEL no modelo BFG. O segundo passo gera um conjunto de caminhos de teste baseados no BFG, seguindo um objetivo de cobertura definido. Essa abordagem é baseada em busca no grafo (graph-search) para gerar casos de teste. O terceiro passo filtra caminhos não-executáveis e gera dados de teste para os caminhos executáveis. Ferramentas para resolução de restrições (constraint solving) são propostas para encontrar caminhos não-executáveis e os dados de teste seriam gerados usando ferramentas de geração de dados aleatórios. O último passo gera casos de teste, combinando caminhos e dados de teste.

Em Chan et al. (2007), é proposta uma nova taxonomia de defeitos para composição de Web Services. A taxonomia divide os defeitos em físicos (physical), de desenvolvimento (development) e defeitos de interação (interactions faults). Essas três categorias de defeitos são combinadas com classes elementares de criação ou ocorrência, limites do sistema (systems boundaries) e dimensão. Baseado nessa combinação, uma matriz mostrada na Figura 4.10 é apresentada. A combinação pode fornecer uma explicação de causas e conseqüências de falhas. Eles não objetivam fornecer 
mecanismos para detectar defeitos, focando principalmente em caracterizar e classificar tipos de defeitos.

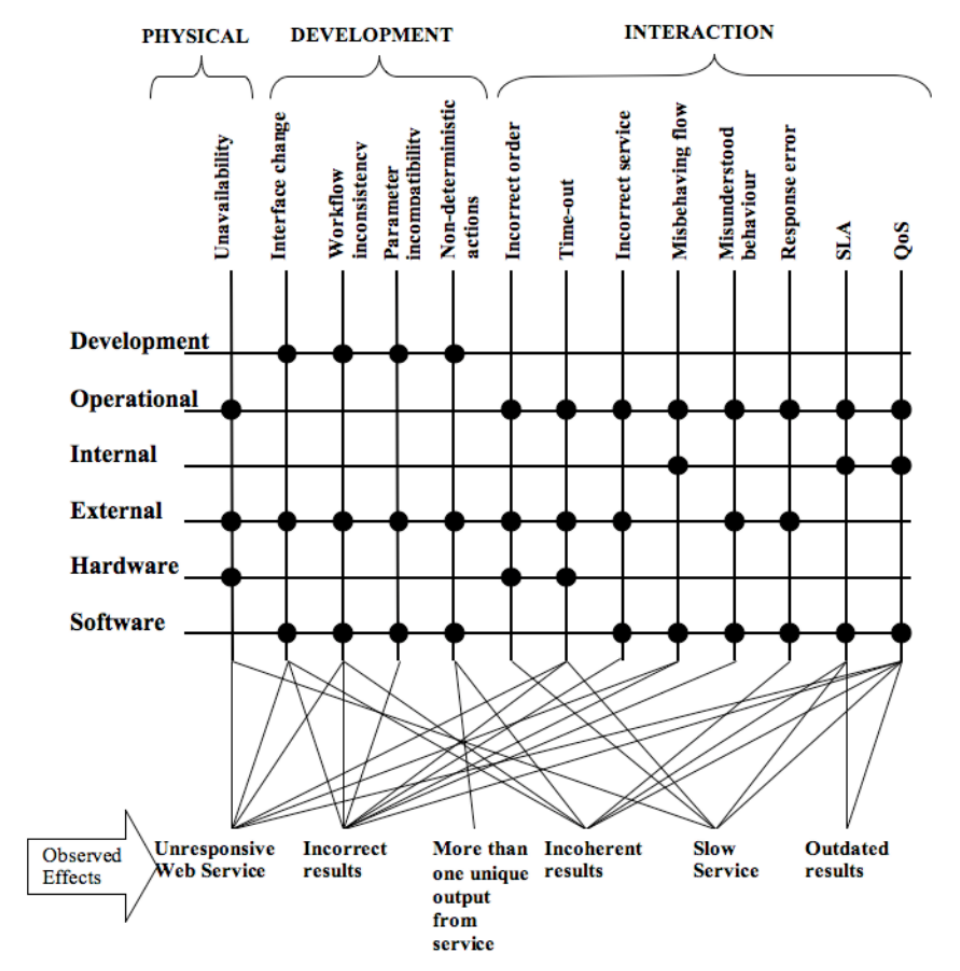

Figura 4.10: Taxonomia de defeitos combinada com efeitos observados.

O trabalho de Bertolino et al. (2007) apresenta um position paper que demonstra perspectivas de trabalhos futuros na área de validação baseada em fluxo de dados para CWS. A idéia principal é definir uma linguagem para modelar o fluxo de dados com propósito de executar testes. É previsto também tentar adaptar abordagens de teste já existentes.

\subsection{Considerações Finais}

Neste capítulo foram apresentados os principais trabalhos relacionados à VV\&T para CWS. Os trabalhos foram classificados em verificação formal e técnicas de teste. Na verificação formal, a maioria dos trabalhos focaliza em model checking, usando como modelos especificações formais, como máquinas de estados e redes de Petri, para representação e verificação das composições.

$\mathrm{Na}$ categoria de técnicas de teste, dois frameworks para teste de unidade foram apresentados ( $\mathrm{Li}$ et al., 2005; Mayer e Lübke, 2006). A técnica WSGT proposta por Tsai et al. (2004) foi descrita. Além disso, foram descritos trabalhos sobre geração de casos de teste, utilização de observadores e o ambiente JOpera. Os trabalhos de Yuan et al. (2006) e Yan et al. (2006) apresentam métodos semelhantes, baseados em exemplos parecidos, focados principalmente na geração de caminhos de teste. A geração de dados de teste fica por conta de resolvedores de restrições. Ambos não apresentam ferramentas de apoio e concentram-se em nível de teste de unidade. Por fim, os trabalhos 
de Chan et al. (2007); Bertolino et al. (2007) apresentam avanços na definição de uma taxonomia de defeitos para CWS e validação de CWS baseada em fluxo de dados.

Por existir na atividade de teste a necessidade de execução do produto sob teste, a maioria dos trabalhos apresentados se concentra na linguagem BPEL (Li et al., 2005; Mayer e Lübke, 2006; García-Fanjul et al., 2006; Yan et al., 2006; Yuan et al., 2006), por enquanto a principal linguagem executável para CWS.

Recentemente estudos sobre VV\&T para CWS vêm sendo desenvolvidos pela academia. Nesse contexto, o teste de CWS ainda é uma disciplina imatura, embora muitas técnicas e metodologias de teste já existentes possam ser reutilizadas (Bucchiarone et al., 2007). No trabalho de Li et al. (2005) são apontadas algumas lacunas no teste de unidade para processo BPEL:

- Processos raramente são testados isoladamente, porque são dependentes de seus parceiros. Ou seja, não se pode executar o processo se seus parceiros não estão prontos.

- Raramente um processo é testado isoladamente pela simulação de seus parceiros. Os parceiros são escritos de maneira ad hoc, subjetiva e incompleta.

- Todas as atividades de teste são executadas manualmente, sem nenhuma ferramenta de apoio.

Pelos trabalhos existentes que foram apresentados, surgem inúmeras oportunidades de pesquisa em aplicações de técnicas de teste em CWS, como teste estrutural, teste baseado em erros, geração de casos de teste, infraestruturas de suporte ao teste, entre outras. Em geral, a maioria dos trabalhos lida principalmente com o teste de unidade. Este trabalho está inserido no contexto de teste de integração, considerando principalmente a comunicação entre processos BPEL. No próximo capítulo é apresentada uma estratégia de teste, no qual procura-se explorar potencialidades da aplicação de técnicas de teste de programas paralelos no contexto do teste de CWS. 


\section{Estratégia de Teste para Composição de Web Services}

\subsection{Considerações Iniciais}

A CWS possibilita que novas funcionalidades sejam definidas e implementadas pela combinação de WSs existentes, acelerando o desenvolvimento de aplicações e melhorando o reúso de WSs. A CWS é um assunto que vem sendo pesquisado atualmente (Peltz, 2003; Milanovic e Malek, 2004; Kazhamiakin et al., 2006; Benharref et al., 2006; Baresi et al., 2007). Assim como no desenvolvimento de software tradicional, o desenvolvimento dessa classe especial de software é uma atividade propensa a erros, necessitando de testes para garantir que requisitos de qualidade sejam atendidos. Entretanto, foram observados poucos trabalhos que utilizam técnicas de teste de software em CWS.

Neste capítulo é apresentada uma estratégia de teste para CWS. É proposta uma transformação de composições especificadas em BPEL para um modelo de teste de programas paralelos proposto por Vergilio et al. (2005). Como uma CWS troca mensagens entre seus elementos de forma semelhantes a programas paralelos baseado em passagem de mensagens, essa transformação foi proposta. O conceito de grupos de elementos requeridos, que também pode ser aplicado em programas paralelos, é proposto para melhorar a cobertura de critérios de teste. É apresentado também um método que aplica redes de Petri na eliminação de pares de sincronização não-executáveis em programas paralelos baseados em passagem de mensagens. Uma ferramenta de apoio à estratégia também é apresentada, bem como os resultados de alguns experimentos realizados. 
O capítulo está organizado da seguinte forma. Na Seção 5.2, conceitos e um exemplo do modelo de teste para programas paralelos são apresentados. Na Seção 5.3 é apresentada a transformação de composições especificadas em BPEL para o modelo PCFG. Critérios de teste e um exemplo também são demonstrados nessa seção. Na Seção 5.4, o conceito de grupos de elementos requeridos é apresentado. Utilizando esse conceito, a cobertura de critérios de teste pode ser melhorada. Na Seção 5.5 é demonstrado um método para eliminação de pares de sincronização não-executáveis utilizando redes de Petri. Exemplos e discussões sobre o método também são apresentados. Na Seção 5.6, a ferramenta ValiBPEL-Web é apresentada. O projeto da ferramenta, aspectos de implementação e o processo de teste utilizado pela ferramenta também são apresentados nessa seção. Na Seção 5.7 são apresentados resultados experimentais sobre a aplicação da estratégia proposta em três exemplos.

\subsection{Modelo PCFG}

A seguir são apresentados os conceitos do Parallel Control Flow Graph (PCFG) (Vergilio et al., 2005) necessários para o entendimento do trabalho. O modelo foi definido para capturar o fluxo de controle, dados e comunicação em programas paralelos baseados em passagem de mensagens. $\mathrm{O}$ modelo considera um número $n$ fixo e conhecido de processos dado pelo conjunto Prog $=$ $\left\{p^{0}, p^{1}, \ldots p^{n-1}\right\}$. A comunicação entre esses processos é feita por meio das primitivas send e receive. Cada processo $p$ possui seu próprio grafo de fluxo de controle $C F G^{p}$ (Rapps e Weyuker, 1985; Zhu et al., 1997).

O PCFG é composto pelos GFCs dos processos e pela representação da comunicação entre os processos. $N$ e $E$ representam os conjuntos de nós e arcos, respectivamente. Cada nó $n_{i}$ no processo $p$ é representado com a notação $n_{i}^{p}$. Dois subconjuntos de $N$ são definidos: $N_{s}$ e $N_{r}$, compostos de nós que são associados às primitivas send e receive, respectivamente. $\mathrm{O}$ conjunto $E$ também possui dois subconjuntos: $E_{i}^{p}$ contém os arcos intra-processo (internos) do processo $p$ e $E_{s}$ contém os arcos inter-processos (representam a comunicação) do $P C F G$. A criação dos arcos inter-processos pode ser realizada utilizando uma abordagem conservativa, em que são combinados todos os nós send com todos os nós receive, exceto os que estão no mesmo processo. Um problema desse tipo de abordagem é o grande número de arcos inter-processos que são gerados.

Um caminho $\pi^{p}$ em um $C F G^{p}$ é chamado caminho intra-processo. Um caminho interprocessos possui pelo menos um arco inter-processos e é dado por um conjunto de caminhos, $\Pi=\left(\pi^{0}, \pi^{1}, \ldots \pi^{k}, S\right)$, onde $S$ é o conjunto de arcos inter-processos (pares de sincronização) que foram executados. Note que $S \subseteq E_{s}$.

Uma variável é geralmente definida em atribuições e comandos de entrada. No contexto de ambientes de passagem de mensagens, uma variável também pode ser definida em funções de comunicação como o receive. Essas funções definem uma ou mais variáveis com valores recebidos na mensagem (Vergilio et al., 2005). Um conjunto de variáveis que são definidas no nó $n_{i}^{p}$ é re- 
presentado por de $f\left(n_{i}^{p}\right)$, ou seja, de $f\left(n_{i}^{p}\right)=\left\{x \mid x\right.$ é uma variável definida em $\left.n_{i}^{p}\right\}$. Um caminho $\pi=\left(n_{1}, n_{2}, \ldots, n_{k-1}, n_{k}\right)$ é livre de definição com respeito à variável $x$ do nó $n_{1}$ para o nó $n_{k}$ ou $\operatorname{arco}\left(n_{k-1}, n_{k}\right)$, se $x \in \operatorname{def}\left(n_{1}\right)$ e $x \notin \operatorname{def}\left(n_{i}\right)$, para $i=2 . . k-1$.

Além dos tradicionais uso predicativo (p-uso) e uso computacional ( $c$-uso) de variáveis, o modelo PCFG adiciona o uso de comunicação ( $s$-uso). Um $s$-uso ocorre quando uma variável é usada em uma sentença de comunicação, relacionada a um arco inter-processos. Essas associações são definidas a seguir:

- Um c-uso é definido pela tripla $\left(n_{i}^{p}, n_{j}^{p}, x\right) \mid x \in \operatorname{def}\left(n_{i}^{p}\right)$ e, $n_{j}^{p}$ possui um $c$-uso de $x$ e, existe um caminho livre de definição em relação à $x$ de $n_{i}^{p}$ para $n_{j}^{p}$.

- Um p-uso é definido pela tripla $\left(n_{i}^{p},\left(n_{j}^{p}, n_{k}^{p}\right), x\right) \mid x \in \operatorname{def}\left(n_{i}^{p}\right)$ e, $\left(n_{j}^{p}, n_{k}^{p}\right)$ possui um $p$-uso de $x$ e, existe um caminho livre de definição em relação à $x$ de $n_{i}^{p}$ para $\left(n_{j}^{p}, n_{k}^{p}\right)$.

- Um s-uso é definido pela tripla $\left(n_{i}^{p 1},\left(n_{j}^{p 1}, n_{k}^{p 2}\right), x\right) \mid x \in \operatorname{de} f\left(n_{i}^{p 1}\right)$ e, $\left(n_{j}^{p 1}, n_{k}^{p 2}\right)$ possui um $s$-uso de $x$ e, existe um caminho livre de definição em relação à $x$ de $n_{i}^{p 1}$ para $\left(n_{j}^{p 1}, n_{k}^{p 2}\right)$.

- Um s-c-uso é definido por $\left(n_{i}^{p 1},\left(n_{j}^{p 1}, n_{k}^{p 2}\right), n_{l}^{p 2}, x^{p 1}, x^{p 2}\right)$, onde existe uma associação $s$ - $u s o$ $\left(n_{i}^{p 1},\left(n_{j}^{p 1}, n_{k}^{p 2}\right), x^{p 1}\right)$ e uma associação $c$-uso $\left(n_{k}^{p 2}, n_{l}^{p 2}, x^{p 2}\right)$.

- Um s-p-uso é definido por $\left(n_{i}^{p 1},\left(n_{j}^{p 1}, n_{k}^{p 2}\right),\left(n_{l}^{p 2}, n_{m}^{p 2}\right), x^{p 1}, x^{p 2}\right)$, onde existe uma associação s-uso $\left(n_{i}^{p 1},\left(n_{j}^{p 1}, n_{k}^{p 2}\right), x^{p 1}\right)$ e uma associação $p$-uso $\left(n_{k}^{p 2},\left(n_{l}^{p 2}, n_{m}^{p 2}\right), x^{p 2}\right)$.

Para ilustrar o modelo, a seguir é apresentado o exemplo GCD. Esse exemplo é implementado usando a biblioteca PVM (Listagem 5.1 e Listagem 5.2) (Krawczyk e Wiszniewski, 1994). O programa utiliza quatro processos $\left(p^{m}, p^{0}, p^{1}, p^{2}\right)$ para calcular o máximo divisor comum entre três números. O processo mestre $p^{m}$ cria os processos escravos $p^{0}, p^{1}$ and $p^{2}$, que executam o código "gcd.c". Cada escravo espera o recebimento de dois valores enviados pelo processo $p^{m} \mathrm{e}$ calculam o máximo divisor comum para esses valores. Ao final, os processos escravos enviam o valor calculado para o processo mestre.

Listagem 5.1: Programa GCD em PVM - processo mestre.

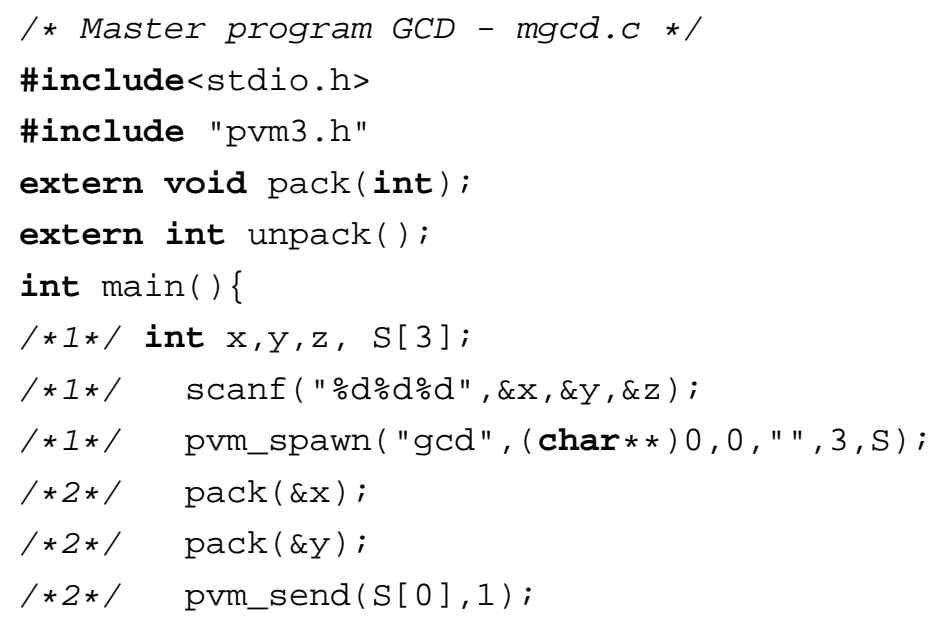




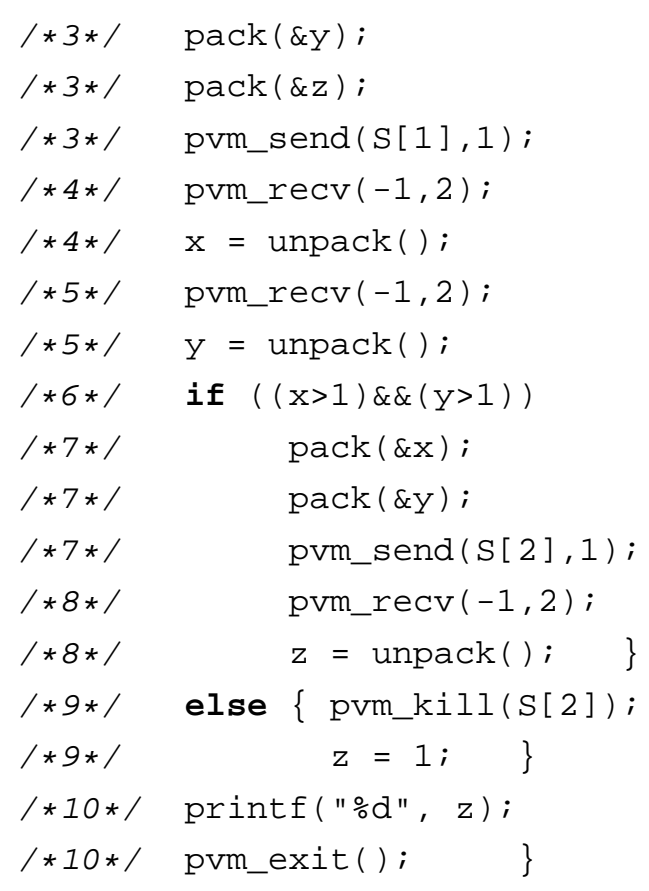

Listagem 5.2: Programa GCD em PVM - processo escravo.

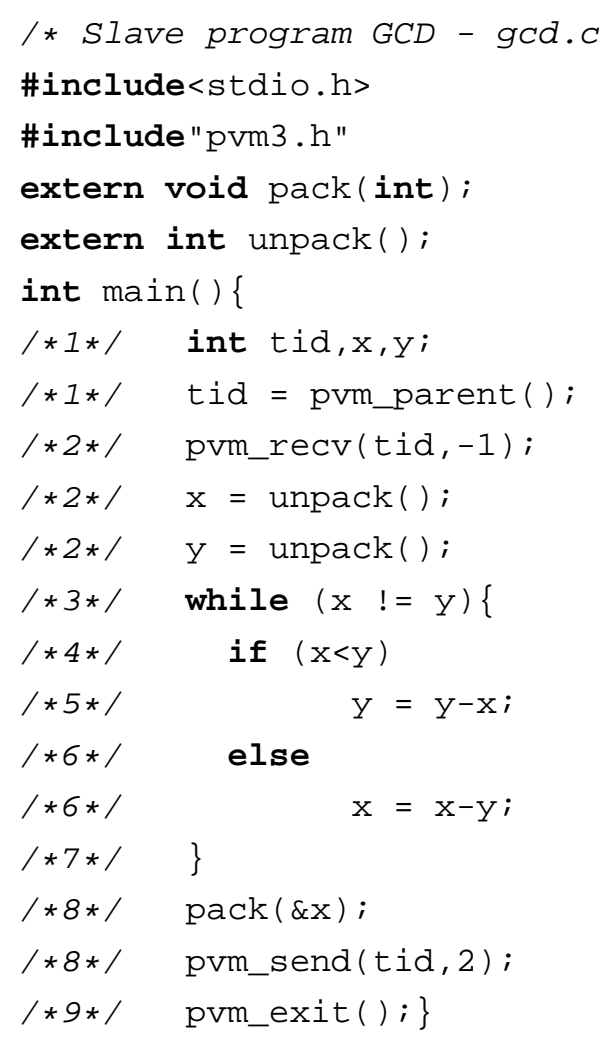

O PCFG é apresentado na Figura 5.1. O número à esquerda do código-fonte (Listagem 5.1 e 5.2) representa o nó no grafo associado a cada comando. Arcos inter-processos são representados por arcos tracejados. 


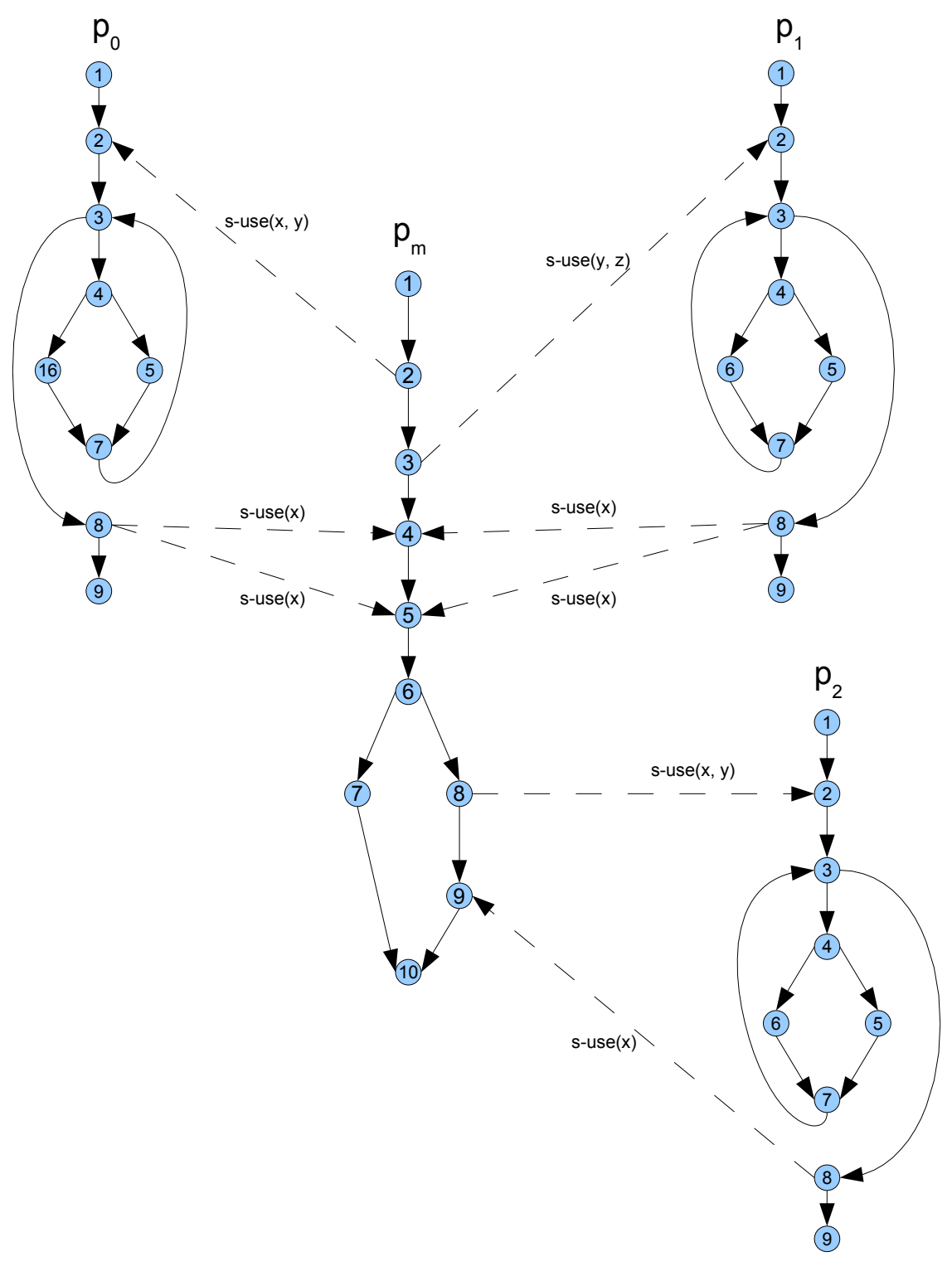

Figura 5.1: PCFG para o programa GCD (Vergilio et al., 2005).

\subsection{Transformação}

Nesta seção é apresentada a transformação de uma CWS especificada em BPEL para um PCFG com o intuito de fornecer um modelo de teste que pode ser utilizado para testar essa classe específica de software. A transformação aqui apresentada foi publicada em Endo et al. (2007).

Nessa transformação, é necessário que o desenvolvedor da composição tenha acesso à implementação dos WSs participantes. Supõe-se que todos os WSs envolvidos na composição e a própria composição podem ser representados em BPEL. Dessa forma, a composição e cada WS participante da composição será um processo BPEL. Supõe-se também que cada processo BPEL pode ser representado como um GFC e o número de grafos do PCFG é conhecido estaticamente.

O primeiro passo é transformar cada possível instância dos processos BPEL em um GFC tradicional (Rapps e Weyuker, 1985) (O GFC é descrito em detalhes na Seção 3.4). A relação entre o 
código BPEL e o nós e arcos gerados é apresentada, de forma genérica, para as seguintes atividades: Assign, Throw, Wait, Empty e ReThrow (Figura 5.2); Sequence e Flow (Figura 5.3); If (Figura 5.4); While e ForEach (Figura 5.5); e RepeatUntil (Figura 5.6).

$<$ Assign $>$
$<$ Throw $>$
$<$ Wait $>$
$<$ Empty>
$<$ ReThrow $>$

Figura 5.2: Transformação para as atividades Assign, Throw, Wait, Empty e ReThrow.

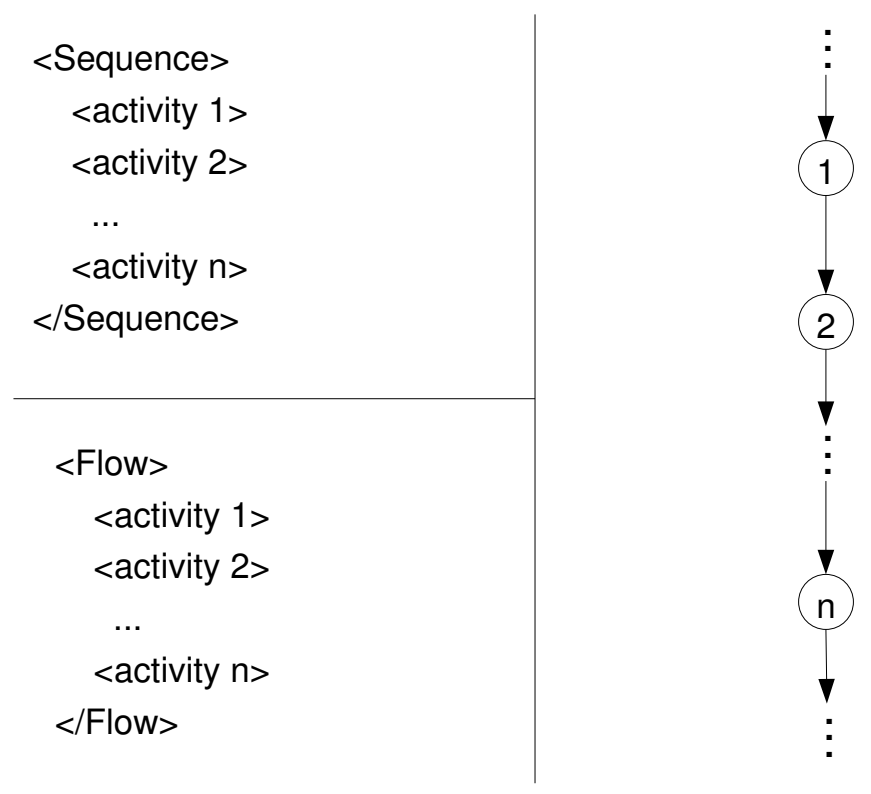

Figura 5.3: Transformação para as atividades Sequence e Flow.

As atividades Receive, Reply, Invoke e Pick são transformadas em nós no modelo PCFG do tipo send e/ou receive. Para cada uma dessas atividades, informações, como a operação e o PartnerLink, são guardadas e relacionadas aos respectivos nós criados para, em um passo subseqüente, criar os arcos inter-processos.

A atividade Receive no processo BPEL é transformada diretamente em um nó $n_{i}^{p} \in N_{r}$, sem a necessidade de adaptação. O mesmo acontece com a atividade Reply que é transformada em um nó $n_{j}^{p} \in N_{s}$. É guardada a informação de que essa atividade Reply envia uma mensagem relacionada a uma comunicação síncrona.

A atividade Invoke pode interagir com operações síncronas ou assíncronas. Para operações assíncronas, a Invoke é transformada em um único nó $n_{j}^{p} \in N_{s}$. Já em operações síncronas, além 

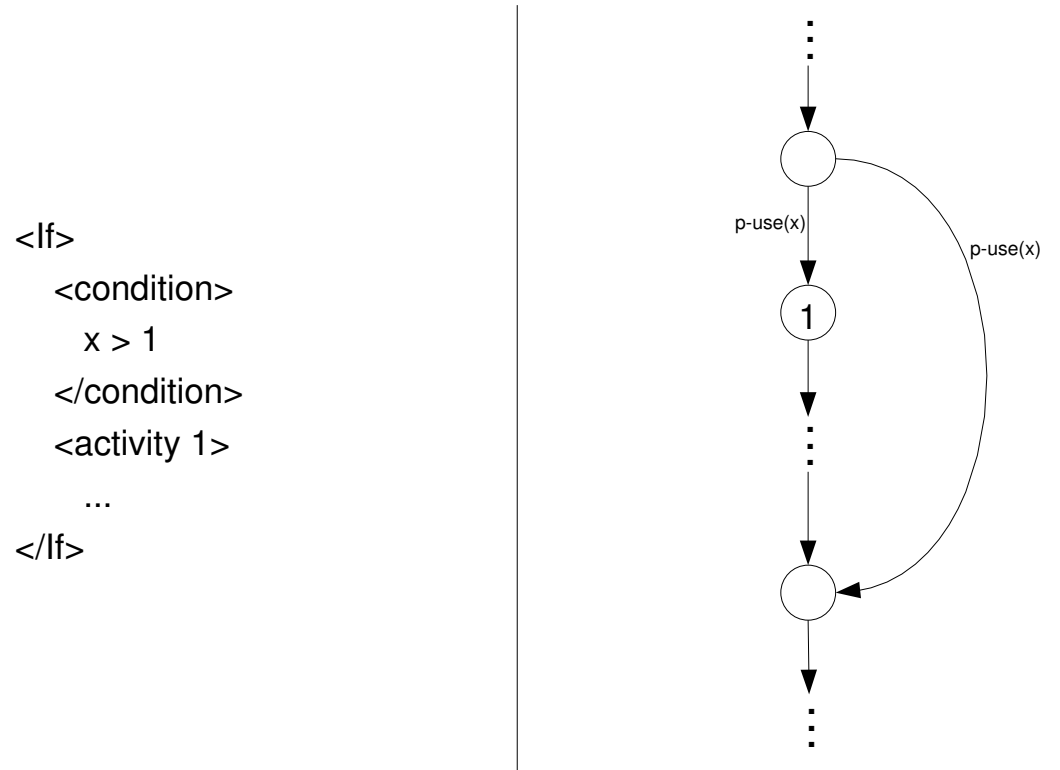

Figura 5.4: Transformação para a atividade If.

$<$ While $>$
$<$ condition $>x>4<$ condition $>$
$<$ activity $1>$
$\quad \ldots$
$<$ While $>$

$<$ ForEach $>$
$<$ condition $>$ x $>4</$ condition $>$
$<$ Scope $1>$
$\quad \ldots$
$<$ ForEach $>$

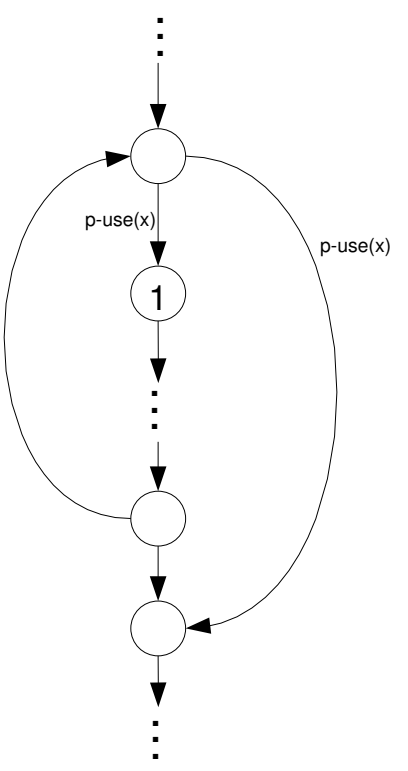

Figura 5.5: Transformação para as atividades While e ForEach.

de criar um nó $n_{j}^{p} \in N_{s}$, deve ser criado imediatamente a seguir um nó $n_{j+1}^{p} \in N_{r}$. O nó $n_{j+1}^{p}$ representa o bloqueio do processo BPEL que espera pela mensagem de resposta.

A atividade Pick considerada terá somente eventos do tipo onMessage. A atividade Pick é transformada em um nó $n_{i}^{p} \in N_{r}$ que pode receber mensagens referentes a cada um de seus eventos onMessage. Esse nó criado será seguido de desvios, um para cada evento. Essa transformação mantém a semântica entre os dois modelos, uma vez que o nó $n_{i}^{p}$ receberá apenas uma mensagem, assim como somente um evento será executado na atividade pick.

Um sumário das transformações para as atividades Receive, Reply, Invoke e Pick pode ser visto nas Figuras 5.7, 5.8 e 5.9. 


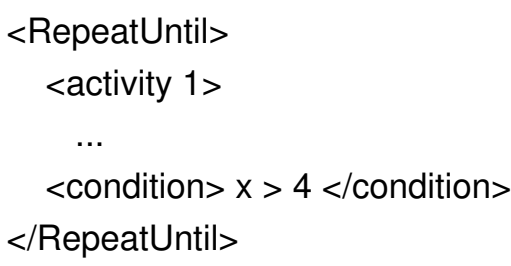

Figura 5.6: Transformação para a atividade RepeatUntil.

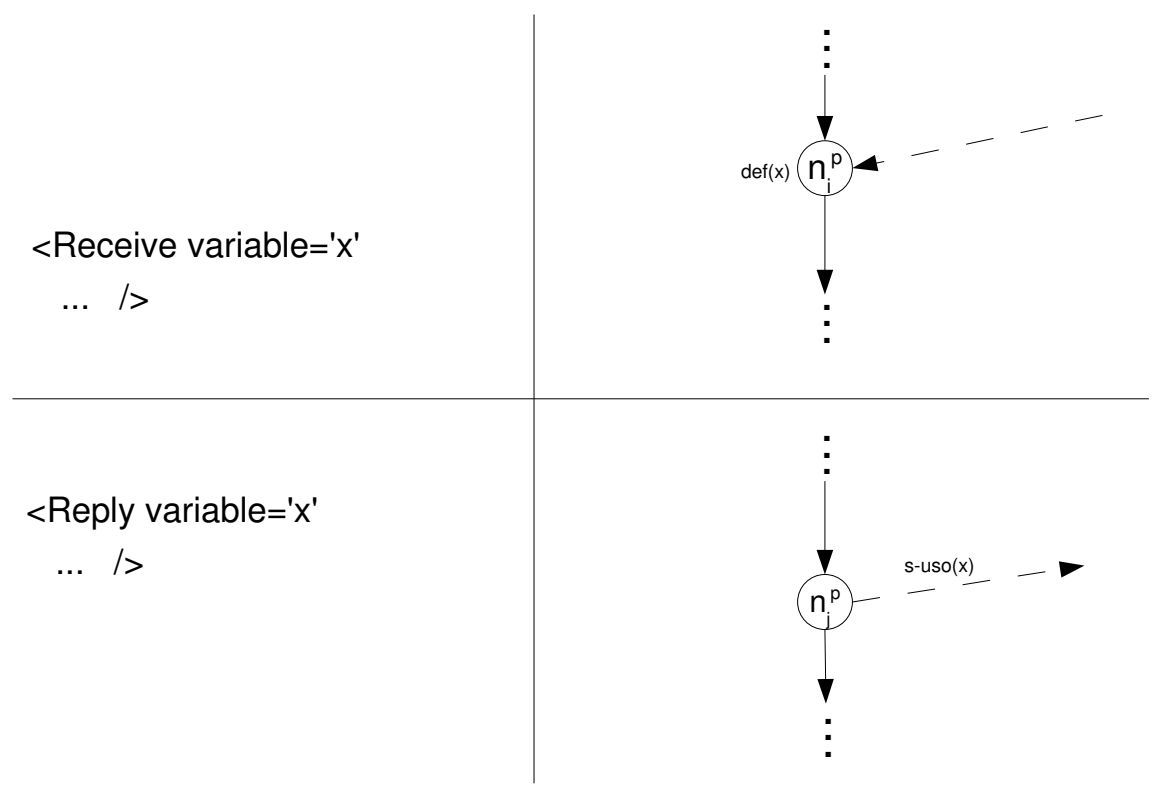

Figura 5.7: Transformação para as atividades Receive e Reply.

O GFC referente ao processo principal não terá arcos inter-processos nos nós referentes a sua atividade iniciadora e nem na respectiva atividade reply, caso exista.

Terminado esse passo, os arcos inter-processos são construídos. Por meio das informações do PartnerLink e operações de cada atividade de troca de mensagens do BPEL, consegue-se criar os arcos inter-processos entre os sends e receives do modelo PCFG. Por exemplo, a partir de uma invoke tem-se a informação do PartnerLink e da operação que será invocada. Tendo essas informações, chega-se ao respectivo receive em outro processo BPEL. Dessa forma, é criado um arco inter-processos do nó referente ao invoke para o nó referente ao receive. Para cada nó $n_{j}^{p} \in$ 


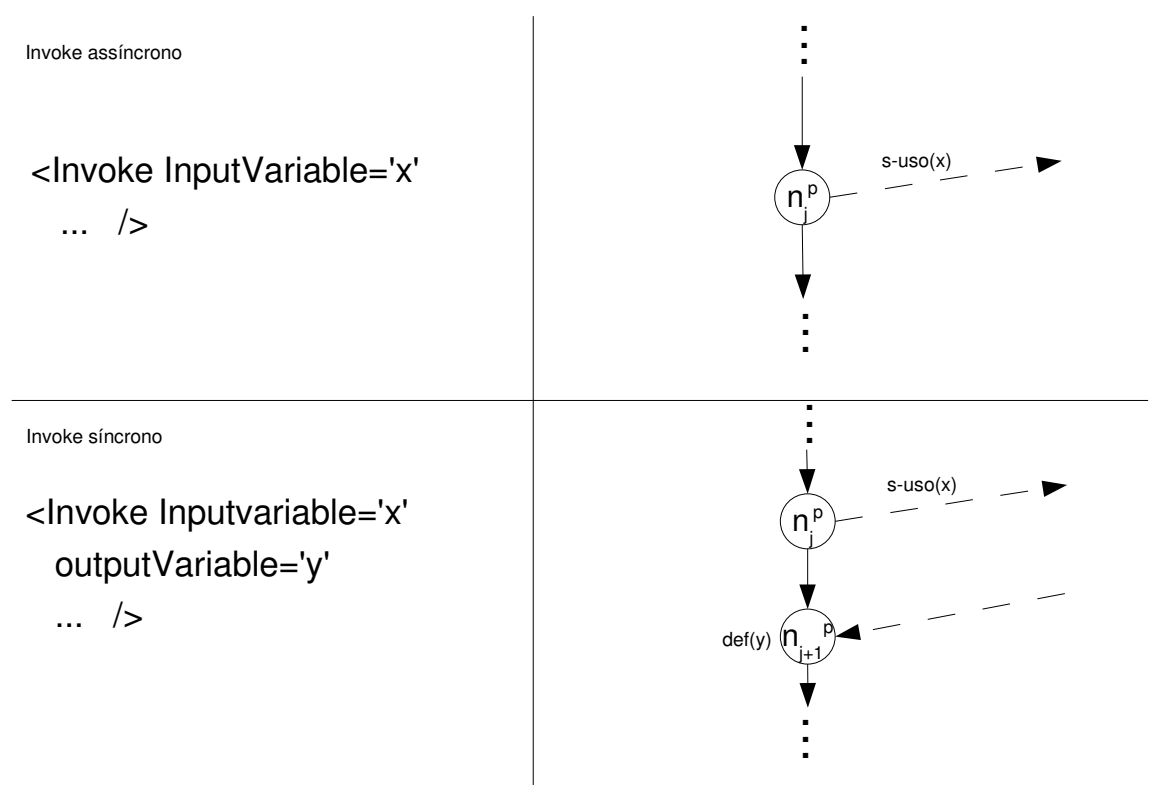

Figura 5.8: Transformação para a atividade Invoke.
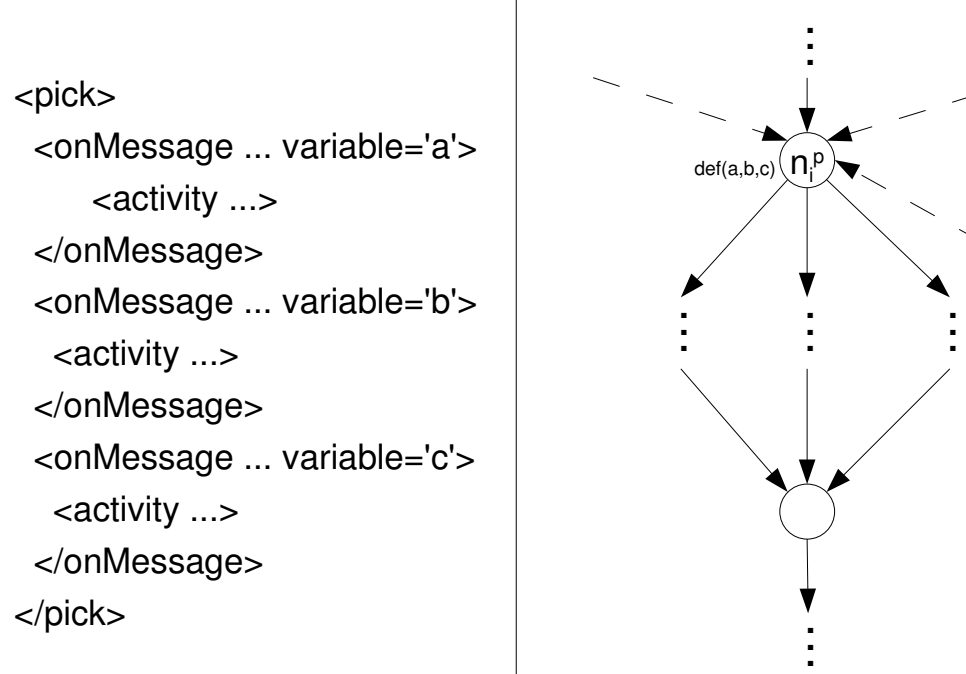

Figura 5.9: Transformação para a atividade Pick.

$N_{s}$, encontra-se os nós $n_{i}^{q} \in N_{r}$ com a mesma operação de $n_{j}^{p}$ e cria-se um arco inter-processos $\left(n_{j}^{p}, n_{i}^{q}\right) \in E_{s}$.

A complexidade de transformar processos BPEL em um PCFG é dada por:

1. uma busca completa em profundidade (depth-first search) na árvore XML de cada processo BPEL é executada. Esta busca obtém informação para construir o grafo, fluxo de dados e instrumentação. Sabe-se que uma árvore com $n$ nós e $e$ arcos, o custo de uma busca em profundidade é $O(n+e)$ (Cormen et al., 2002). Considerando que na composição existem $1 . . k$ processos e o custo de efetuar a busca na árvore XML do processo $i$ é $O\left(T_{i}\right)$. O custo de executar a busca para $1 . . k$ processos BPEL é $O\left(\sum_{i=1}^{k} T_{i}\right)$. 
2. Para criar arcos inter-processos, para cada nó send, tenta-se conectar a um nó receive com a mesma operação. Considerando que $N_{s e n d}$ é o número de nós send e $N_{r c v}$ é o número de nós receive, a complexidade de criar arcos inter-processos é $O\left(N_{s e n d} N_{r c v}\right)$.

3. Dessa forma, o custo total de transformar BPEL em PCFG é $O\left(\sum_{i=1}^{k} T_{i}+N_{\text {send }} N_{\text {rcv }}\right)$. Essa medida mostra que a transformação é executada em tempo polinomial.

Devido às particularidades da especificação BPEL, algumas características a diferenciam dos programas paralelos baseados em passagem de mensagens e precisam ser consideradas em relação ao PCFG:

1. Um nó send pode ter arcos inter-processos para dois ou mais processos diferentes, com a restrição de que ambos sejam GFCs iguais representando várias instâncias de um mesmo processo. Diferentemente de programas paralelos, em que o send envia mensagem para um processo específico. Esse caso caracteriza um send com um comportamento não-determinístico. Um caso que pode acontecer é quando há a definição dinâmica de um PartnerLink, como descrito na Seção 2.3.2. Nesse caso, uma atividade send pode enviar mensagens para processos com GFCs distintos.

2. Os primeiros nós dos grafos que compõem o PCFG serão sempre nós do tipo receive referentes às atividades receive ou pick. Isso acontece por causa das atividades iniciadoras.

3. O PCFG gerado é mais compacto que os grafos PCFG de programas paralelos. Isso acontece porque os arcos inter-processos são criados por meio de informações obtidas estaticamente sobre a operação e o PartnerLink. Apesar de gerar menos arcos inter-processos que usando uma abordagem conservativa, arcos inter-processos não-executáveis ainda são gerados pela transformação. Um método para reduzir o número desses arcos é apresentado na Seção 5.5. A existência de muitos arcos inter-processos no modelo PCFG torna mais custosa a cobertura de alguns critérios como todos-s-c-usos e todos-s-p-usos. Como um grafo PCFG é mais compacto, a aplicabilidade do modelo PCFG para o teste de CWS é melhorada.

Outra possibilidade que pode ser abordada pelo modelo é a definição do nível de abstração do teste realizado. Por exemplo, um dos WSs utilizados é um componente proprietário e o códigofonte não é fornecido. Nesse caso, o engenheiro de testes pode abstrair esse WS, considerando que instruções invoke e receive para esse WS não possuem nenhum arco inter-processos. Apesar de perder informações sobre a cobertura nesse WS, critérios como todos-nós-s e todos-nós-r (apresentados na Seção 5.3.2) podem ser utilizados para requerer que a comunicação com esse WS seja coberta pelos testes.

\subsubsection{Exemplo de Aplicação}

Na Figura 5.10(a) é apresentado o exemplo de um processo de empréstimo (adaptado de (Oracle, 2004)). Esse é apresentado graficamente para melhorar a clareza do exemplo em relação ao 
código BPEL. A seguir é dada uma breve descrição do exemplo: 1) O processo principal recebe informações sobre o cliente e o valor desejado para o empréstimo. 2) O WS Credit Rating Service é chamado para recuperar informações relacionadas ao crédito do cliente. Dessas informações, a mais relevante é a reputação, que varia de zero a dez, calculada por meio dos dados do cliente. Essa primeira chamada é uma operação síncrona. 3) Dois WSs de agências de empréstimo são invocados usando chamadas assíncronas. A UnitedLoan oferece baixas taxas para valores de empréstimos abaixo de dez mil e com reputação maior ou igual a cinco. Já a StarLoan oferece baixas taxas para clientes que pedem valores abaixo de quinze mil e com reputação maior ou igual a oito. 4) No processo principal, após receber mensagens dos dois WSs é feita uma decisão. 5) A decisão escolhe a melhor oferta para o cliente (menor taxa) e envia uma confirmação de interesse para a agência escolhida. 6) A melhor oferta é enviada para o cliente.

Na Figura 5.10(b), é apresentado o grafo PCFG referente ao problema do empréstimo. As setas tracejadas representam os arcos inter-processos. O mapeamento dos processos BPEL para o PCFG aconteceu de acordo com a transformação descrita no início da Seção 5.3.
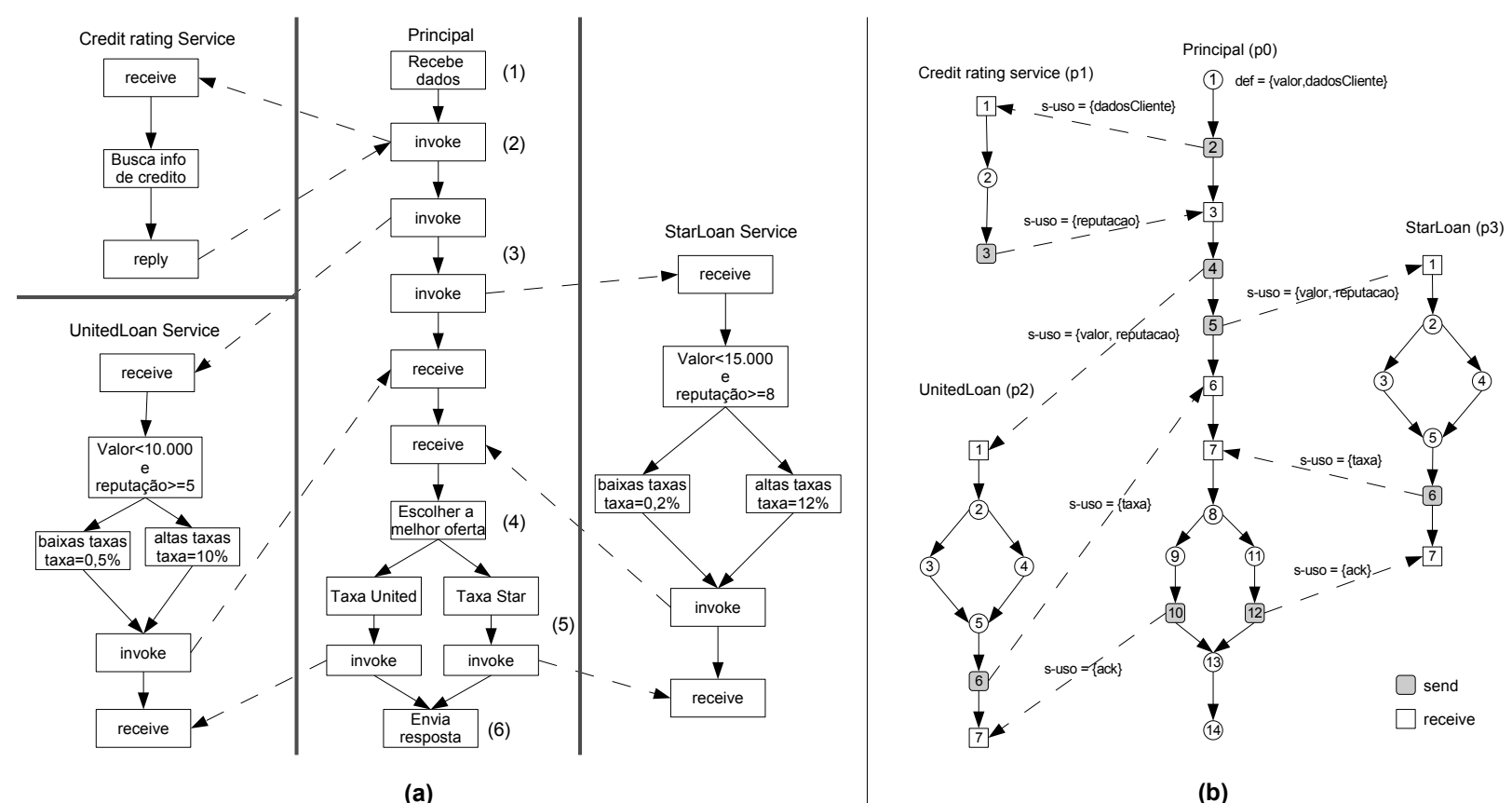

(b)

Figura 5.10: Exemplo de aplicação

\subsubsection{Critérios de Teste de CWS}

Durante a atividade de teste, é essencial avaliar a qualidade dos testes realizados. Um critério de teste define propriedades ou requisitos que precisam ser testados para garantir a qualidade do software (Zhu et al., 1997). Critérios de teste são usados para avaliar sistematicamente casos de teste e guiar a seleção de casos de teste. Baseado no modelo PCFG, Vergilio et al. (2005) definiram um conjunto de critérios de cobertura. Esses critérios podem ser utilizados no contexto da CWS e são sumarizados a seguir: 
- Todos-Nós-s: os suites de teste devem exercitar cada nó $n_{i}^{p} \in N_{s}$, ou seja, os casos de teste devem executar no mínimo uma vez cada atividade invoke e reply.

- Todos-Nós-r: os suites de teste devem exercitar cada nó $n_{i}^{p} \in N_{r}$, i.e., u seja, os casos de teste devem executar no mínimo uma vez cada atividade receive, pick e invoke síncrono.

- Todos-Nós: os casos de teste devem executar todas as atividades em todos os processos.

- Todos-Arcos-s: os casos de teste devem executar no mínimo uma vez cada comunicação entre os WSs.

- Todos-Arcos: os casos de teste devem executar todos os desvios de execução e comunicação entre WSs.

- Todos-s-usos: os casos de teste devem executar todas as associações $s-u s o$.

- Todos-s-c-usos: os casos de teste devem executar todas as associações $s$-c-uso.

- todos-s-p-usos: os casos de teste devem executar todas as associações $s$ - $p$-uso.

Durante a análise de cobertura, que consiste basicamente em determinar o percentual de elementos requeridos de critério de teste que foram exercitados pelo conjunto de casos de teste, é fundamental o conhecimento sobre as limitações inerentes à atividade de teste (Maldonado et al., 2004). Sabe-se que alguns elementos requeridos podem ser não-executáveis, e em geral, determinar a não executabilidade de um dado requisito de teste é feita de forma manual.

Seguindo o exemplo apresentado na Figura 5.10. Ao utilizar como caso de teste um cliente com reputação igual a cinco e valor do empréstimo igual a 5000, obtém-se o seguinte caminho: $\Pi^{1}=\left(\pi^{0}, \pi^{1}, \pi^{2}, \pi^{3}, S^{1}\right)$, onde $\pi^{0}=$ $\{1,2,3,4,5,6,7,8,9,10,13,14\}, \pi^{1}=\{1,2,3\}, \pi^{2}=\{1,2,3,5,6,7\}, \pi^{3}=\{1,2,4,5,6\}$ e $S^{1}=\left\{\left(2^{0}, 1^{1}\right),\left(3^{1}, 3^{0}\right),\left(4^{0}, 1^{2}\right),\left(5^{0}, 1^{3}\right),\left(6^{2}, 6^{0}\right),\left(6^{3}, 7^{0}\right),\left(10^{0}, 7^{2}\right)\right\}$. Devido a decisão que ocorre no nó $8^{0}$, a execução desse caso de teste não cobre o arco inter-processos $\left(12^{0}, 7^{3}\right)$. Com a adição do caso de teste em que um cliente cuja reputação é oito e o valor do empréstimo é 12000, obtém-se o seguinte caminho: $\Pi^{2}=\left(\pi^{0}, \pi^{1}, \pi^{2}, \pi^{3}, S^{2}\right)$, onde $\pi^{0}=\{1,2,3,4,5,6,7,8,11,12,13,14\}, \pi^{1}=\{1,2,3\}, \pi^{2}=\{1,2,4,5,6\}, \pi^{3}=\{1,2,3,5,6,7\}$ e $S^{2}=\left\{\left(2^{0}, 1^{1}\right),\left(3^{1}, 3^{0}\right),\left(4^{0}, 1^{2}\right),\left(5^{0}, 1^{3}\right),\left(6^{2}, 6^{0}\right),\left(6^{3}, 7^{0}\right),\left(12^{0}, 7^{3}\right)\right\}$. Considerando os caminhos $\Pi^{1}$ e $\Pi^{2}$, o critério todos-nós foi coberto, ou seja, os casos de testes exercitaram pelo menos uma vez cada atividade nos processos BPEL.

Considerando os critérios baseados em fluxo de dados, o critério todos-s-usos é coberto com os caminhos $\Pi^{1}$ e $\Pi^{2}$, pois o caminho $\Pi^{2}$ inclui o arco inter-processos $\left(12^{0}, 7^{3}\right)$. Considerando a variável valor, as suas associações $s$-uso $\left(1^{0},\left(4^{0}, 1^{2}\right)\right.$, valor $)$ e $\left(1^{0},\left(5^{0}, 1^{3}\right)\right.$, valor $)$ estão presentes nesses caminhos. 
Assim como em programas paralelos, o PCFG gerado para CWS também pode apresentar nãodeterminismo no envio e recebimento de mensagens. No exemplo, é possível verificar a aplicabilidade dos critérios de teste baseados no PCFG para CWS. Mais evidências sobre a aplicabilidade da estratégia é mostrada na Seção 5.7.

\subsection{Grupos de Elementos Requeridos}

Nesta seção, é demonstrado o conceito de grupos de elementos requeridos para o modelo PCFG. Em algumas situações, pode-se considerar que quando um elemento requerido foi coberto, outros elementos também podem ser considerados cobertos. Então, condições para agrupar elementos requeridos podem ser definidas. Por exemplo, é possível agrupar elementos requeridos quando somente um é executável e outros são não-executáveis, desde que seja possível definir uma condição de agrupamento entre esses elementos.

Considere um critério de teste $C$ do modelo de teste PCFG, e $E_{C}=\left\{e_{1}, e_{2}, \ldots, e_{k}\right\}$, onde $E_{C}$ é o conjunto de elementos requeridos do critério $C$ e $k \geq 1$. O conjunto de casos de teste $T C$ cobre o critério de teste $C$ se todos os elementos requeridos $e_{1}, e_{2}, \ldots, e_{k}$ são exercitados por $T C$.

Utilizando o conceito de grupos de elementos, pode-se definir um subconjunto de $E_{C}, S_{C}=$ $\left\{a_{1}, \ldots, a_{j}\right\}$ onde $j \geq 1$ e os elementos de $S_{C}$ estão de acordo com uma condição de agrupamento. Se o conjunto de casos de teste $T C$ cobre um elemento requerido de $S_{C}$, o subconjunto $S_{C}$ será coberto por $T C$.

A seguir será apresentado um exemplo ilustrativo, apenas para o melhor entendimento do conceito de grupos de elementos. Considerando o exemplo GCD apresentado na Seção 5.2 (Figura 5.1), e o critério todos-nós aplicado a esse exemplo, tem-se que: $E_{\text {todos-nos }}=$ $\left\{1^{m}, 2^{m}, 3^{m}, 4^{m}, 5^{m}, 6^{m}, 7^{m}, 8^{m}, 9^{m}, 10^{m}, 1^{0}, 2^{0}, 3^{0}, 4^{0}, 5^{0}, 6^{0}, 7^{0}, 8^{0}, 9^{0}, 1^{1}, 2^{1}, 3^{1}, 4^{1}, 5^{1}, 6^{1}, 7^{1}\right.$, $\left.8^{1}, 9^{1}, 1^{2}, 2^{2}, 3^{2}, 4^{2}, 5^{2}, 6^{2}, 7^{2}, 8^{2}, 9^{2}\right\}$.

É definido como condição de agrupamento os nós pertencerem a diferentes GFCs, mas representarem o mesmo trecho de código. Por exemplo, os nós $5^{0}, 5^{1}$ e $5^{2}$ representam o mesmo trecho de código do programa escravo ( $/ 5 * /$ na Listagem 5.2). Essa condição de agrupamento é apenas para fins de ilustração. Considerando essa condição de agrupamento, pode-se montar o seguinte grupo $S_{\text {todos-nos } 1}=\left\{1^{0}, 1^{1}, 1^{2}\right\}$. Utilizando o conceito de grupos de elementos, se o caso de teste $T C_{1}$ cobrir o elemento $1^{0}$, todos os demais elementos $1^{1}$ e $1^{2}$ também são cobertos.

Esse mecanismo pode ser utilizado para melhorar a cobertura dos critérios, sem enfraquecêlos. Pode ser utilizado para detectar elementos requeridos não-executáveis ou equivalentes. Neste trabalho, esse conceito é usado para (i) eliminar associações $s$-c-uso e $s$-p-uso não-executáveis gerados pela atividade Pick e (ii) para eliminar associações $s$-uso equivalentes.

Uma atividade Pick pode ter vários eventos onMessage. Cada evento onMessage pode definir diferentes variáveis (Figura 5.11(a)). Na transformação proposta, essas definições ocorrem no nó receive $n_{p k}$ (Figura 5.11(b)). Será adotada nessa seção a notação [s-use $(l)$, c-use $(m)$ ] para 
representar a associação $s$-c-uso. Essa notação é adequada porque ela relaciona uma mensagem recebida (s-uso) com o uso computacional dessa mensagem ( $c$-uso). Para o exemplo mostrado na Figura 5.11, serão geradas as seguintes associações $s$ - $c$-uso (elementos requeridos) para o critério todos-s-c-usos:

$[\operatorname{s-use}(x), \operatorname{c-use}(a)],[\operatorname{s-use}(x), \operatorname{c-use}(b)],[\operatorname{s-use}(x), \operatorname{c-use}(c)],[\operatorname{s-use}(y), \operatorname{c-use}(a)],[\operatorname{s-use}(y)$,

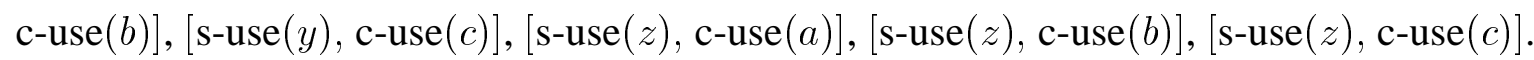

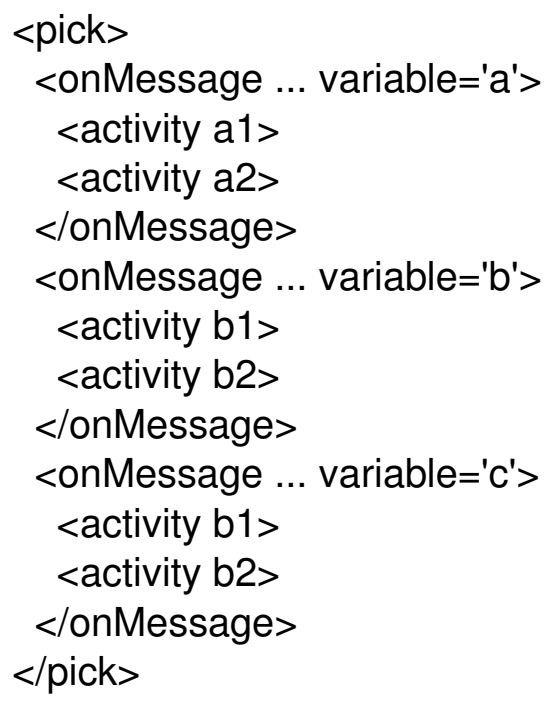

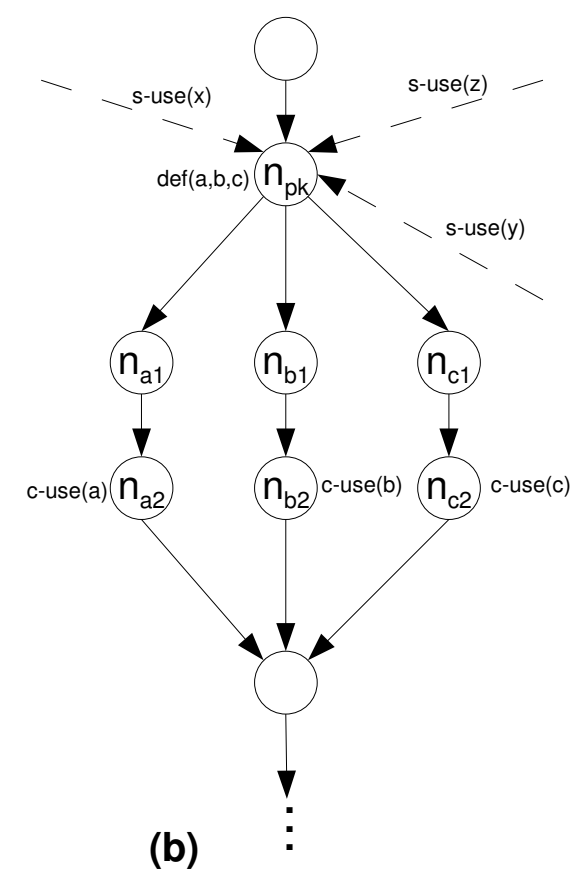

Figura 5.11: Problema da atividade Pick.

Essas associações são geradas pela combinação de cada associação $s$-uso com cada associação $c$-uso que possui uma definição no nó $n_{p k}$. Entretanto, sabe-se que quando uma mensagem chega, somente um arco inter-processos é executado (s-uso(x), s-uso(y) or s-uso(z)) e uma variável (a, b ou c) é definida (Figure 5.11(b)). Então, nessa situação, pode-se agrupar:

- $S_{C 1}=\{[\operatorname{s-use}(x), \operatorname{c-use}(a)],[\operatorname{s-use}(x), \operatorname{c-use}(b)],[\operatorname{s-use}(x)$, c-use $(c)]\}$;

- $S_{C 2}=\{[\operatorname{s-use}(y), \operatorname{c-use}(a)],[\operatorname{s-use}(y), \operatorname{c-use}(b)],[\operatorname{s-use}(y)$, c-use $(c)]\}$

- $S_{C 3}=\{[\operatorname{s-use}(z), \mathrm{c}-$ use $(a)],[\operatorname{s-use}(z), \mathrm{c}-$ use $(b)],[\operatorname{s-use}(z), \mathrm{c}-$ use $(c)]\}$.

Nesses grupos, sabe-se que apenas um elemento requerido é executável e os outros dois são não-executáveis. Quando o elemento executável for coberto, os outros dois também serão considerados cobertos, melhorando assim a cobertura do critério.

Formalmente, uma atividade pick é representada por um nó $n_{i}$ com $k$ eventos onMessage que recebe diferentes tipos de mensagens. No nó $n_{i}$, existem definições de $k$ diferentes variáveis e $l$ 
arcos inter-processos. Note que $E_{C}$ é um conjunto de elementos requeridos do critério todos-sc-usos ou todos-s-p-usos. Para cada s-uso(var $\left.{ }_{m}\right), 1 \leq m \leq l$ existirá um subconjunto $S_{C m}$ que agrupa associações $s$-c-uso ou $s$-p-uso que contém o $s$-uso $\left(\right.$ var $\left._{m}\right)$. Para cada associação $c$-uso ou p-uso que está contida em $S_{C m}$, somente uma pode ser definida por $s$-uso(var $\left.{ }_{m}\right)$. Então, $S_{C m}$ é formada por elementos $e \in E_{C}$ em que $s$-uso(var $\left.{ }_{m}\right)$ está contida na associação e e o $c$-uso(var $x$ ) ou $p$-uso $\left(v a r_{x}\right)$, que é definido por $s$-uso $\left(v a r_{m}\right)$, está dentro da atividade Pick.

Outro caso de grupos de elementos ocorre com as atividades iniciadoras, que criam novas instâncias de processo. Instâncias de processos BPEL são criadas pelo recebimento de uma mensagem, que pode não ser enviada, dependendo dos casos de teste que são usados. Dessa forma, existem processos BPEL que podem não ser instanciados. Esse padrão é diferente de programas baseados em passagem de mensagem, os quais podem criar processos que nunca receberão mensagens.

No caso mais simples, se um processo BPEL possui $k$ possíveis instâncias, o primeiro nó receive de cada instância, que corresponde à atividade inciadora, irá possuir $k$ arcos inter-processos incidentes. Entretanto, somente um arco inter-processos pode criar uma instância. Os $k$ arcos são equivalentes, desde que um arco seja coberto, todos os $k$ arcos também serão cobertos. Assim, pode-se eliminar $k-1$ elementos requeridos por instância de processo.

\subsection{Eliminação de Arcos Não-Executáveis Usando Re- des de Petri}

Caminhos não-executáveis em modelos de teste baseados em grafos são caminhos que nunca serão executados para um determinado dado de entrada. Em GFC para programas sequienciais, caminhos não-executáveis acontecem devido à dependência de dados e de expressões condicionais. Segundo Yang et al. (1998), em programas paralelos, um outro tipo de caminho não-executável pode ocorrer por causa de dependências de sincronização. Esse tipo de dependência pode causar deadlock ou espera infinita nos programas paralelos em tempo de execução.

No teste de cobertura de programas paralelos baseados em passagem de mensagens, existem muitos pares de sincronização send-receive que não são executáveis. Fornecer métodos para detectar esse tipo de problema melhoraria a realização dos testes nessa classe de programas. Outras classes de software que possuem comportamento semelhante, como os WSs e a CWS, poderiam se beneficiar desses métodos.

Nesta seção, é apresentada uma aplicação do modelo formal redes de Petri na eliminação de pares de sincronização não-executáveis em programas paralelos baseados em passagem de mensagens. A aplicação de redes de Petri na análise de programas concorrentes é um tema pesquisado, visto que as redes de Petri apresentam características importantes para a representação de paralelismo e sincronização. 
Iniciativas por parte da academia para análise de programas concorrentes usando redes de Petri foram desenvolvidas. Em Murata et al. (1989), é proposto uma representação de programas concorrentes escritos em Ada (Barnes, 2006) como redes de Petri. É apresentado um algoritmo que traduz um programa Ada em uma rede de Petri que preserva o fluxo de controle e de mensagens, de forma que deadlocks possam ser detectados. No trabalho de Cheng e Ushijima (1991), um modelo de rede de Petri extendida foi usada para detectar livelock e deadlock. Para isso, métodos de álgebra linear foram utilizados. Já em Chamillard e Clarke (1996), é apresentada uma abordagem para melhorar a precisão (accuracy) da análise de redes de Petri para programas concorrentes. Para isso, informações adicionais sobre estados do programa são incluídas na rede de Petri gerada. Essas informações podem ser inseridas na forma de seqüências de sentenças ou valores de variáveis.

Entretanto, alguns estudos teóricos mostram que a análise de programas concorrentes é um problema complexo. No trabalho de Taylor (1983), é formalizada uma notação de estruturas de sincronização de programas concorrentes que usam o mecanismo rendezvous para realizar sincronização. Os resultados obtidos por Taylor (1983) mostram que muitas tarefas de análise em programas concorrentes são intratáveis. O trabalho de Ramalingam (2000) ilustra a dificuldade existente na execução de análise estática de programas concorrentes. Resultados teóricos também são apresentados mostrando que uma análise baseada em sincronizações e baseada no contexto do programa em programas concorrentes é indecidível.

\subsubsection{Caracterização do Problema}

Em Yang et al. (1998), os autores apresentam um tipo de caminho não-executável que ocorre devido a dependências de sincronização. Essas dependências podem causar deadlock ou espera infinita em tempo de execução. No teste de cobertura de programas paralelos baseados em passagem de mensagens, existem muitos pares send-receive que não são executáveis. As possíveis sincronizações no modelo PCFG são representadas pelos arcos inter-processos. Como, atualmente, uma abordagem conservativa é adotada para gerar os arcos inter-processos, é importante fornecer um método para que alguns desses arcos sejam eliminados. Em geral, um par send-receive não é executável por duas razões: lógica do programa e seqüência de execução.

A primeira razão é relacionada a pares que não são executáveis porque a lógica do programa não os torna possível. É um problema semelhante aos caminhos não-executáveis do teste de caminhos tradicional. Essa situação gera caminhos não-executáveis devido a dependência de dados e/ou condicionais (Yang et al., 1998). Esse tipo de caso também acontece em programas tradicionais e é muito difícil ser detectado (Offutt e Pan, 1997). Esse problema pode ser abordado usando uma análise de caminho alcançável (Goldberg et al., 1994).

A segunda razão está relacionada a pares que são não-executáveis porque a seqüência de execução não torna possível a sua ocorrência. Por exemplo, um determinado par send1-receive2 nunca acontece porque antes que esse par possa acontecer, o par send1-receive 1 acontece primeiro. Logo, 
o par send1-receive2 é não-executável. O método proposto pretende focar nesse tipo de problema. Um exemplo disso pode ser visto na Figura 5.12. Tem-se dois processos, $p_{0}$ e $p_{1}$, os nós $2^{0}, 4^{0} \in N_{r}$ são referentes a primitiva receive, e os nós $2^{1}, 3^{1} \in N_{s}$ são referentes a primitiva send. Nota-se que os arcos inter-processos em pontilhado $\left(2^{1}, 4^{0}\right)$ e $\left(3^{1}, 2^{0}\right)$ são não-executáveis. Como o arco inter-processos $\left(2^{1}, 2^{0}\right)$ é executado primeiro pela sequiência, os dois outros arcos em pontilhado não podem ser executados, logo resta a execução do arco $\left(3^{1}, 4^{0}\right)$.

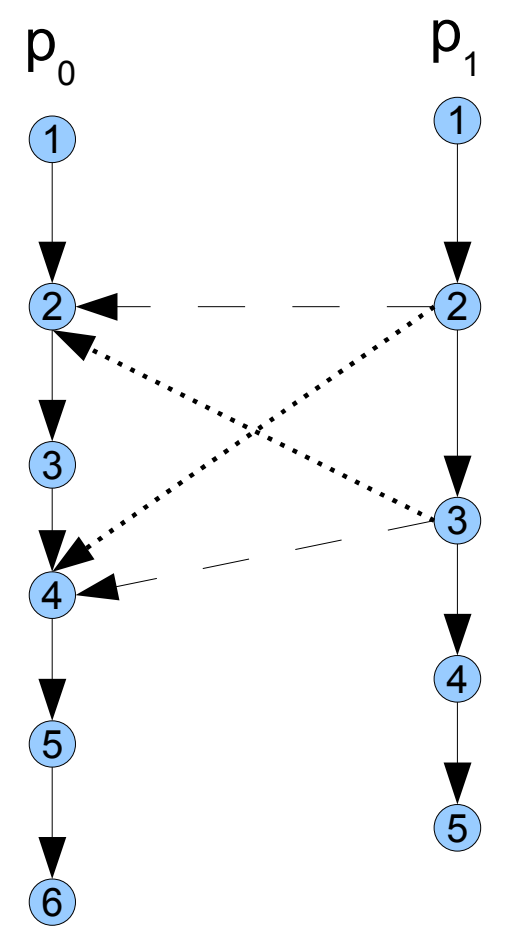

Figura 5.12: Exemplo de pares não-executáveis.

O modelo PCFG representa concorrência e comunicação, mas as operações que poderiam ser realizadas seriam a de um grafo comum. Seria necessário um modelo formal que pudesse representar concorrência e fornecesse estruturas para análise de alcançabilidade. Nesse contexto, foram escolhidas as redes de Petri. Não se pretende criar um novo modelo para representar programas paralelos, as redes de petri serão utilizadas apenas como um modelo intermediário para identificar os arcos inter-processos não-executáveis.

O método proposto transforma o PCFG em uma rede de Petri. Para essa rede de Petri é gerada sua árvore de cobertura, a partir do qual é possível obter informação sobre quais arcos não são executáveis.

\subsubsection{Método}

O método proposto fornece dois algoritmos para transformar um PCFG em uma rede de Petri: algoritmo A e algoritmo B. Essa rede de Petri armazena informações sobre o PCFG com as quais, ao realizar uma análise em sua árvore de cobertura, é possível determinar arcos inter-processos do PCFG que são não-executáveis. 
A diferença entre os dois algoritmos propostos é que o algoritmo B produz uma rede de Petri em que o send tem um comportamento bloqueante, ou seja, o token só passa para o próximo lugar caso a sincronização (arco inter-processos) ocorra. Já no algoritmo A, o send apresenta um comportamento não-bloqueante. Inicialmente, é definida uma rede de Petri $C F P N=(P, T, F, \mu)$ por meio de um $P C F G$, de acordo com um dos algoritmos: algoritmo A e algoritmo B.

\section{Algoritmo A}

- Para cada nó $n_{i} \in N$, existe um lugar distinto $p_{n_{i}} \in P$.

- A marcação inicial para todos os lugares é 0 , exceto os lugares relacionados aos nós iniciais dos processos. Formalmente,

$$
\mu\left(p_{n}\right)= \begin{cases}1 & \text { se } n \text { é o nó inicial } \\ 0 & \text { caso contrário }\end{cases}
$$

- Para cada arco intra-processo $\left(n_{i}, n_{j}\right) \in E \backslash E_{s}$, existe uma transição $t_{n_{i}, n_{j}} \in T$ e o arco $\left(t_{n_{i}, n_{j}}, p_{n_{j}}\right) \in F$. Se $n_{i} \notin N_{r}$, então $\left(p_{n_{i}}, t_{n_{i}, n_{j}}\right) \in F$.

- para cada nó $n_{i} \in N_{s}$, existe um lugar $s_{n_{i}} \in P$ e, para cada arco intra-processo $\left(n_{j}, n_{i}\right) \in E$, existe um $\operatorname{arco}\left(t_{n_{j}, n_{i}}, s_{n_{i}}\right) \in F$.

- para cada nó $n_{i} \in N_{r}$, existe um lugar $r_{n_{i}} \in P$ e, para cada arco intra-processo $\left(n_{i}, n_{j}\right) \in E$, existe um $\operatorname{arco}\left(r_{n_{i}}, t_{n_{i}, n_{j}},\right) \in F$.

- Para cada arco inter-processos $\left(n_{i}, n_{j}\right) \in E_{s}$, existe uma transição $s y n c_{n_{i}, n_{j}} \in T$, e $\operatorname{arcos}$ $\left(s_{n_{i}}\right.$, sync $\left._{n_{i}, n_{j}}\right),\left(\operatorname{sync}_{n_{i}, n_{j}}, r_{n_{j}}\right),\left(p_{n_{j}}\right.$, sync $\left._{n_{i}, n_{j}}\right) \in F$.

\section{Algoritmo B}

- Para cada nó $n_{i} \in N$, existe um lugar distinto $p_{n_{i}} \in P$.

- A marcação inicial para todos os lugares é 0, exceto os lugares relacionados aos nós iniciais dos processos. Formalmente,

$$
\mu\left(p_{n}\right)= \begin{cases}1 & \text { se } n \text { é o nó inicial } \\ 0 & \text { caso contrário }\end{cases}
$$

- Para cada arco intra-processo $\left(n_{i}, n_{j}\right) \in E \backslash E_{s}$, sendo que $n_{i} \notin N_{r}$, existe uma transição $t_{n_{i}, n_{j}} \in T$ e o $\operatorname{arco}\left(t_{n_{i}, n_{j}}, p_{n_{j}}\right),\left(p_{n_{i}}, t_{n_{i}, n_{j}}\right) \in F$.

- para cada nó $n_{i} \in N_{s}$, existe um lugar $s_{n_{i}} \in P$ e, para cada arco intra-processo $\left(n_{j}, n_{i}\right) \in E$, existe um arco $\left(t_{n_{j}, n_{i}}, s_{n_{i}}\right) \in F$. É adicionado um lugar $y_{n_{i}} \in P$ e para cada arco intraprocesso $\left(n_{i}, n_{j}\right) \in E$, existe um arco $\left(y_{n_{i}}, t_{n_{i}, n_{j}}\right) \in F$. 
- Para cada arco inter-processos $\left(n_{i}, n_{j}\right) \in E_{s}$, existe uma transição sync $_{n_{i}, n_{j}} \in T$, e ar$\cos \left(s_{n_{i}}\right.$, sync $\left._{n_{i}, n_{j}}\right),\left(p_{n_{j}}\right.$, sync $\left._{n_{i}, n_{j}}\right),\left(\right.$ sync $\left._{n_{i}, n_{j}}, y_{n_{i}}\right) \in F$. Para cada arco intra-processo $\left(n_{j}, n_{k}\right) \in E$, existe um arco $\left(\operatorname{sync}_{n_{i}, n_{j}}, p_{n_{k}}\right) \in F$. Se $n_{k} \in N_{s}$, então existe um arco $\left(\right.$ sync $\left._{n_{i}, n_{j}}, s_{n_{k}}\right) \in F$.

O próximo passo após construir a rede de Petri é identificar os arcos inter-processos que não são executáveis. Dado o PCFG $g$, é gerada uma rede de Petri $P N_{g}$ usando um dos algoritmos propostos. É criada a árvore de cobertura $C G_{P N g}$, utilizando o algoritmo apresentado na Seção 4.2.1. Para cada arco inter-processos $e=\left(n_{i}, n_{j}\right) \in E_{s}$ de $g$, se $e$ é não-executável, então sync $_{n_{i}, n_{j}}$ não aparece na $C G_{P N g}$. Nada pode-se afirmar sobre os arcos inter-processos que aparecem na $C G_{P N g}$, apenas que podem ser executados pela sequiência de execução. Fatores como condições condicionais e dados de entrada podem tornar esses arcos não-executáveis.

Percebeu-se que utilizando o algoritmo A, os arcos inter-processos não-executáveis do exemplo apresentado na Figura 5.12 não são eliminados. Isso acontece porque o send (nó $2^{1}$ ) gerado pelo algoritmo A é não-bloqueante, possibilitando que um token alcance o segundo send (nó $3^{1}$ ). Apesar disso, o algoritmo A é capaz de eliminar os arcos em outros exemplos como o apresentado na Seção 5.5.2.

A rede de Petri gerada pelo algoritmo A possui uma semântica mais próxima ao comportamento dos programas paralelos. Já o algoritmo B é mais restritivo, pois insere na rede de Petri gerada sends com comportamento bloqueante. Isso deixa a rede gerada pelo algoritmo B capaz de detectar os arcos não-executáveis dos dois exemplos apresentados. O algoritmo B também apresentou um número menor de iterações na execução do algoritmo que gera a árvore de cobertura. A rede gerada pelo algoritmo B apresenta uma semântica diferente de um programa paralelo, mas possui as vantagens já citadas.

Exemplos Na Figura 5.13, o exemplo GCD (apresentado na Seção 5.2) é reapresentado no contexto do problema desta seção. Nessa figura, os arcos inter-processos que não são executáveis aparecem em linhas pontilhadas. Os arcos inter-processos que são executáveis aparecem em linhas tracejadas. O método proposto busca justamente eliminar os arcos pontilhados.

É apresentada na Figura 5.14 a rede de Petri gerada para o exemplo da Figura 5.12, usando o algoritmo B. Na figura, as transições em branco representam os arcos inter-processos. As transições em preto são referentes aos arcos intra-processo. Após gerar a árvore de cobertura, as transições em branco serão analisadas, para determinar quais são executáveis ou não-executáveis.

A árvore de cobertura para a rede de Petri, apresentada na Figura 5.14, pode ser vista na Figura 5.15. Para melhor visualização, as marcações são apresentadas na Tabela 5.1. Os arcos referentes às transições de sincronizações (arcos inter-processos) aparecem em negrito na árvore. Percebe-se que as transições referentes aos arcos inter-processos $\left(2^{1}, 2^{0}\right)$ e $\left(3^{1}, 4^{0}\right)$ aparecem na árvore, enquanto as transições referentes aos arcos $\left(2^{1}, 4^{0}\right)$ e $\left(3^{1}, 2^{0}\right)$ não aparecem, logo são não-executáveis. 


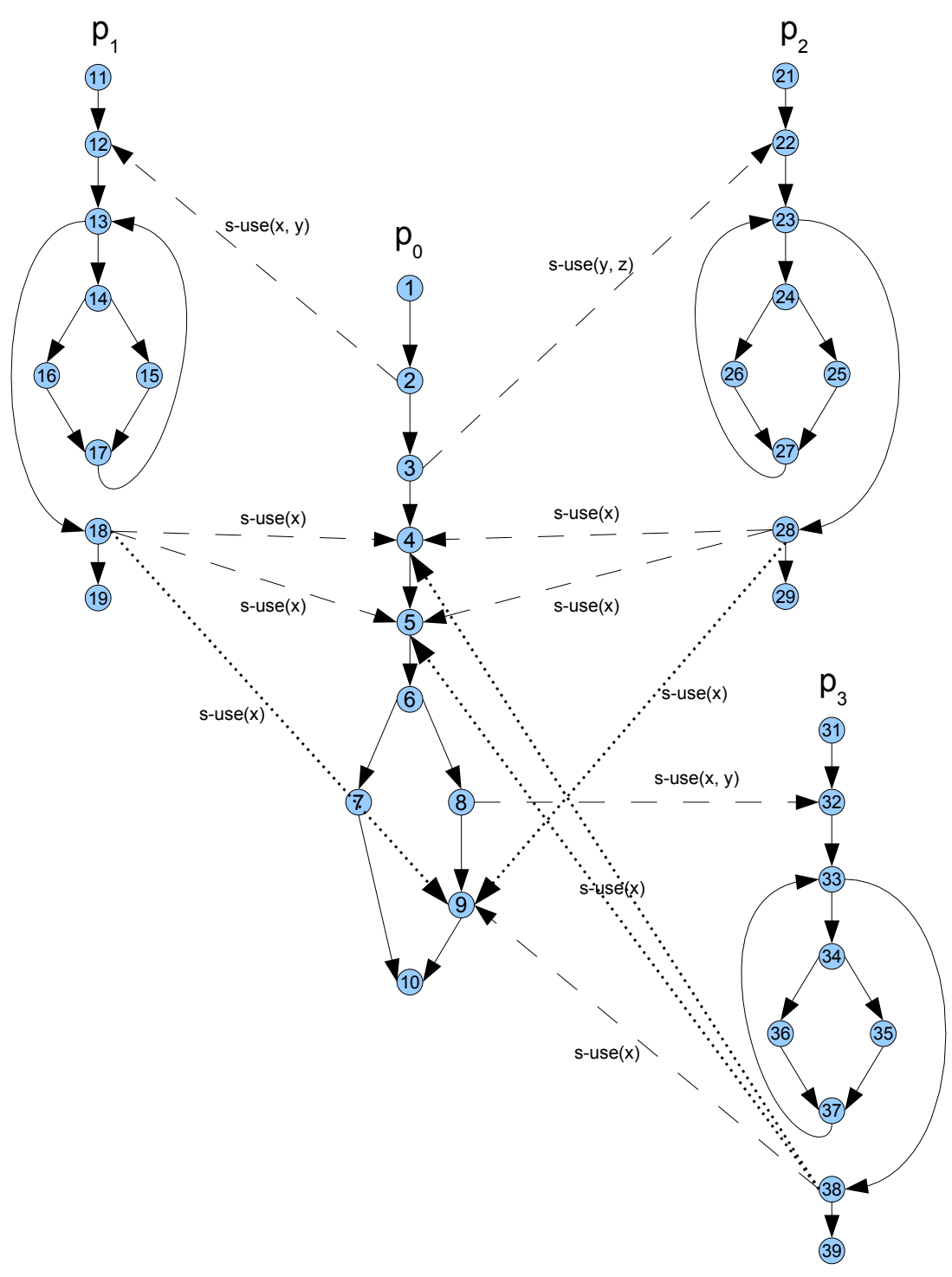

Figura 5.13: Exemplo GCD.

Na Figura 5.16, são apresentados os resultados alcançados na aplicação do método proposto no exemplo da Figura 5.12. Inicialmente são apresentados os dados do PCFG, seguido das redes de Petri geradas e resultados obtidos para os dois algoritmos propostos. Percebe-se que o algoritmo A não consegue detectar os arcos inter-processos não-executáveis e apresenta um número de iterações para o algoritmo que gera a árvore bem maior que o algoritmo B. O algoritmo B consegue detectar o problema, detectando que os arcos $\left(2^{1}, 4^{0}\right)$ e $\left(3^{1}, 2^{0}\right)$ são não-executáveis.

O método foi também aplicado ao exemplo GCD, como mostrado na Figura 5.17. Para esse exemplo, os dois algoritmos conseguem capturar os arcos inter-processos não-executáveis, com a diferença que o número de iterações do algoritmo A (2.265) é mais que o dobro do algoritmo B (1.013).

Discussão Uma desvantagem do método proposto seria o seu custo. A transformação do modelo PCFG para a rede de Petri e a análise da árvore de cobertura apresentam custos baixos. O 


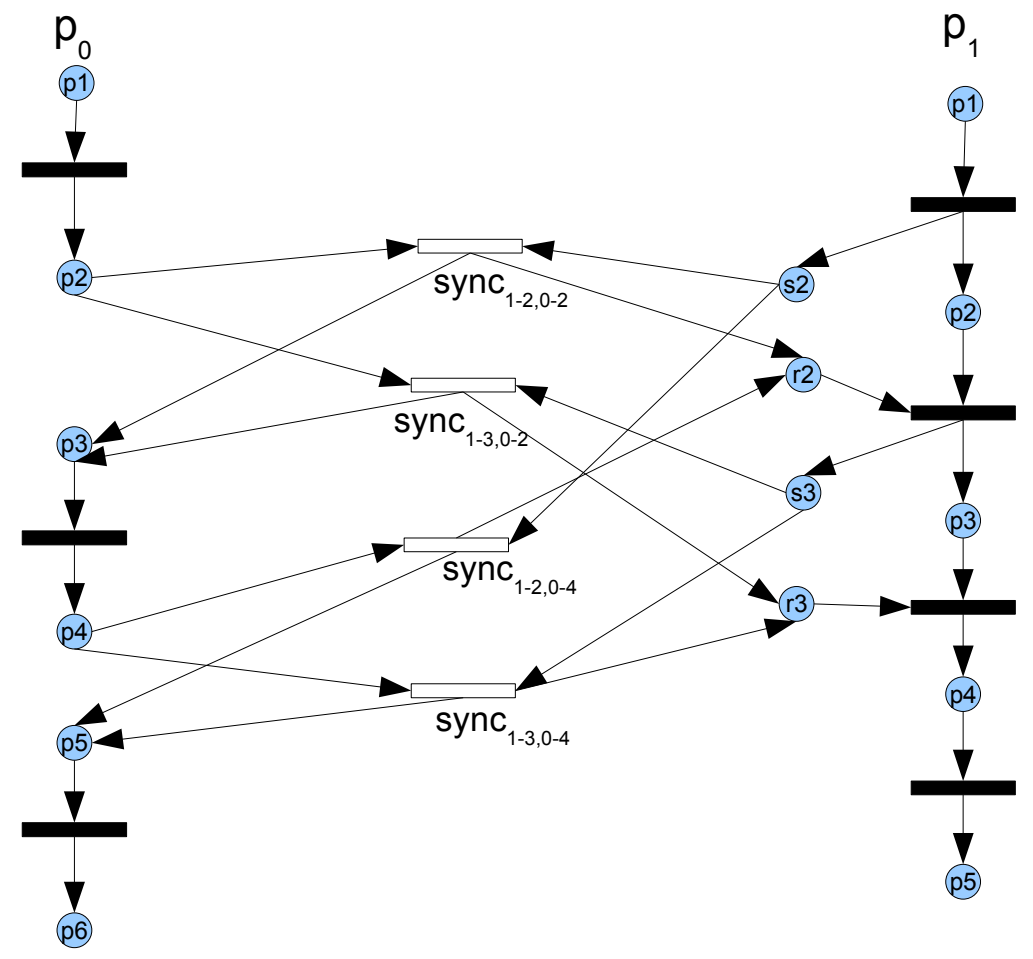

Figura 5.14: Rede de Petri para o exemplo 1.

problema seria a construção da árvore de cobertura que é um problema NP-completo (Lipton, 1975; Karp e Miller, 1969). Algumas medidas poderiam ser tomadas para diminuir esse custo, como aplicar regras de redução propostas na literatura (Berthelot et al., 1980; Murata, 1989) ou criar algumas dessas regras, visto que a análise da árvore objetiva apenas verificar as transições referentes aos arcos inter-processos.

O método proposto considera uma comunicação simples entre primitivas send e receive. Buffers para envio e recebimento de mensagens e matches por tipos de dados presentes em bibliotecas como o MPI e o PVM não são tratados e precisam ser melhor estudados nesse contexto.

A árvore de cobertura poderia ser utilizada para outros propósitos como detectar deadlock e livelock. Nesse cenário, a relação de custo e benefício da geração da árvore de cobertura poderia ser melhorada. Outro fator interessante é que, o engenheiro de testes tem que se preocupar menos com a identificação de caminhos não-executáveis, apesar do método não eliminar todos os arcos que não podem ser executados. 


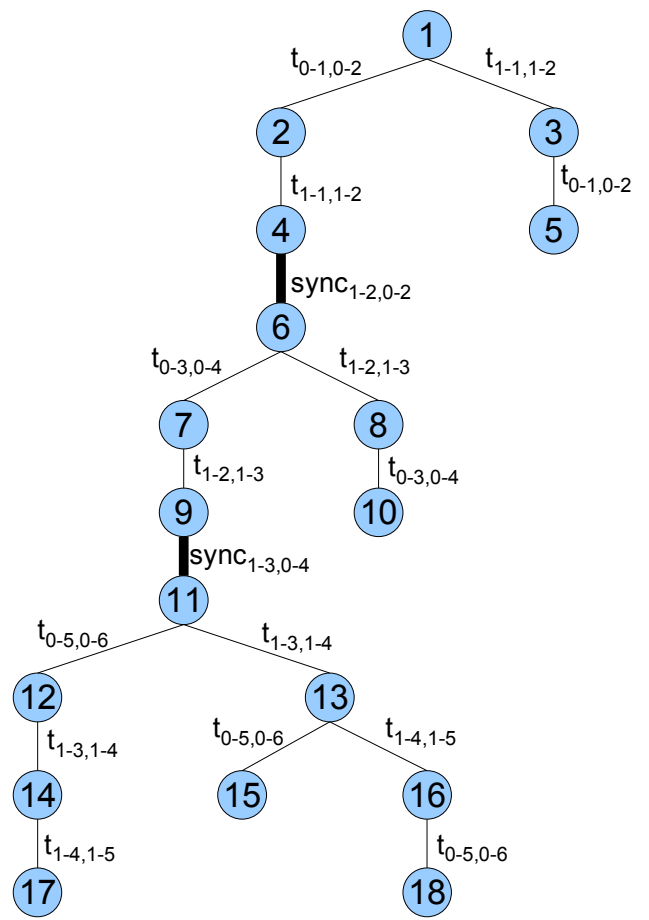

Figura 5.15: Árvore de cobertura para a rede de Petri da Figura 5.14.

\begin{tabular}{|c|c|}
\hline Nó & Marcação \\
& $\mathrm{p} 0-1, \mathrm{p} 0-2, \mathrm{p} 0-3, \mathrm{p} 0-4, \mathrm{p} 0-5, \mathrm{p} 0-6, \mathrm{p} 1-1, \mathrm{p} 1-2, \mathrm{p} 1-3, \mathrm{p} 1-4, \mathrm{p} 1-5, \mathrm{~s} 1-2, \mathrm{r} 1-2, \mathrm{~s} 1-3, \mathrm{r} 1-3$ \\
\hline 1 & $1,0,0,0,0,0,1,0,0,0,0,0,0,0,0$ \\
\hline 2 & $0,1,0,0,0,0,1,0,0,0,0,0,0,0,0$ \\
\hline 3 & $1,0,0,0,0,0,0,1,0,0,0,1,0,0,0$ \\
\hline 4 & $0,1,0,0,0,0,0,1,0,0,0,1,0,0,0$ \\
\hline 5 & $0,1,0,0,0,0,0,1,0,0,0,1,0,0,0$ \\
\hline 6 & $0,0,1,0,0,0,0,1,0,0,0,0,1,0,0$ \\
\hline 7 & $0,0,0,1,0,0,0,1,0,0,0,0,1,0,0$ \\
\hline 8 & $0,0,1,0,0,0,0,0,1,0,0,0,0,1,0$ \\
\hline 9 & $0,0,0,1,0,0,0,0,1,0,0,0,0,1,0$ \\
\hline 10 & $0,0,0,1,0,0,0,0,1,0,0,0,0,1,0$ \\
\hline 11 & $0,0,0,0,1,0,0,0,1,0,0,0,0,0,1$ \\
\hline 12 & $0,0,0,0,0,1,0,0,1,0,0,0,0,0,1$ \\
\hline 13 & $0,0,0,0,1,0,0,0,0,1,0,0,0,0,0$ \\
\hline 14 & $0,0,0,0,0,1,0,0,0,1,0,0,0,0,0$ \\
\hline 15 & $0,0,0,0,0,1,0,0,0,1,0,0,0,0,0$ \\
\hline 16 & $0,0,0,0,1,0,0,0,0,0,1,0,0,0,0$ \\
\hline 17 & $0,0,0,0,0,1,0,0,0,0,1,0,0,0,0$ \\
\hline 18 & $0,0,0,0,0,1,0,0,0,0,1,0,0,0,0$ \\
\hline
\end{tabular}

Tabela 5.1: Tabela das marcações para a árvore de cobertura. 


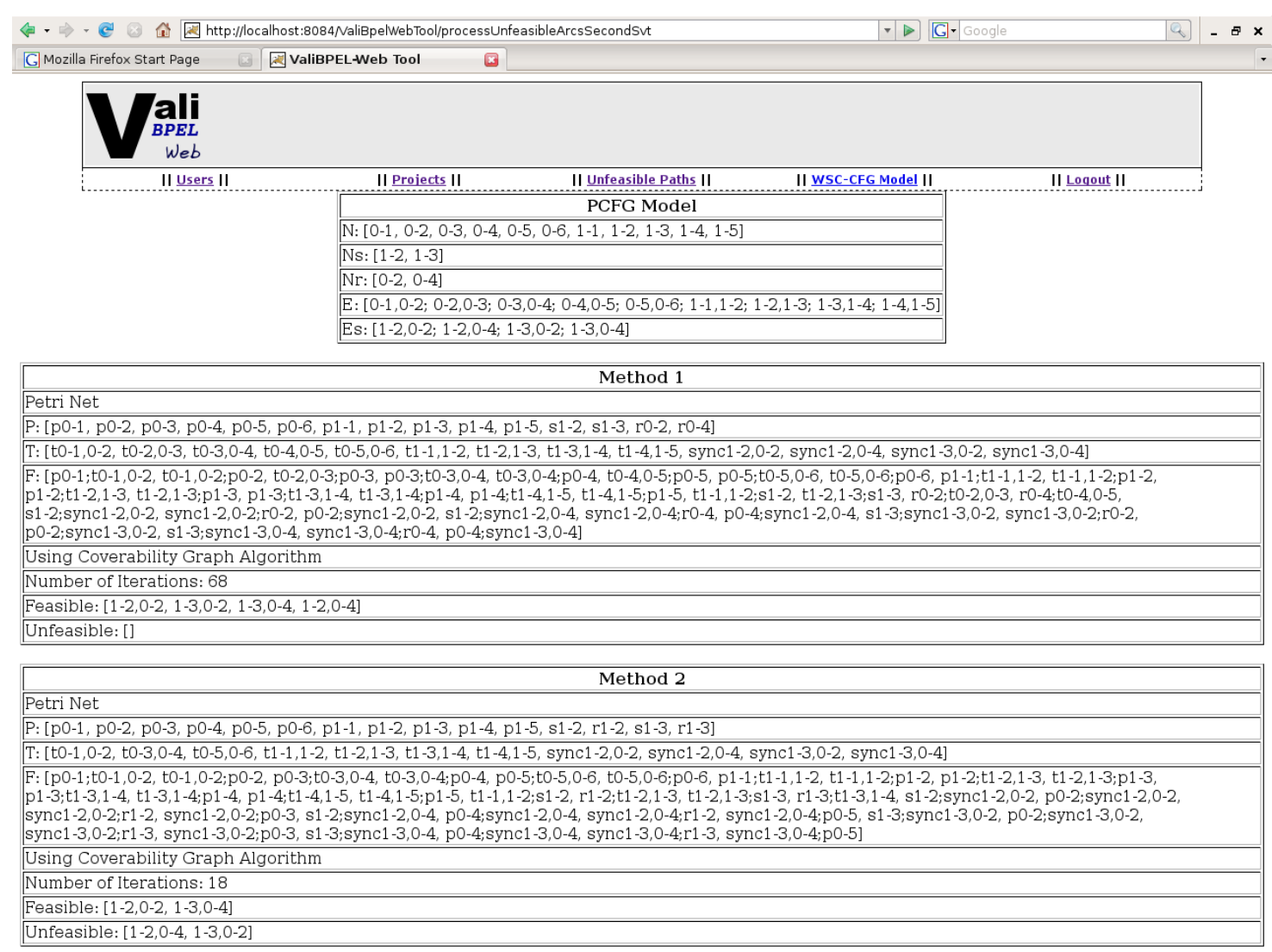

Developed by André Takeshi Endo (2007-2008)

Figura 5.16: Resultados obtidos com a execução do método proposto para o exemplo da Figura 5.12 . 


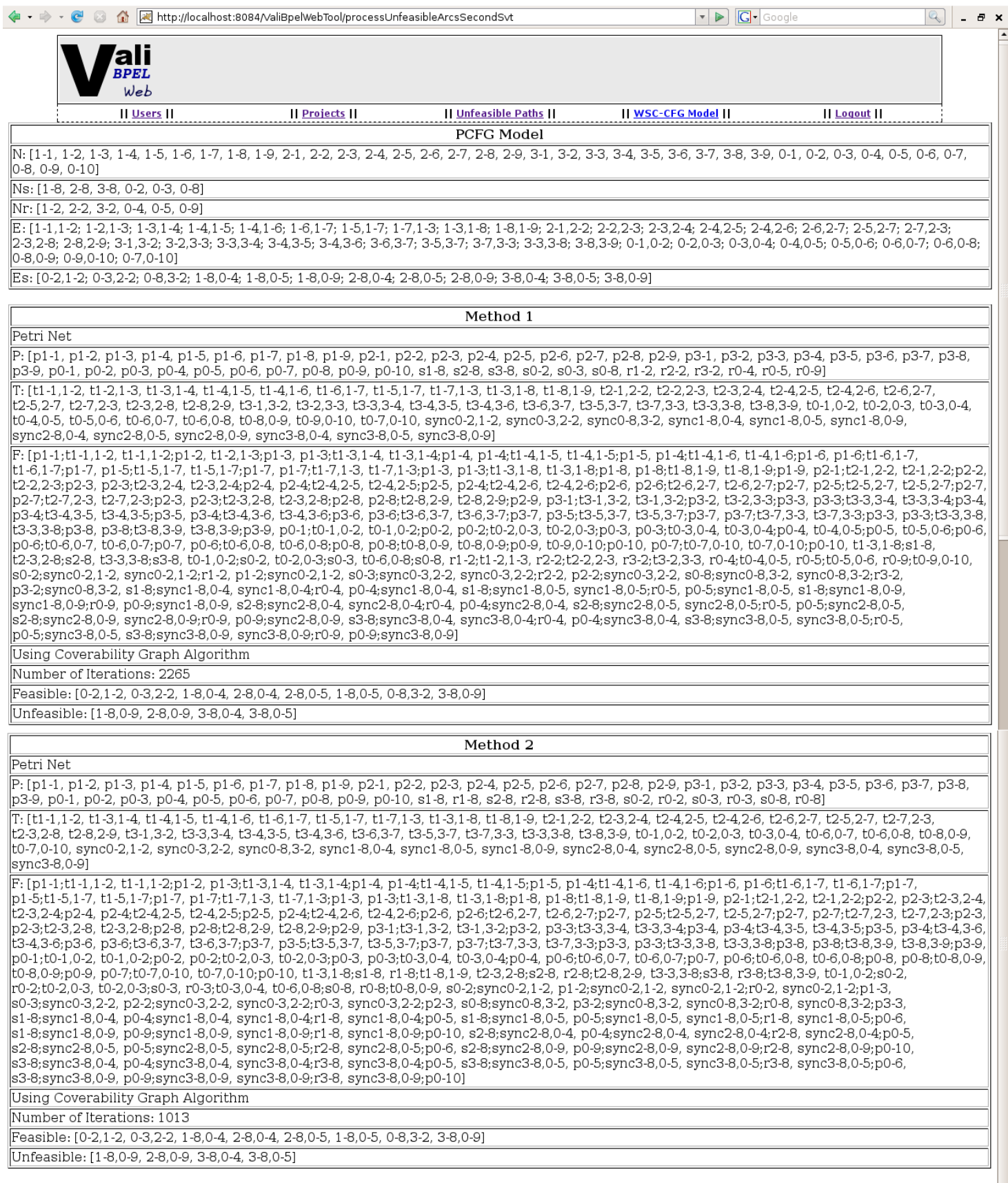

Figura 5.17: Resultados obtidos com a execução do método proposto para o exemplo GCD. 


\subsection{Ferramenta ValiBPEL-Web}

Nesta seção, a ferramenta ValiBPEL-Web, que apóia a estratégia proposta, é apresentada. A ferramenta ValiBPEL-Web é especificada utilizando como base a ferramenta ValiPar (Souza et al., 2005). Dessa forma, a ferramenta ValiBPEL-Web implementa alguns módulos da ValiPar e reutiliza os demais módulos.

Esta seção está organizada da seguinte forma. Na Seção 5.6.1, a ferramenta ValiPar e seus módulos serão apresentados. Na Seção 5.6.2, os módulos implementados pela ferramenta ValiBPELWeb são apresentados. Na Seção 5.6.3 são apresentados aspectos de implementação da ferramenta. Na Seção 5.6.4 é apresentado o processo para realização dos testes usando a ferramenta ValiBPELWeb.

\subsubsection{Ferramenta ValiPar}

A ValiPar (Souza et al., 2005) é uma ferramenta que apóia a validação de programas paralelos em diferentes ambientes de passsagem de mensagens, usando os critérios de teste estabelecidos para o modelo PCFG. A ValiPar fornece funcionalidades para criar sessões de teste, salvar e executar dados de teste e avaliar a cobertura dos testes em relação ao critério selecionado. A ValiPar é formada por quatro módulos principais: Vali-Inst, Vali-Exec, Vali-Elem e Vali-Eval. A arquitetura da ferramenta pode ser vista na Figura 5.18. A seguir é dada uma breve descrição de cada módulo da ferramenta.

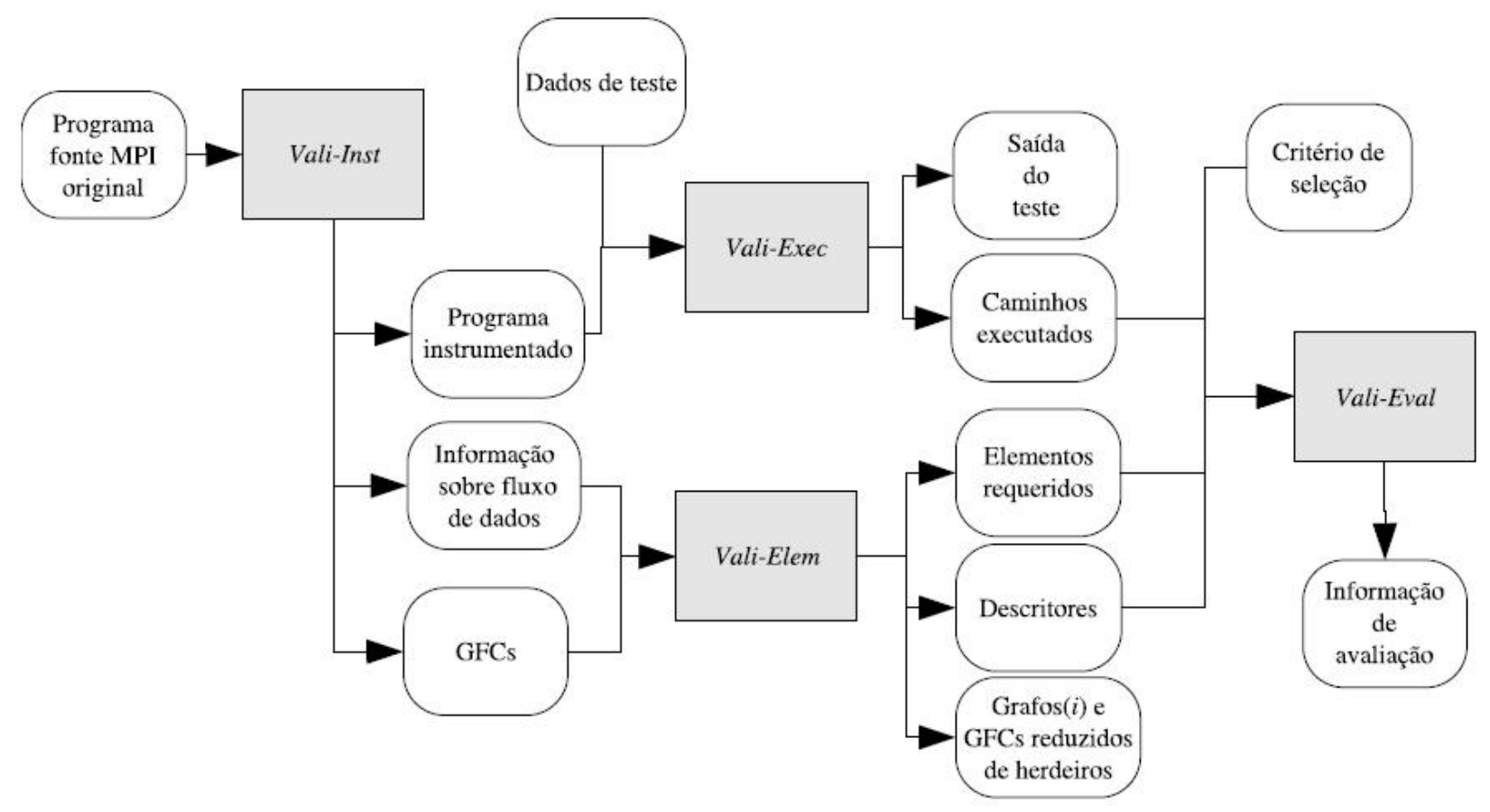

Figura 5.18: Arquitetura da Ferramenta ValiPar (Hausen, 2005). 
Vali-Inst: é responsável pela geração do modelo de teste, instrumentação e extração das informações de fluxo de dados. A geração do modelo de teste cria uma representação do programa de entrada no modelo PCFG. A ferramenta ValiPar utiliza uma abordagem conservativa para gerar os arcos inter-processos. A instrumentação gera um programa instrumentado em que comandos são inseridos no programa original para gravar informações sobre trechos executados. A extração das informações de fluxo de dados armazena informações sobre definições e usos de variáveis.

Vali-Exec: é responsável pela execução controlada do programa instrumentado e gravação das instruções ocorridas. O programa é executado com os casos de teste fornecidos pelo usuário. As saídas dos testes e os traces são armazenados para realização da análise de cobertura.

Vali-Elem: é responsável pela geração dos elementos requeridos dos critérios de teste do modelo PCFG. Esses elementos são gerados por meio do modelo de teste e informações de fluxo de dados fornecidos pelo módulo Vali-Inst.

Vali-Eval: é responsável pela avaliação da cobertura dos casos de teste em relação aos critérios de teste selecionados. Utiliza informações dos módulos Vali-Elem e Vali-Exec para determinar qual foi a cobertura alcançada pelos casos de teste executados.

Na ferramenta ValiBPEL-Web, o módulo Vali-Inst é implementado para que o modelo de teste e programas instrumentados sejam gerados a partir de processos BPEL. O módulo Vali-Exec é implementado com o apoio do software ActiveBPEL. Foi escolhido o ambiente de execução ActiveBPEL (ActiveBPEL, 2006), por se tratar de um software livre que possui suporte completo a execução da linguagem WS-BPEL. Esse ambiente de execução realiza a entrega (deployment) dos processos por meio de um arquivo compactado BPR (Business Process Archive File) que contém arquivos BPEL, WSDL e de configuração. Os módulos Vali-Elem e Vali-Eval da ValiPar serão reutilizados na ferramenta ValiBPEL-Web.

\subsubsection{Projeto da Ferramenta}

A implementação da ferramenta ValiBPEL-Web concentra-se nos módulos Vali-Inst e Web Interface, visto que os demais módulos da ValiPar foram reutilizados. A implementação do módulo Vali-Inst é dividida em dois submódulos: GraphGen e Instrumentor. O diagrama de classes referente a esses submódulos pode ser visto na Figura 5.19.

\section{Submódulo GraphGen}

O submódulo GraphGen é responsável pela geração do modelo de teste (PCFG) por meio do arquivo BPR. O arquivo BPR é descompactado e para cada arquivo de processo BPEL é gerado um grafo. A geração do grafo é feita seguindo a transformação proposta na Seção 5.3. Como o arquivo BPEL é baseado no XML, uma estrutura de dados de um grafo é gerada à medida que a 


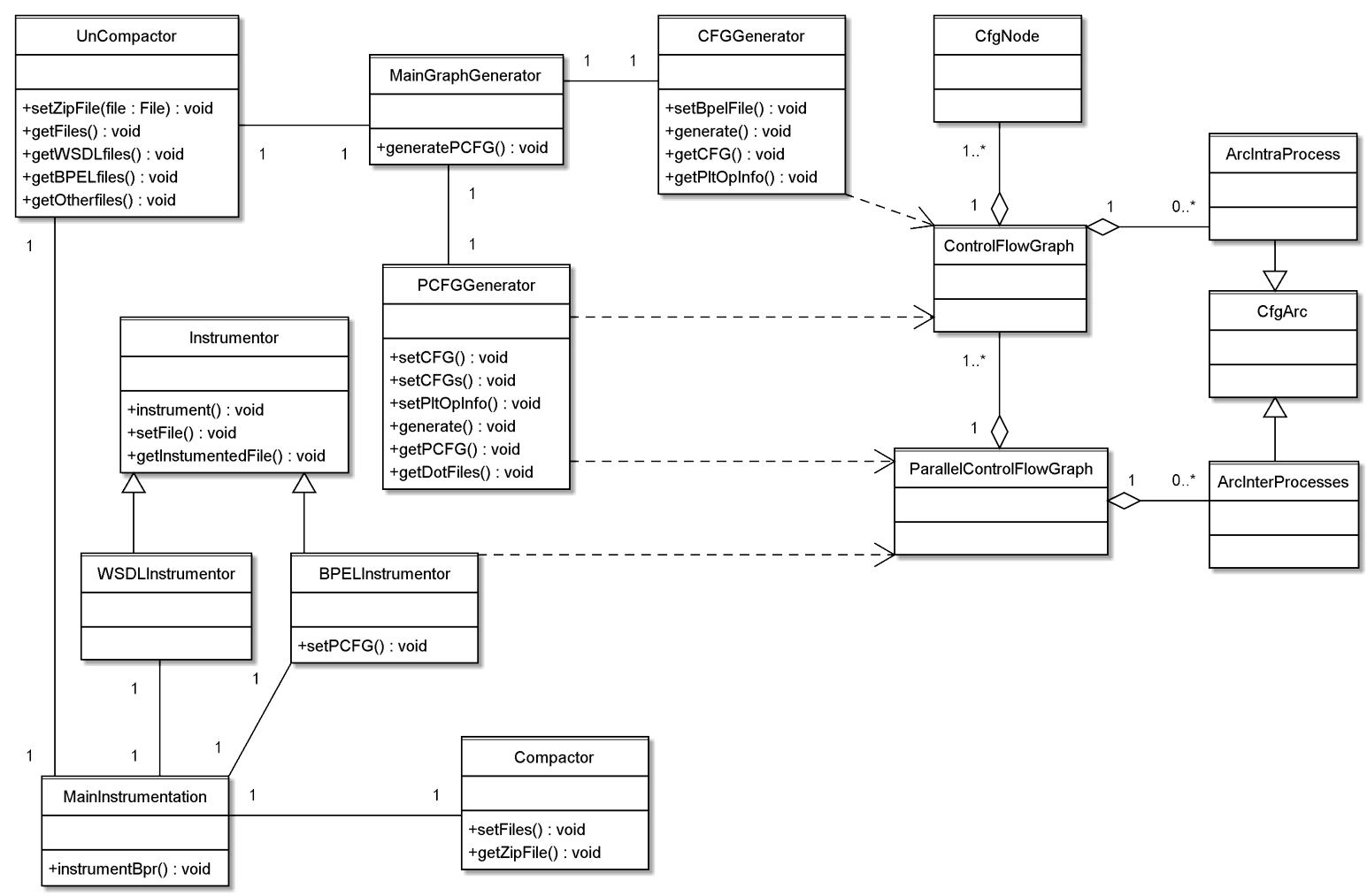

Figura 5.19: Diagrama de Classes para os submódulos GraphGen e Instrumentor.

árvore XML é percorrida. Nesse momento, informações necessárias à instrumentação também são armazenadas. As classes desse submódulo são descritas na Tabela 5.2.

\begin{tabular}{|c|l|}
\hline Classe & Função \\
\hline MainGraphGenerator & $\begin{array}{l}\text { instancia outras classes com objetivo final de gerar o mo- } \\
\text { delo de teste. }\end{array}$ \\
\hline CFGGenerator & $\begin{array}{l}\text { recebe um arquivo BPEL e gera um objeto ControlFlow- } \\
\text { Graph e informações sobre fluxo de dados. }\end{array}$ \\
\hline PCFGGenerator & $\begin{array}{l}\text { inclui vários objetos ControlFlowGraph e por meio de infor- } \\
\text { mações sobre partnerlink e } \text { operation gera um objeto Paral- } \\
\text { lelControlFlowGraph. }\end{array}$ \\
\hline UnCompactor & $\begin{array}{l}\text { recebe um arquivo compactado BPR e o descompacta, pos- } \\
\text { sibilitando acessar os demais arquivos. }\end{array}$ \\
\hline CfgNode & representa um nó de um grafo. \\
\hline CfgArc & representa um arco de um grafo. \\
\hline ArcIntraProcess & representa o tipo de arco intra-processo do PCFG. \\
\hline ArcInterProcesses & representa o tipo de arco inter-processos do PCFG. \\
\hline ControlFlowGraph & representa um grafo de fluxo de controle tradicional. \\
\hline ParallelControlFlowGraph & representa um grafo de fluxo de controle paralelo (PCFG). \\
\hline
\end{tabular}

Tabela 5.2: Classes do Módulo GraphGen

\section{Submódulo Instrumentor}


O submódulo Instrumentor é responsável pelo processo de instrumentação dos processos BPEL, de forma que, as atividades executadas durante os testes sejam armazenadas para futura análise de cobertura.

Esse módulo insere atividades nos arquivos BPEL para que os rastros de execução sejam gravados durante a realização dos testes. É necessário também gravar a informação de qual instância de processo BPEL uma determinada mensagem foi recebida. Para isso, os arquivos WSDL também precisam ser instrumentados.

Na Tabela 5.3, as classes desse submódulo são descritas.

\begin{tabular}{|c|l|}
\hline \multicolumn{1}{|c|}{ Classe } & Função \\
\hline MainInstrumentation & $\begin{array}{l}\text { instancia outras classes com objetivo final de instrumentar } \\
\text { os processos BPEL. }\end{array}$ \\
\hline Instrumentor & classe base para instrumentar um arquivo. \\
\hline WSDLInstrumentor & instrumenta arquivos WSDL. \\
\hline BPELInstrumentor & $\begin{array}{l}\text { instrumenta os processos BPEL para gravar informações } \\
\text { das execuções. }\end{array}$ \\
\hline Compactor & $\begin{array}{l}\text { gera um novo arquivo BPR com os processos BPEL que } \\
\text { foram instrumentados. }\end{array}$ \\
\hline
\end{tabular}

Tabela 5.3: Classes do Módulo Instrumentator

\section{Módulo Web Interface}

Esse módulo tem como objetivo fornecer uma interface gráfica para o gerenciamento e controle dos testes realizados. Um diagrama de classes para os objetos que são gerenciados por esse módulo é apresentado na Figura 5.20.

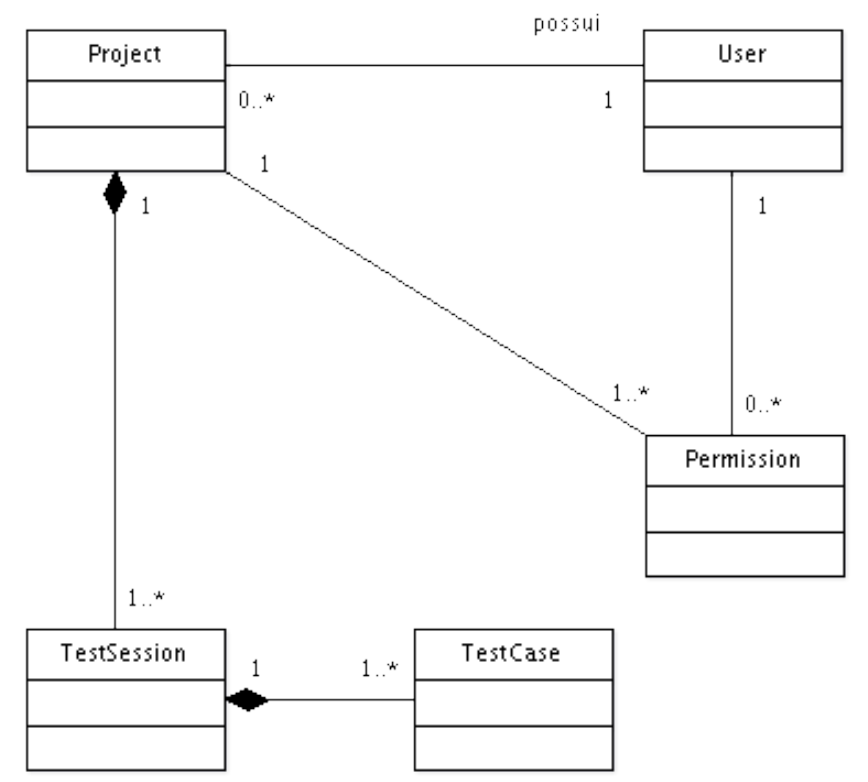

Figura 5.20: Diagrama de Classes para os objetos gerenciados pelo módulo Web Interface. 
Controle de acesso e usuários A ferramenta possibilita a criação, alteração e remoção de usuários. Inicialmente existe apenas o usuário "admin", que não pode ser removido. Esse usuário é o único com permissão para gerenciar os usuários. O acesso à ferramenta é permitido apenas para usuários cadastrados. A tela de autenticação da ferramenta é apresentada na Figura 5.21. A tela com a listagem dos usuários cadastrados pode ser vista na Figura 5.22.

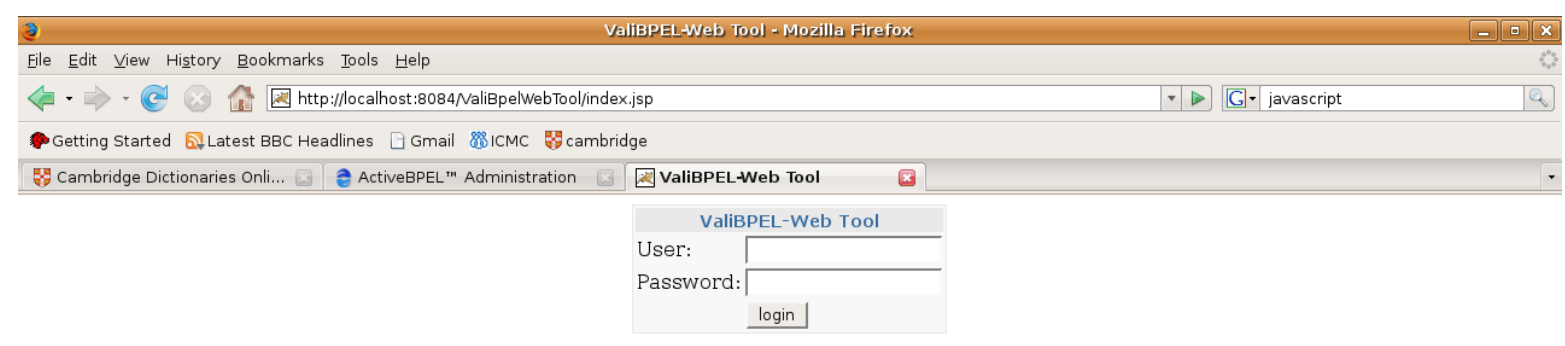

Figura 5.21: Tela de autenticação.

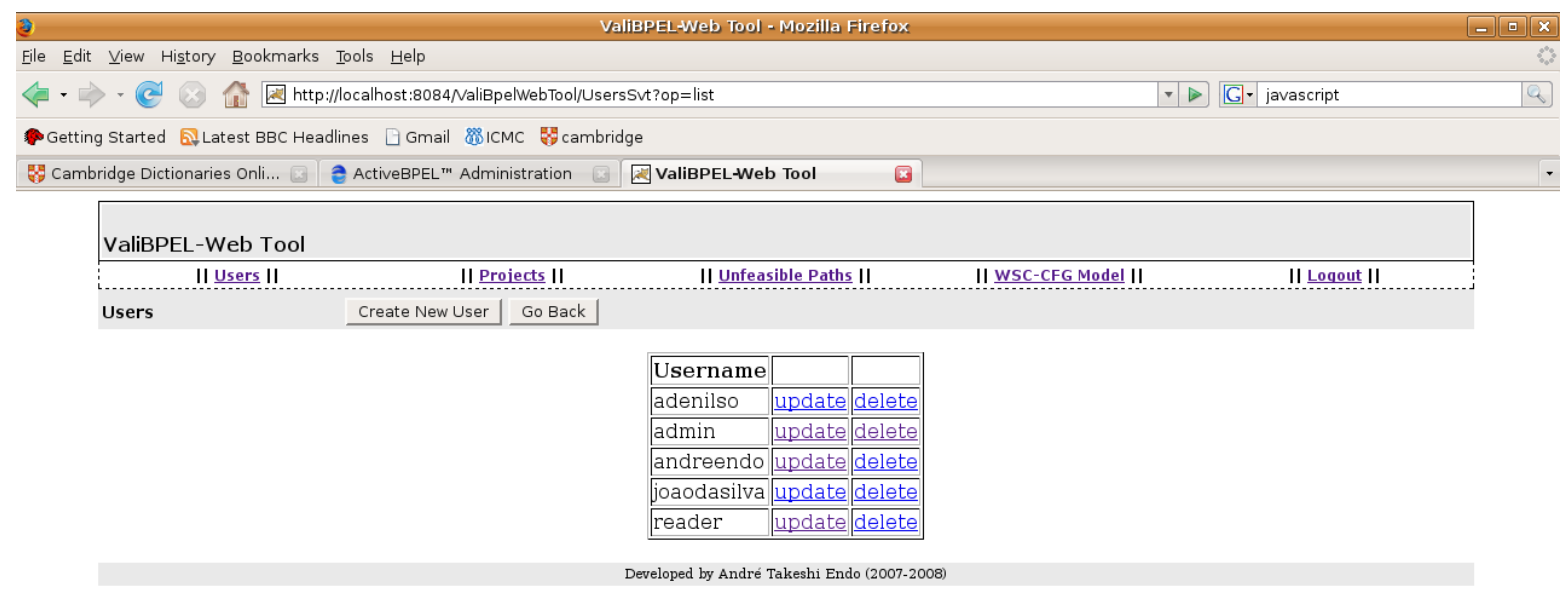

Figura 5.22: Tela de listagem de usuários.

Projetos Os projetos são criados em dois passos: No primeiro passo, é fornecido o nome do projeto, que deve ser único, e o arquivo BPR contendo os processos BPEL (Figura 5.23(a)). No segundo passo, a ferramenta identifica e informa quais são os processos BPEL contido no arquivo. Nesse passo, o usuário fornece o número de instâncias e o "id" de cada processo (Figura 5.23(b)). O proprietário do projeto é o usuário que o criou. Esse também tem permissão de administrador para esse projeto. A listagem de projetos criados é apresentada na Figura 5.24.

Permissões Na ferramenta ValiBPEL-Web, as permissões são definidas por projeto. Na Figura 5.25, são mostradas as permissões para o projeto "gcd_joao". As permissões são atribuídas para cada usuário cadastrado. Existem quatro tipos de permissões:

- No Access: usuário sem acesso ao projeto. 


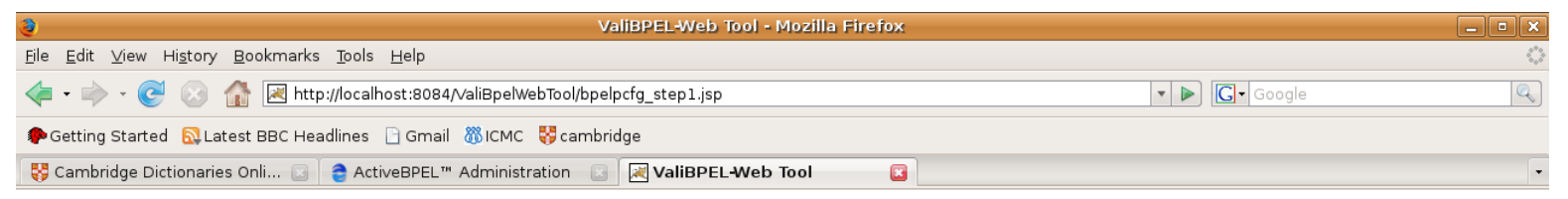

(a)

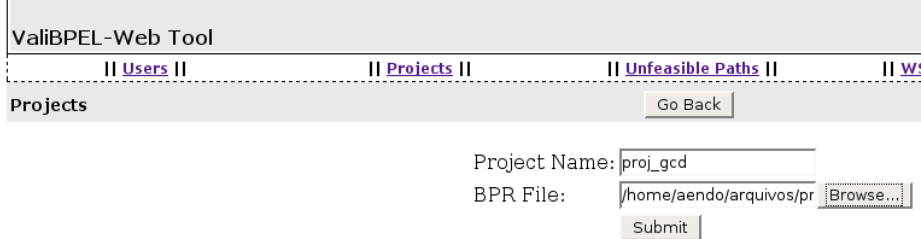

Developed by André Takeshi Endo (2007-2008)

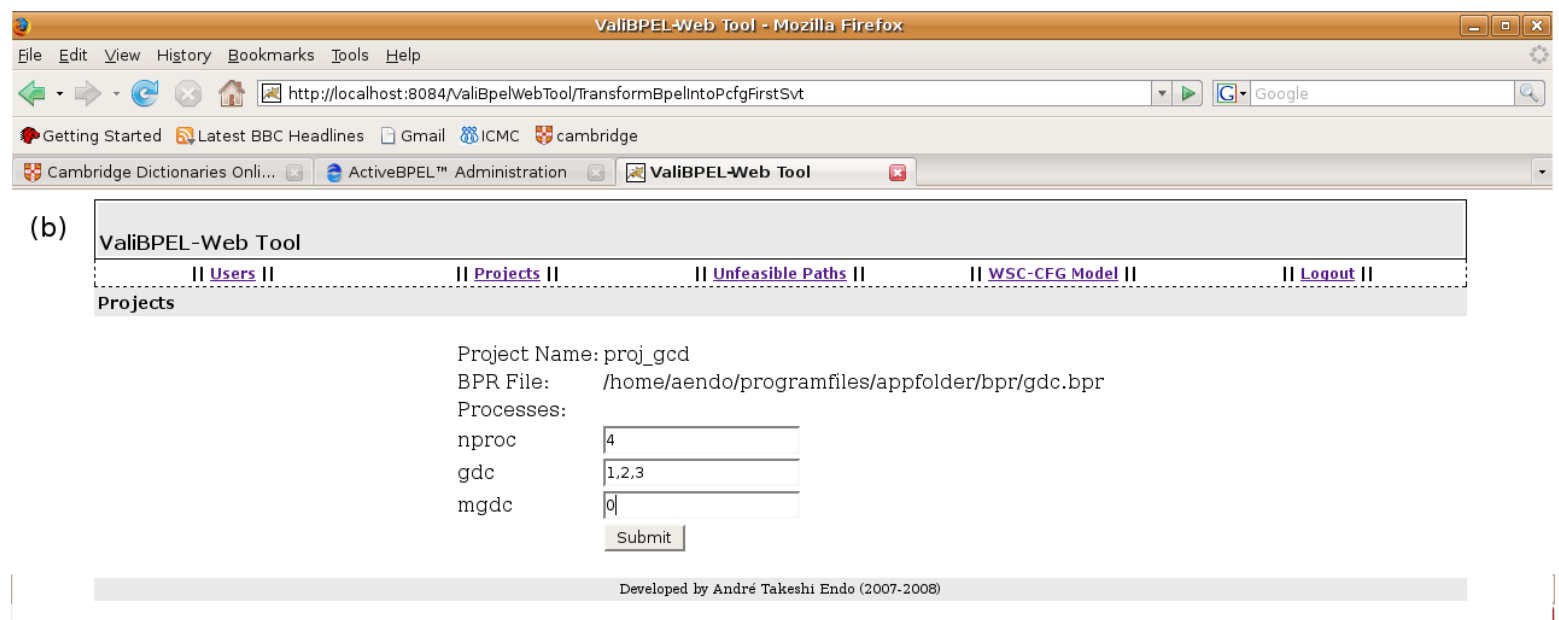

Figura 5.23: Telas de criação de um projeto.

- Reader: usuário com permissão de visualização do projeto e geração de relatórios.

- Editor: usuário com as mesmas permissões de Reader, mais permissão para criar sessões de teste e casos de teste. Não possui permissão para apagar.

- Admin: usuário com as mesmas permissões de Editor, além de apagar sessões e casos de teste e definir permissões para o projeto. Pode também apagar o projeto, desde que não possua nenhuma sessão de teste criada.

Sessão de teste Uma sessão de teste pode ser criada na tela de abertura do projeto (Figura 5.26). A partir dessa tela, é possível visualizar os grafos dos processos, os critérios e quantidade de elementos requeridos e as sessões de teste criadas.

Casos de Teste Os casos de teste executados podem ser vistos na tela de abertura da sessão (Figura 5.27). Nessa mesma tela, o usuário tem oportunidade de selecionar os casos de teste e gerar um relatório de cobertura (Figura 5.29). O usuário também pode escolher a visualização dos rastros de execução para o caso de teste (Figura 5.28). 


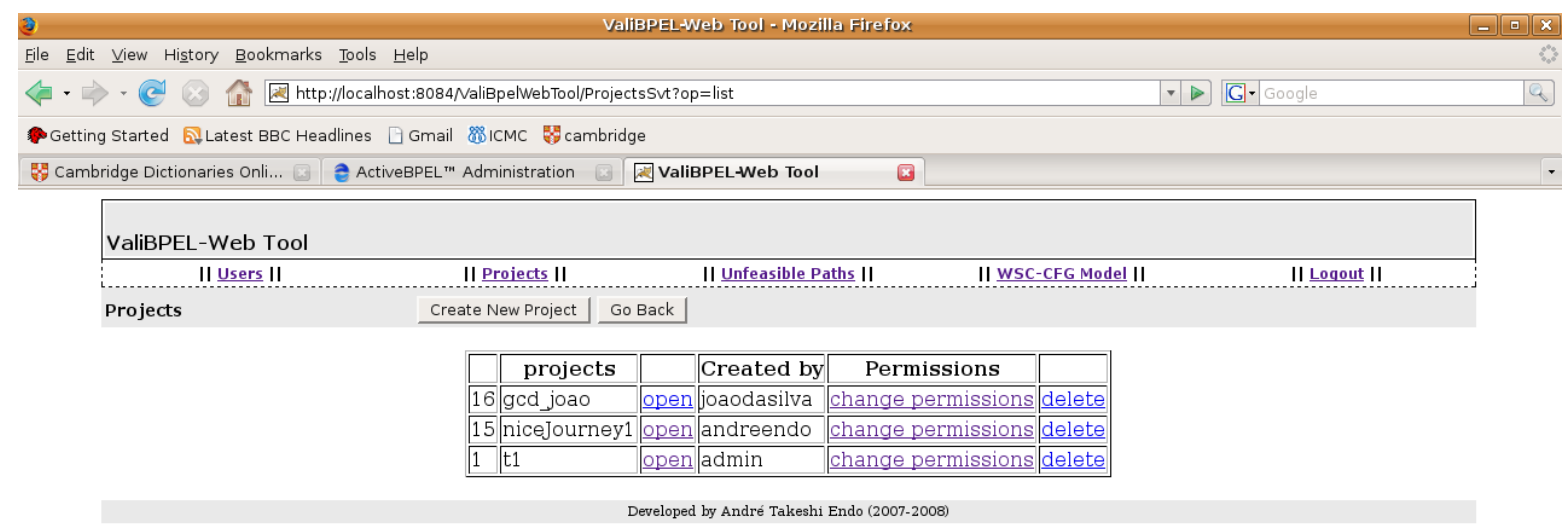

Figura 5.24: Tela de listagem de projetos.

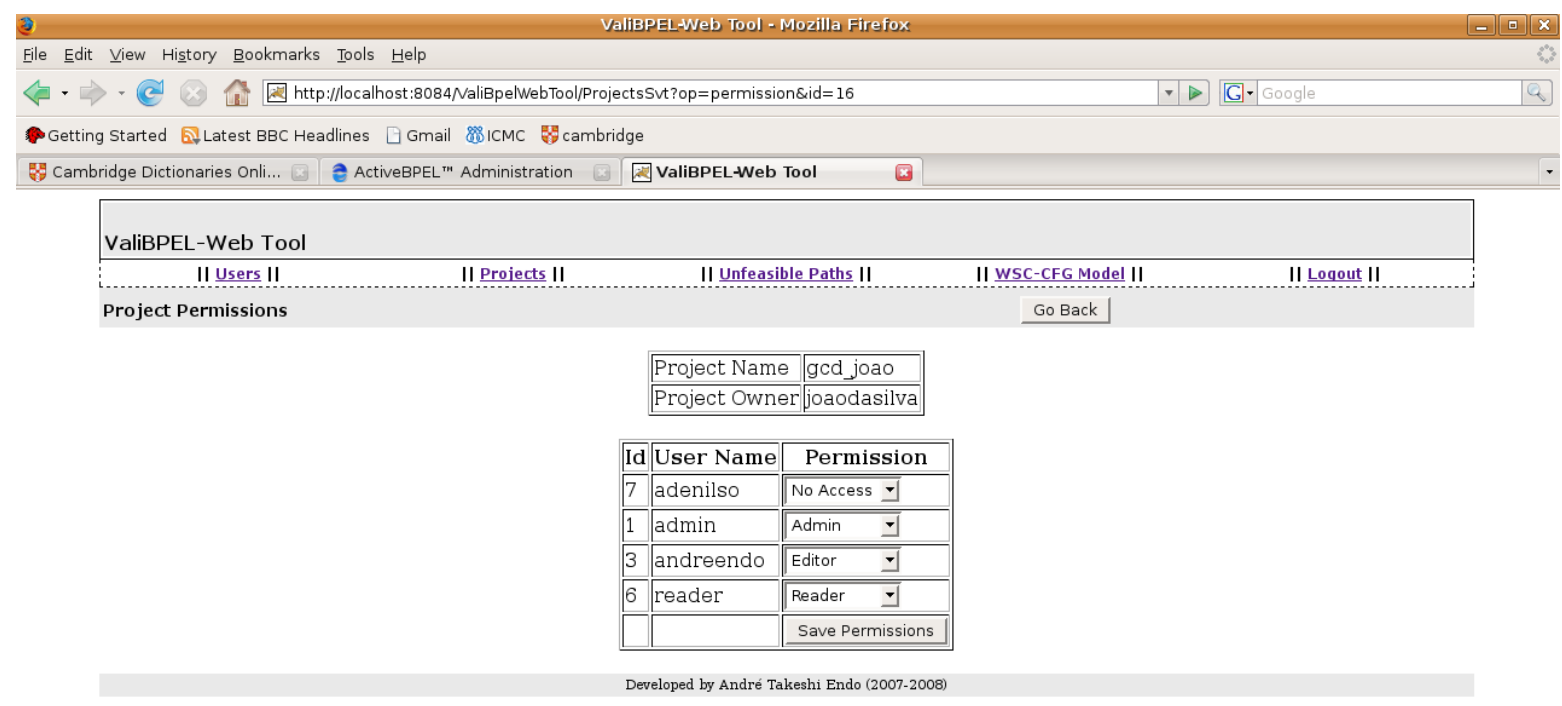

Figura 5.25: Tela de listagem de permissões.

Relatórios de Cobertura Os relatórios da ferramenta ValiBPEL-Web estão focados na cobertura dos critérios de teste. O relatório mostrado na Figura 5.29 apresenta os dados de cobertura para os casos de teste selecionados. São demostrados os critérios de teste, quantidade de elementos requeridos, quantidade de elementos cobertos e não cobertos e porcentagem de cobertura. Já o relatório apresentado na Figura 5.30 mostra informações sobre a cobertura para um critério de teste específico. São apresentados os elementos requeridos que foram cobertos e por qual caso de teste, além daqueles que não foram cobertos. 


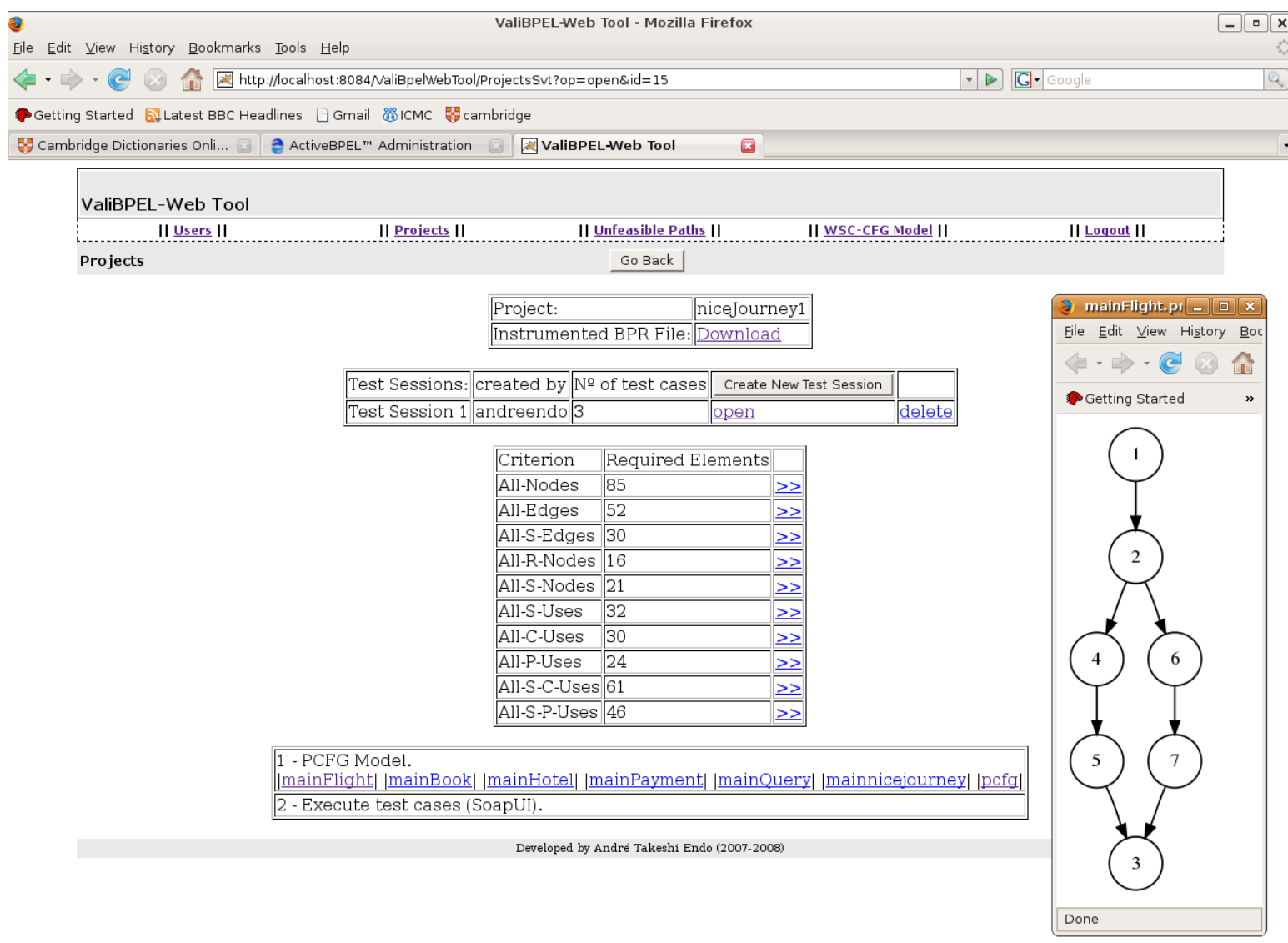

Figura 5.26: Tela de abertura de um projeto.

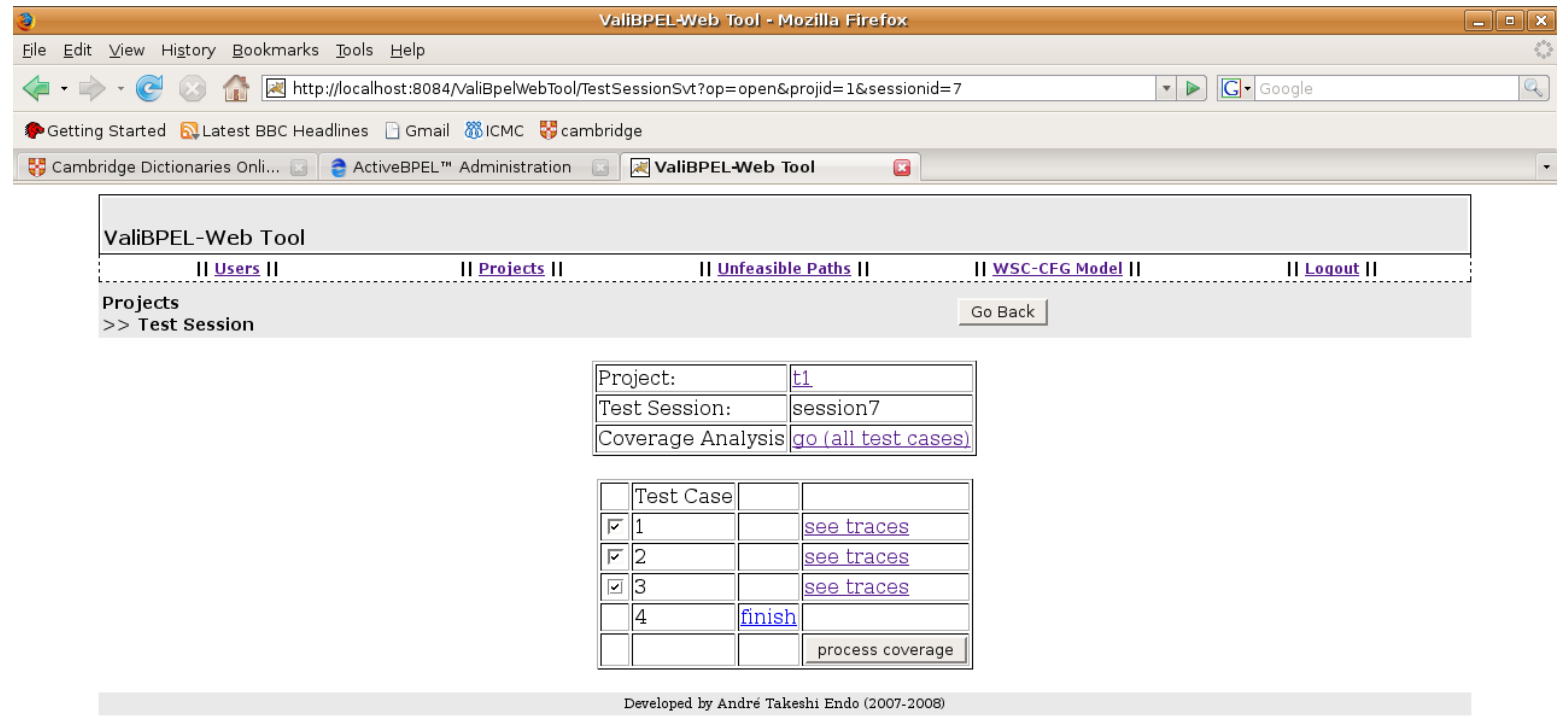

Figura 5.27: Tela de Sessão de Teste. 


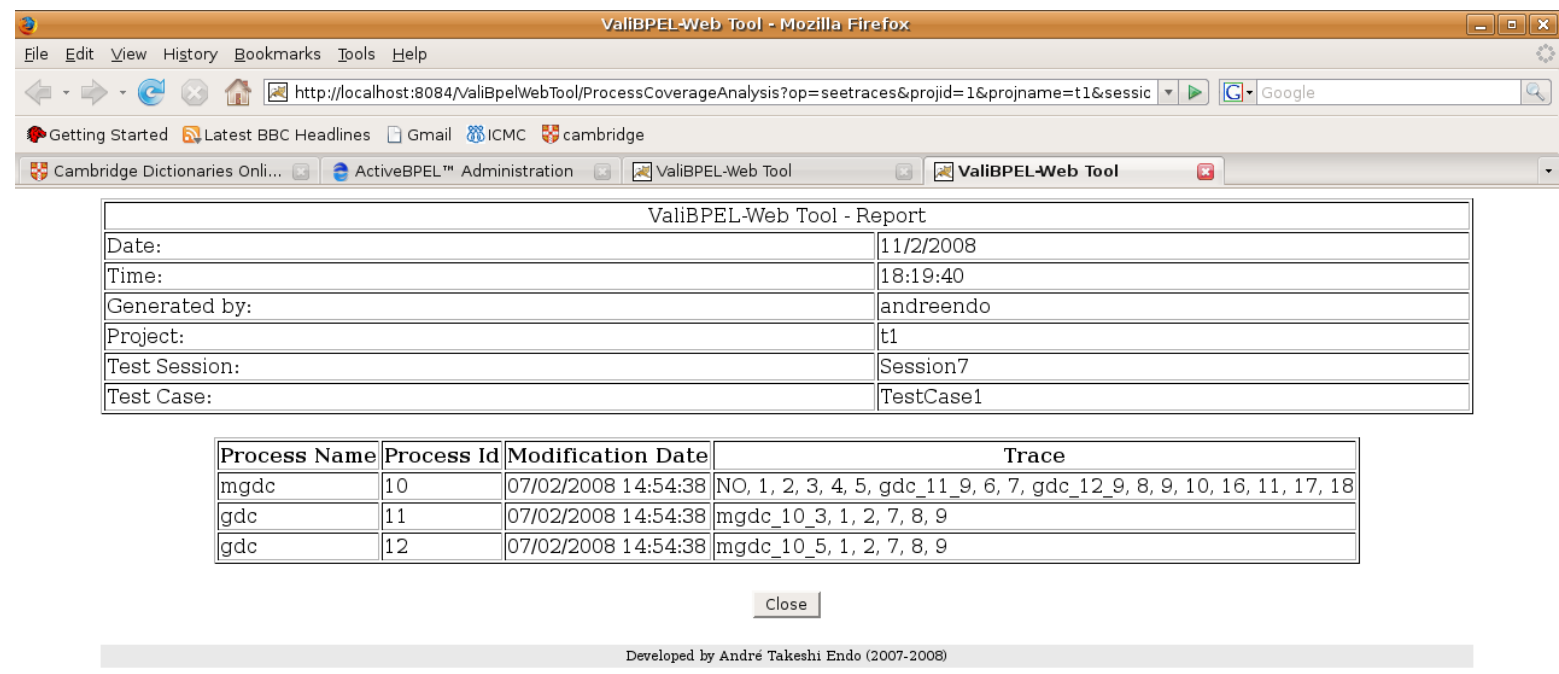

Figura 5.28: Tela de visualização dos rastros de execução do caso de teste.

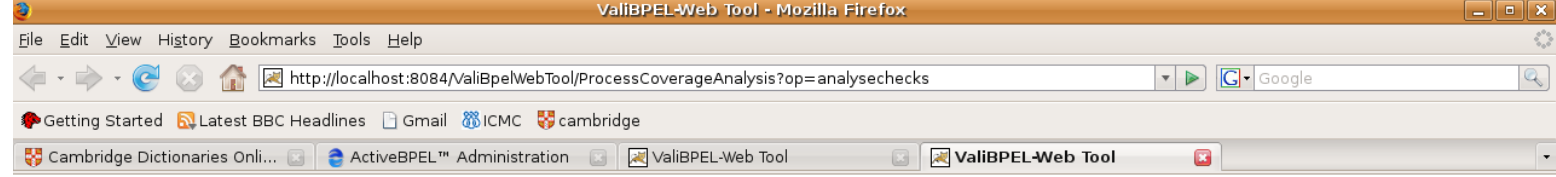

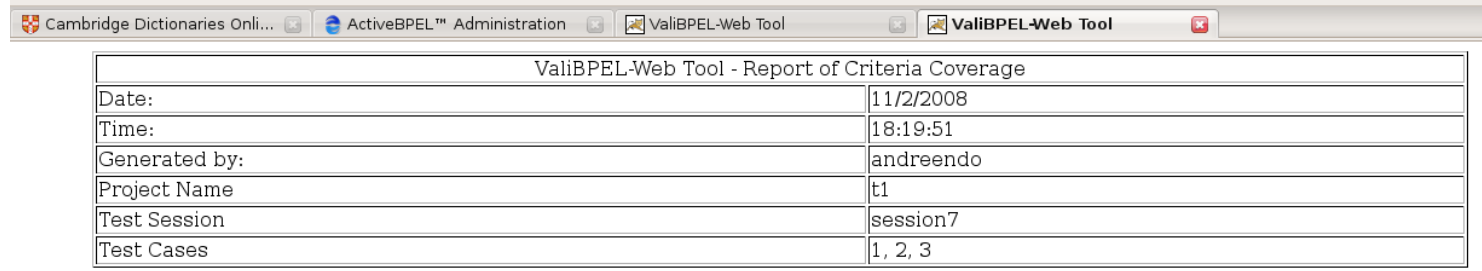

\begin{tabular}{|l|l|l|l|l|l|l|}
\hline Criterion & & Required Elements & Covered elements & Not Covered elements & Coverage Percentage \\
\hline todos-nos & details & 45 & 40 & 5 & $88,89 \%$ \\
\hline todos-nosS & details & 7 & 7 & 0 & $100,00 \%$ \\
\hline todos-nosR & details & 7 & 7 & 0 & $100,00 \%$ \\
\hline todos-c-usos & details & 38 & 19 & 19 & $50,00 \%$ \\
\hline todos-p-usos & details & 40 & 15 & 25 & $37,50 \%$ \\
\hline todos-s-usos & details & 18 & 13 & $27,78 \%$ \\
\hline todas-arestas & details & 29 & 16 & 13 & $55,17 \%$ \\
\hline todas-arestass & details & 18 & 18 & 10 & $44,44 \%$ \\
\hline
\end{tabular}

Close

Developed by André Takeshi Endo (2007-2008)

Figura 5.29: Telas de visualização da cobertura dos critérios em uma determinada sessão de teste. 


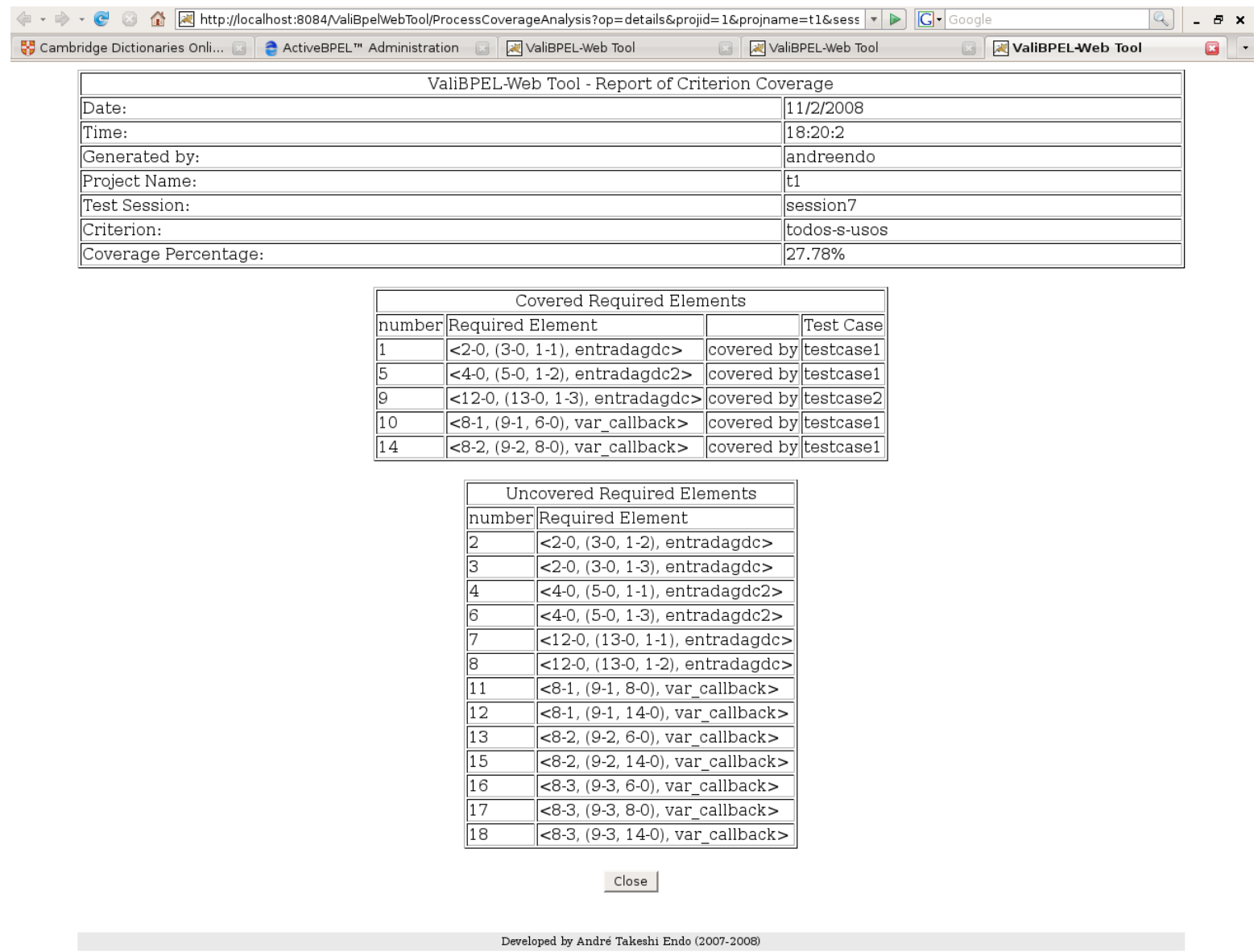

Figura 5.30: Telas de visualização da cobertura para um critério específico. 


\subsubsection{Aspectos de Implementação}

No desenvolvimento da ferramenta foram utilizados os seguintes softwares: o ambiente de desenvolvimento NetBeans 5.5 ${ }^{1}$, o sistema gerenciador de banco de dados MySQL ${ }^{2}$, o servidor Web Apache Tomcat 5.5 ${ }^{3}$, a engine ActiveBPEL (ActiveBPEL, 2006) e a ferramenta ValiMPI (Hausen, 2005).

A ferramenta ValiBPEL-Web foi implementada na linguagem de programação Java. Essa linguagem foi escolhida por sua portabilidade e porque o ambiente ActiveBPEL também é implementado em Java. A ferramenta foi desenvolvida como uma aplicação Web. Logo, foram utilizadas tecnologias como JSP e Servlets (Sun, 2007). Está sendo usada uma biblioteca padrão do Java para manipulação do XML (W3C, 2003), seguindo a estrutura de representação do padrão DOM (W3C, 2005).

A persistência dos dados foi feita em um banco de dados MySQL, podendo ser portada para outros sistemas gerenciadores de banco de dados. A interface Web foi implementada seguindo o padrão de projeto MVC (Sun Microsystems, 2002), sendo a interface desenvolvida em JSP, os controles em servlets e o modelo em classes java.

\subsubsection{Processo de Teste da Ferramenta}

Nesta seção é apresentado o processo que deve ser realizado para a execução dos testes na ferramenta ValiBPEL-Web. A arquitetura da ferramenta pode ser vista na Figura 5.31. Os passos do processo de teste são descritos a seguir:

1. A ferramenta recebe como entrada um arquivo BPR que contém todos os processos envolvidos na composição. A entrada do arquivo é feita por meio do módulo Web Interface.

2. O módulo Web Interface fornece esse arquivo como entrada para o módulo Vali-Inst. O módulo Vali-Inst da ferramenta ValiBPEL-Web é dividido em dois submódulos: GraphGen e Instrumentor.

3. O primeiro submódulo a ser executado é o GraphGen. Esse submódulo cria os grafos de fluxo de controle referentes aos processos BPEL. Em seguida, os arcos inter-processos são construídos formando um PCFG. Esse módulo basicamente implementa a transformação apresentada na Seção 5.3. A saída principal desse módulo é a criação de um PCFG referente aos processos BPEL do arquivo BPR.

4. O passo seguinte é instrumentar os arquivos BPEL e WSDL para que informações sobre as atividades ocorridas sejam gravadas durante a execução dos casos de teste. Para realizar isso,

\footnotetext{
${ }^{1}$ http://www.netbeans.org/

${ }^{2}$ http://www.mysql.com/

${ }^{3}$ http://tomcat.apache.org/
} 
o submódulo Instrumentor recebe como entradas os arquivos WSDL, os arquivos BPEL e o PCFG gerado pelo submódulo GraphGen e gera como saída um arquivo BPR com os processos instrumentados.

5. Deve ser feito o deployment do arquivo BPR instrumentado no módulo Vali-Exec. Na ferramenta ValiBPEL-Web, esse módulo é implementado pelo ambiente de execução ActiveBPEL e por uma função customizada para gravação de arquivos texto. Essa função é utilizada para gravar os rastros de execução (traces) dos processos BPEL.

6. Em seguida, os casos de teste devem ser executados para os processos BPEL instrumentados disponibilizados no ActiveBPEL. Processos BPEL podem ser acessados como WSs comuns. Logo, ferramentas de teste caixa-preta de WSs podem ser utilizados para gerenciar e executar os casos de teste. Neste trabalho foi utilizada a ferramenta soapUI (soapUI, 2008).

7. Após os casos de teste serem executados, os processos instrumentados gerarão arquivos contendo traces das execuções.

8. Arquivos gerados pelo submódulo GraphGen são utilizados como entrada para o módulo Vali-Elem para gerar os elementos requeridos pelos critérios.

9. Os arquivos com traces da execução dos testes e os elementos requeridos são utilizados como entrada para o módulo Vali-Eval que gera um relatório com a análise de cobertura para os testes realizados.

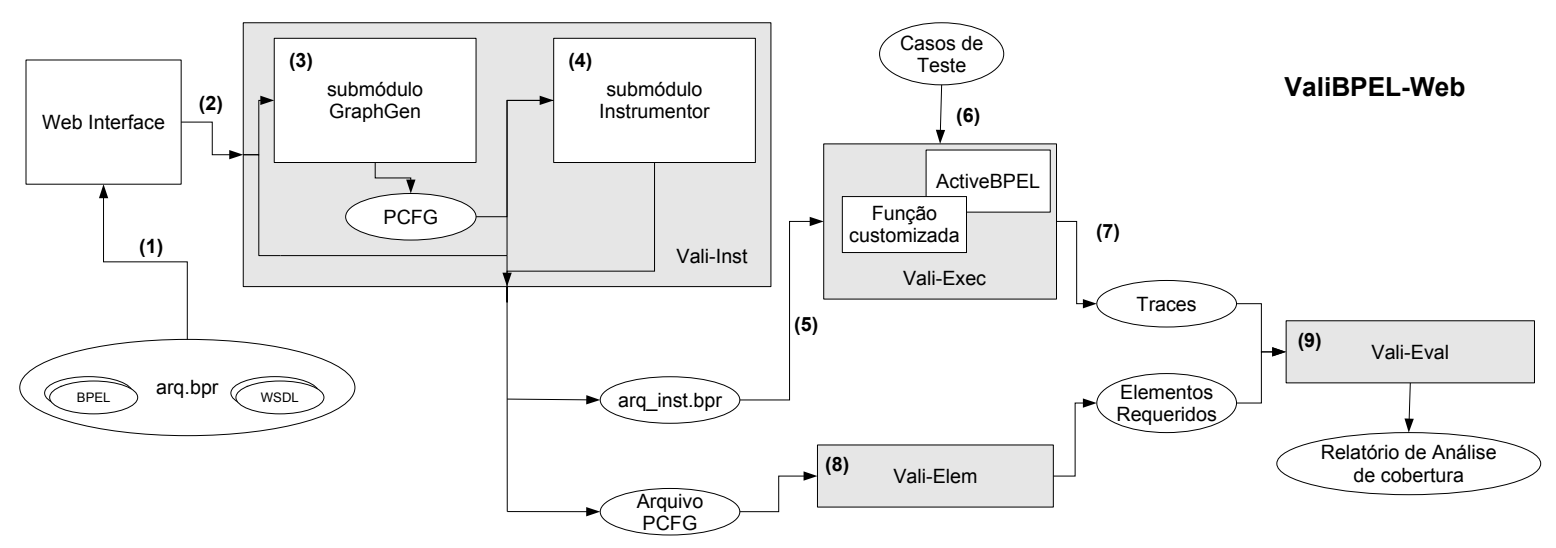

Figura 5.31: Arquitetura da Ferramenta ValiBPEL-Web.

\subsection{Experimentos}

O objetivo dos experimentos realizados foi avaliar se a estratégia proposta era aplicável no teste de CWS especificada em WS-BPEL. Para realizar os experimentos, a estratégia foi aplicada em três exemplos. O estudo experimental foi conduzido com o apoio da ferramenta ValiBPEL-Web 
(Seção 5.6). A ferramenta ValiBPEL-Web foi utilizada para gerar o modelo PCFG e elementos requeridos dos critérios, instrumentar os processos BPEL para gravar os rastros de execução e analisar a cobertura dos testes. O uso da ferramenta facilitou os experimentos e o processo de teste tornou-se menos propenso a erros.

É importante enfatizar que a composição e os WSs participantes são modelados como processos BPEL, mas isso não é necessário para todas as situações. Essa consideração facilitou a implementação da ferramenta e condução do experimento. Apesar disso, a estratégia pode ser aplicada em outros cenários que, por exemplo, usam diferentes linguagens de programação para implementar os WSs. Nesse cenário, ferramentas específicas para cada linguagem deveriam ser utilizadas para a geração dos GFCs.

\subsubsection{Exemplos}

Com o objetivo de avaliar a estratégia de teste proposta, essa foi aplicada em alguns estudos de caso. Os três estudos de casos selecionados e definidos são apresentados a seguir:

1. GCD: esse exemplo é usado no contexto de programas paralelos (extraído de Hausen (2005)). O exemplo consiste de calcular o máximo divisor comum (Greatest Common Divisor) (GCD) entre três números. Existe um processo mestre e três processos escravos. O processo mestre coordena os resultados dos processos escravos. Cada escravo calcula o máximo divisor comum entre dois números. Esse exemplo é interessante porque apresenta diferentes padrões de sincronização.

2. Processo de empréstimo: foi apresentado na Seção 5.3.1.

3. Nice Journey: Nice journey é uma agência de viagens que consulta e/ou reserva viagens. Nesse exemplo, existe um processo principal que pode chamar um processo de reserva e um processo de consulta. Esses processos invocam processos de vôo e hotel para reservar ou consultar. O processo de consulta pode invocar o processo de reserva se o cliente fornecer um valor máximo de aceitação. O processo de reserva chama um outro processo de pagamento. Esse exemplo é uma extensão do apresentado na Seção 2.4.

\subsubsection{Resultados}

Nessa seção, os dados obtidos na realização dos estudos de casos são apresentados. Por não existir outros trabalhos semelhantes que tratem o problema do teste estrutural para CWS, não foi possível efetuar uma comparação com outros trabalhos. O objetivo desse experimento foi aplicar a estratégia proposta em três exemplos, de maneira que diversos cenários fossem exercitados.

Os exemplos são compostos de diferentes processos BPEL e cada processo pode ter zero ou mais instâncias. Isso ocorre porque os processos podem executar diferentes seqüências de atividades e em alguns casos, menos ou mais instâncias podem ser criadas. Na Tabela 5.4, o número de 
diferentes processos BPEL, o número mínimo e o número máximo de instâncias de processos que podem ser criadas são apresentados para cada um dos exemplos.

\begin{tabular}{|l|l|l|l|}
\hline & $\begin{array}{l}\mathbf{N}^{\mathbf{0}} \text { de Pro- } \\
\text { cessos }\end{array}$ & $\begin{array}{l}\mathbf{N}^{\mathbf{0}} \text { mínimo de } \\
\text { instâncias }\end{array}$ & $\begin{array}{l}\mathbf{N}^{\mathbf{0}} \text { máximo de } \\
\text { instâncias }\end{array}$ \\
\hline GCD & 2 & 3 & 4 \\
\hline LoanProcess & 4 & 4 & 4 \\
\hline NiceJourney & 6 & 4 & 8 \\
\hline
\end{tabular}

Tabela 5.4: Tabela de Exemplos.

Na Tabela 5.5, é mostrado o número de nós e arcos, divididos por tipos. Esses valores foram coletados considerando o número máximo de instâncias, de acordo com o modelo PCFG. Tentouse escolher os exemplos de forma que representassem diferentes situações de implementação. $\mathrm{O}$ exemplo GCD contém dois processos, mas possui mais possíveis sincronizações $(\operatorname{arcos}-s)$ que o exemplo LoanProcess. O exemplo LoanProcess contém quatro processos e cada um deles possui somente uma instância. O exemplo NiceJourney contém mais processos que os outros e possui várias instâncias e sincronizações.

\begin{tabular}{|l|l|l|l|}
\hline & GCD & LoanProcess & NiceJourney \\
\hline nós-r & 7 & 9 & 16 \\
\hline nós-s & 7 & 9 & 21 \\
\hline nós & 45 & 63 & 85 \\
\hline arcos-s & 18 & 8 & 30 \\
\hline arcos-intra & 48 & 71 & 88 \\
\hline arcos & 66 & 79 & 118 \\
\hline
\end{tabular}

Tabela 5.5: Tabela de nós e arcos.

Na Tabela 5.6, comparam-se três situações que podem ocorrer usando o modelo PCFG para testar CWS em relação aos arcos inter-processos. O primeiro item é o Lower Bound. Lower Bound é a melhor situação em que somente os arcos inter-processos executáveis estão presentes no PCFG. Esses dados foram obtidos pela eliminação manual dos arcos não-executáveis. O segundo item é o Upper Bound. Upper Bound é uma abordagem conservativa que é implementada pela ferramenta ValiPar (Souza et al., 2005), combinando todos os nós send com todos os nós receive, exceto os que estão no mesmo processo. O último item é a transformação BPEL/PCFG. Como já foi explicado, a transformação proposta neste trabalho usa informações sobre a operation e o PartnerLink para gerar os arcos inter-processos. Esses valores foram coletados usando a ferramenta ValiBPEL-Web.

\begin{tabular}{|l|l|l|l|}
\hline & Lower Bound & Upper Bound & BPEL/PCFG \\
\hline GCD & 8 & 30 & 18 \\
\hline LoanProcess & 8 & 52 & 8 \\
\hline NiceJourney & 20 & 282 & 32 \\
\hline
\end{tabular}

Tabela 5.6: Comparação do número de elementos do critério todos-arcos-s. 
Embora a transformação proposta não elimine todos os arcos inter-processos não-executáveis, os valores apresentados não estão distantes do lower bound e são melhores do que o upper bound. A redução de arcos-s é importante porque o número de elementos de alguns critérios (todos-s-usos, todos-s-c-usos e todos-s-p-usos) diminui a medida que o número de arcos-s diminui. O método proposto na Seção 5.5 pode ser utilizado para que mais arcos inter-processos sejam eliminados.

$\mathrm{Na}$ Tabela 5.7, é apresentado o número de elementos requeridos gerados para os critérios de teste do PCFG. Os dados referentes aos critérios todos-arcos-s, todos-s-usos, todos-s-c-usos e todos-s-p-usos consideram a estratégia deste trabalho para geração de arcos inter-processos (implementada pela ferramenta ValiBPEL-Web). É importante ressaltar que a estratégia proposta gerou um número menor de elementos requeridos que a abordagem conservativa (como demonstrado na Tabela 5.6), melhorando assim a aplicabilidade da estratégia proposta.

\begin{tabular}{|l|l|l|l|}
\hline & GCD & LoanProcess & NiceJourney \\
\hline todos-nós-r & 7 & 9 & 16 \\
\hline todos-nós-s & 7 & 9 & 21 \\
\hline todos-arcos-s & 18 & 8 & 30 \\
\hline todos-s-usos & 18 & 10 & 32 \\
\hline todos-s-c-usos & 36 & 10 & 61 \\
\hline todos-s-p-usos & 36 & 30 & 46 \\
\hline
\end{tabular}

Tabela 5.7: Número de Elementos Requeridos para critérios de cobertura.

Resultados sobre a utilização do conceito de grupos de elementos requeridos foram coletados usando a ferramenta ValiBPEL-Web. Foram calculados quantos elementos requeridos poderiam ser eliminados usando o conceito de grupos de elementos requeridos. Aplicando o conceito de grupos para atividades iniciadoras no exemplo GCD, foram criados 3 grupos com 3 elementos requeridos para o critério todos-arcos-s. Por meio disso, conclui-se que 6 elementos requeridos não precisarão ser cobertos, já que apenas um elemento requerido é coberto por grupo.

Utilizando grupos Pick no exemplo NiceJourney, foram criados 4 grupos de 2 elementos e 4 grupos de 3 elementos para o critério todos-s-c-usos e 4 grupos de 3 elementos para o critério todos$s$-p-usos, usando grupos para a atividade Pick. Então, conclui-se que 12 elementos requeridos do critério todos-s-c-usos e 8 elementos do critério todos-s-p-usos não precisam ser cobertos.

Tendo em vista os resultados apresentados, pode-se perceber que a aplicação da estratégia de teste proposta é possível. A implementação de uma ferramenta de apoio também facilitará a realização de novos estudos com outros exemplos e com outros tipos de dados.

\subsection{Considerações Finais}

Neste capítulo foi apresentada uma proposta para aplicar o modelo PCFG no teste de CWS especificadas em WS-BPEL. Atualmente, poucos trabalhos focam em fornecer mecanismos para teste de CWS, e nenhum artigo foi encontrado, até o momento, em teste estrutural de integração. 
Dessa forma, espera-se que essa estratégia contribua para melhorar a qualidade de CWS, fornecendo requisitos de teste para isso.

O conceito de grupos de elementos requeridos foi proposto para melhorar a cobertura de alguns critérios de teste. Foram definidas duas condições de agrupamento baseadas na atividade Pick e em associações $s$-uso equivalentes (atividades iniciadoras). Neste capítulo também foi apresentado um método para eliminar arcos inter-processos não-executáveis usando redes de Petri. Essa iniciativa é muito interessante porque ao eliminar esses arcos, diminui-se a quantidade de elementos requeridos, facilitando assim a cobertura desses critérios.

Vale ressaltar que a transformação proposta evita a geração de alguns arcos inter-processos não-executáveis. O método que utiliza redes de Petri pode ser aplicado para que mais arcos nãoexecutáveis sejam eliminados. Esses dois fatos contribuem para a diminuição de elementos requeridos de critérios que envolvem pares de sincronização. O conceito de grupos de elementos requeridos também pode ser utilizado nessa direção.

A implementação de uma ferramenta de apoio à estratégia, bem como os resultados de alguns experimentos realizados, demonstram a aplicabilidade da estratégia de teste para melhorar a qualidade da CWS, fornecendo mecanismos para análise de cobertura.

No próximo capítulo, as conclusões deste trabalho de mestrado serão apresentadas, destacando as principais contribuições, limitações e dificuldades encontradas e sugestões de trabalhos futuros. 
Neste trabalho foi apresentada uma estratégia para o teste de CWS especificada em BPEL. Atualmente, poucos trabalhos objetivam fornecer mecanismos para teste de CWS, e nenhum artigo foi encontrado na literatura em teste estrutural de integração aplicado à CWS. Portanto, este trabalho contribui com a melhoria da qualidade da CWS, fornecendo requisitos de teste.

É proposta uma estratégia de teste que, inicialmente, transforma composições BPEL no modelo de teste PCFG. O modelo de teste PCFG fornece uma estrutura para realizar uma análise de cobertura. Uma ferramenta denominada ValiBPEL-Web foi implementada para dar apoio à estratégia de teste proposta. Foi também apresentado um estudo experimental sobre a aplicabilidade da estratégia em alguns estudos de caso.

O conceito de grupos de elementos requeridos foi proposto para melhorar o teste de CWS, diminuindo o número de elementos dos critérios. Esse trabalho definiu duas condições de agrupamento baseadas em atividades pick e atividades iniciadoras do BPEL. O conceito de grupos de elementos também pode ser utilizado em outros contextos, como em programas paralelos, sendo necessário definir condições de agrupamento. Um método baseado em redes de Petri para eliminar arcos inter-processos não-executáveis também foi apresentado. Esse método apresenta dois algoritmos para transformar um PCFG em uma rede de Petri. Por meio dessa rede de Petri, uma árvore de cobertura é gerada para que pares de sincronização não-executáveis sejam identificadas.

\subsection{Contribuições}

Pode-se destacar como principais contribuições deste trabalho: 
- A definição de uma estratégia de teste para composições especificadas em WS-BPEL. A transformação de processos BPEL para o modelo de teste PCFG foi publicada no 1st Brazilian Workshop on Systematic and Automated Software Testing (SAST 2007) (Endo et al., 2007).

- A proposta de grupos de elementos requeridos, conceito usado para melhorar a cobertura dos critérios de teste no contexto de CWS. Esse conceito pode também ser utilizado em outros contextos, como o teste de programas paralelos.

- A implementação da ferramenta ValiBPEL-Web que fornece apoio semi-automatizado à estratégia de teste proposta.

- O método que por meio do PCFG, gera uma representação intermediária em rede de Petri, para a eliminação de arcos inter-processos não-executáveis.

\subsection{Dificuldades e Limitações}

A primeira dificuldade encontrada foi que a liguagem WS-BPEL ainda está em desenvolvimento e padronização, sofrendo, assim, modificações de versão para versão. As engines que utilizam BPEL apresentam diferenças entre suas implementações. Por ser uma linguagem em desenvolvimento, são poucos os exemplos de processos BPEL encontrados na literatura. Dessa forma, os estudos de casos utilizados nos experimentos foram implementados pelo mestrando. Também, não foi possível obter exemplos reais utilizados pela indústria.

Em relação à estratégia proposta, a principal limitação é a impossibilidade de representar concorrência fornecida pela BPEL por meio da atividade Flow. Isso acontece porque o GFC não possibilita a representação de concorrência.

Quanto ao método proposto para eliminar arcos inter-processos não-executáveis, a principal limitação é o custo na geração da árvore de cobertura. Como foi comentando anteriormente, alterações na rede de Petri e extração de mais informações da árvore pode melhorar a relação entre o custo e os benefícios do método.

\subsection{Trabalhos Futuros}

Neste trabalho, considerou-se que um processo BPEL pode ser representado por um GFC, o que não é direto para todos os casos, devido à representação da concorrência. Então, um trabalho futuro seria fornecer um modelo de teste que represente concorrência, estendendo o GFC tradicional. Uma possível solução é tentar adaptar os modelos de Yuan et al. (2006) e/ou Yan et al. (2006) para representar os processos BPEL em teste estrutural.

Outro trabalho futuro é pesquisar quais tipos de erros podem ser revelados usando a estratégia de teste proposta. Um sugestão seria relacionar os critérios de teste com a taxonomia de defeitos 
proposta por Chan et al. (2007) e/ou defeitos padrões existentes na especificação da linguagem BPEL (Jordan et al., 2007).

Existem processos BPEL que são implementados utilizando links em vez de estrutura de controle como laços e desvios. Esses processos são fortemente baseados em expressões condicionais. Como os links são difíceis de representar em modelos baseados em grafos, existe a possibilidade de utilizar critérios de cobertura condição/decisão (Chilenski e Miller, 1994) para esses processos BPEL.

Em relação ao método para eliminação de arcos não-executáveis, seria válido aplicar o método em mais exemplos, tentando avaliar a eficácia do método. Mudanças na rede de Petri e novos algoritmos poderiam ser propostos para reduzir o custo de geração da árvore de cobertura. 

ActiveBPEL The open source BPEL engine. Disponível em: http: / / www a act i vebpel . org/. Último acesso: 15/03/2008, 2006.

Agrawal, H.; Alberi, J. L.; Horgan, J. R.; Li, J. J.; London, S.; Wong, W. E.; Ghosh, S.; WILDE, N. Mining system tests to aid software maintenance. IEEE Computer, v. 31, n. 7, p. 64-73, 1998.

Andrews, T.; Curbera, F.; Dholakia, H.; Goland, Y.; Klein, J.; Leymann, F.; Liu, K.; Roller, D.; Smith, D.; Thatte, S.; Trickovic, I.; WeerawaRANA, S. Business process execution language for web services version 1.1. Disponível em: http://www-128.ibm.com/developerworks/library/specification/ ws-bpel/. Último acesso: 15/03/2008, 2003.

Arkin, A.; Askary, S.; Fordin, S.; Jekeli, W.; KaWaguchi, K.; Orchard, D.; Pogliani, S.; Riemer, K.; Struble, S.; Takacsi-Nagy, P.; Trickovic, I.; Zimek, S. Web service choreography interface (WSCI) 1.0. Disponível em: http://www.w3.org/TR/ wsci/. Último acesso: 15/03/2008, 2002.

Baresi, L.; Bianculli, D.; Ghezzi, C.; Guinea, S.; Spoletini, P. Validation of web service compositions. Software, IET, v. 1, n. 6, p. 219-232, 2007.

Barnes, J. Programming in ada 2005. 1st ed. Addison Wesley, 2006.

Benharref, A.; Dssouli, R.; Glitho, R.; Serhani, M. A. Towards the testing of composed web services in 3rd generation networks. In: Testing of Communicating Systems, Springer Berlin / Heidelberg, 2006, p. 118-133.

BERARDI, D. Automatic service composition: Models, techniques and tools. Tese de Doutoramento, Università degli Studi di Roma "La Sapienza”, Roma, Italy, 2005. 
Berthelot, G.; Roucairol, G.; VAlK, R. Reductions of nets and parallel programs. Net Theory and Applications, p. 277-290, 1980.

Bertolino, A.; Marchetti, E.; PArissis, I. Perspectives on data flow-based validation of web services compositions. In: 3rd ROSATEA Workshop (Role of Software Architecture for Testing and Analysis), Boston, USA, 2007.

Bertolino, A.; Polini, A. The audition framework for testing web services interoperability. In: Software Engineering and Advanced Applications, 2005, 31st EUROMICRO Conference, 2005, p. 134-142.

Betin-Can, A.; Bultan, T. Verifiable web services with hierarchical interfaces. In: IEEE International Conference on Web Services (ICWS'05), Los Alamitos, CA, USA: IEEE Computer Society, 2005, p. 85-94.

Betin-Can, A.; Bultan, T.; Fu, X. Design for verification for asynchronously communicating web services. In: $W W W$ '05: Proceedings of the 14th international conference on World Wide Web, New York, NY, USA: ACM Press, 2005, p. 750-759.

Binder, R. V. Modal testing strategies for oo software. Computer, v. 29, n. 11, p. 97-99, 1996.

BINDER, R. V. Testing object-oriented systems: Models, patterns, and tools. 1st ed. Addison Wesley Longman, Inc., 1248 p., 1999.

BPWS4J Bpws4j a platform for creating and executing bpel4ws processes. Disponível em: http: //www.alphaworks.ibm.com/tech/bpws4j/. Último acesso: 15/03/2008, 2004.

Bucchiarone, A.; Melgratti, H.; Severoni, F. Testing service composition. In: 8th Argentine Symposium on Software Engineering (ASSE'07), Mar del Plata, Argentina, 2007.

Budd, T. A. Mutation analysis: Ideas, example, problems and prospects. Computer Program Testing, p. 129-148, 1981.

CAnfora, G.; Di Penta, M. SOA: Testing and self-checking. In: International Workshop on Web Services - Modeling and Testing - WS-MaTE 2006, Palermo, Italy, 2006, p. 3-12.

Cerami, E. Web services essentials. 1st ed. O'Reilly, 2002.

CHAIm, M. L. Poke-tool - uma ferramenta para suporte ao teste estrutural de programas baseado em análise de fluxo de dados. Dissertação de Mestrado, DCA/FEEC/UNICAMP, Campinas, SP, 1991.

Chamillard, A. T.; Clarke, L. A. Improving the accuracy of petri net-based analysis of concurrent programs. In: ISSTA '96: Proceedings of the 1996 ACM SIGSOFT international symposium on Software testing and analysis, New York, NY, USA: ACM, 1996, p. 24-38. 
Chan, K. M.; Bishop, J.; Steyn, J.; Baresi, L.; Guinea, S. A fault taxonomy for web service composition. In: 3rd International Workshop on Engineering Service Oriented Applications: Analysis, Design and Composition (WESOA'07), Vienna, Austria: ACM, 2007.

Chen, M.; Chen, A. N. K.; Shao, B. B. M. The implications and impacts of web services to eletronic commerce research and pratices. Journal of Electronic Commerce Research, v. 4, n. 4, p. 128-139, 2003.

Cheng, J.; Ushijima, K. Analyzing ada tasking deadlocks and livelocks using extended petri nets. In: Proceedings of the Ada-Europe international conference on ADA : the choice for '92, New York, NY, USA: Springer-Verlag New York, Inc., 1991, p. 125-146.

Chilenski, J.; Miller, S. Applicability of modified condition/decision coverage to software testing. Software Engineering Journal, v. 9, n. 5, p. 193-200, 1994.

Cormen, T. H.; Leiserson, C. E.; Rivest, R. L.; Stein, C. Algoritmos: teoria e prática. 2 ed. Campus, 916 p., 2002.

CRUz Filho, P. N. Teste de software baseado em perturbação de dados dirigidas por padrões. Dissertação de Mestrado, INF/UFPR, Curitiba, PR, 2007.

Cruz Filho, P. N.; Vergilio, S. R. Uma ferramena para o teste de web services baseado em perturbação de dados dirigida por padrões. In: XXI Simpósio Brasileiro de Engenharia de Software - XIV Sessão de Ferramentas, João Pessoa, PB, 2007, p. 63-69.

Curbera, F.; Duftler, M.; Khalaf, R.; Nagy, W.; Mukhi, N.; Weerawarana, S. Unraveling the web services: an introduction to soap, wsdl, and uddi. Internet Computing, v. 6, n. 2, p. 86-93, 2002.

Delamaro, M. E. Proteum - um ambiente de teste baseado na análise de mutantes. Dissertação de Mestrado, ICMC/USP, São Carlos, SP, 1993.

Delamaro, M. E. Mutação de interface: Um critério de adequação interprocedimental para o teste de integração. Tese de Doutoramento, IFSC/USP, São Carlos, SP, 1997.

Delamaro, M. E.; Maldonado, J. C. Proteum/im, version 1.1 c - user's guide. ICMC/USP, 1996.

DeMillo, R. A. Software testing and evaluation. The Benjamim/Commings Publishing Company, Inc, 1978.

DEMillo, R. A. Mutation analysis as a tool for software quality assurance. In: COMPSAC80, Chicago, IL, 1980. 
DeMillo, R. A.; Guindi, D. S.; King, K. N.; McCracken, W. M.; Offutt, A. J. An extended overview of the Mothra software testing environment. In: Second Workshop on Software Testing, Verification and Analysis, Baniff, Canadá, 1988, p. 142-151.

DeMillo, R. A.; Offutt, A. J. Constraint-based automatic test data generation. IEEE Transactions on Software Engineering, v. 17, n. 9, p. 900-910, 1991.

Deutsch, A.; Sui, L.; Vianu, V.; Zhou, D. Verification of communicating data-driven web services. In: PODS '06: Proceedings of the twenty-fifth ACM SIGMOD-SIGACT-SIGART symposium on Principles of database systems, New York, NY, USA: ACM Press, 2006, p. 9099.

Dong, W.-L.; YU, H.; ZHANG, Y.-B. Testing bpel-based web service composition using highlevel petri nets. 10th IEEE International Enterprise Distributed Object Computing Conference, 2006. EDOC '06., p. 441-444, 2006.

Eikerling, H.-J.; Mazzoleni, P.; Plaza, P.; Yankelevich, D.; Wallet, T. Services and mobility: the PLASTIC answer to the beyond $3 \mathrm{G}$ challenge. Disponível em: http: //www.ist-plastic.org/. Último acesso: 15/03/2008, 2007.

Endo, A. T.; Simão, A. S.; SouzA, S. R. S.; SouzA, P. S. L. Aplicação de teste estrutural para composição de web services. 1st Brazilian Workshop on Systematic and Automated Software Testing (SAST'2007) - realizado em conjunto com o XXI Simpósio Brasileiro de Engenharia de Software (SBES'2007), p. 13-20, 2007.

FABBRI, S. C. P. F. A análise de mutantes no contexto de sistemas reativos: Uma contribuição para o estabelecimento de estratégias de teste e validação. Tese de Doutoramento, IFSC/USP, São Carlos, SP, 1996.

Fabbri, S. C. P. F.; Maldonado, J. C.; Delamaro, M. E.; Masiero, P. C. Proteum/FSM - uma ferramenta para apoiar a validação de máquinas de estado finito pelo critério análise de mutantes. In: IX Simpósio Brasileiro de Engenharia de Software, Recife, PE, 1995, p. 475-478.

FAntinato, M. Critérios de teste funcional baseados em máquinas de estados finitos estendidas. Dissertação de Mestrado, DCA/FEEC/UNICAMP, Campinas, SP, 2002.

FERrARA, A. Web services: a process algebra approach. In: ICSOC '04: Proceedings of the 2nd international conference on Service oriented computing, New York, NY, USA: ACM Press, 2004, p. 242-251.

Ferrari, F. C.; Maldonado, J. C.; RAshid, A. Mutation testing for aspect-oriented programs. In: International Conference on Software Testing, Verification and Validation (ICST'2008), Washington, DC - USA: IEEE Computer Society, (accept), 2008. 
Foster, H.; UChitel, S.; Magee, J.; Kramer, J. Model-based verification of web service compositions. In: 18th IEEE International Conference on Automated Software Engineering (ASE'03), Los Alamitos, CA, USA: IEEE Computer Society, 2003.

Foster, H.; UChitel, S.; MAgee, J.; Kramer, J. Compatibility verification for web service choreography. In: IEEE International Conference on Web Services (ICWS'04), 2004, p. 738741.

Foster, H.; UChitel, S.; MAgee, J.; Kramer, J. Tool support for model-based engineering of web service compositions. In: IEEE International Conference on Web Services (ICWS'05), 2005a, p. 95-102.

Foster, H.; Uchitel, S.; Magee, J.; Kramer, J. Model-based analysis of obligations in web service choreography. In: Advanced International Conference on Telecommunications and International Conference on Internet and Web Applications and Services (AICT/ICIW 2006), 2006.

Foster, H.; UChitel, S.; MAgee, J.; Kramer, J.; Hu, M. Using a rigorous approach for engineering web service compositions: A case study. In: IEEE International Conference on Services Computing (SCC'05), 2005b, p. 217-224.

Frankl, P.; Weyuker, E. A data flow testing tool. In: Proceedings of IEEE Softfair II Conference on Software Development Tools, Techniques, and Alternatives, 1985, p. 46-53.

Frankl, P. G.; WeyUKer, E. J. A formal analysis of the fault-detecting ability of testing methods. IEEE Transactions on Software Engineering, v. 19, n. 3, p. 202-213, 1993.

FU, X.; Bultan, T.; Su, J. Analysis of interacting bpel web services. In: WWW '04: Proceedings of the 13th international conference on World Wide Web, New York, NY, USA: ACM Press, 2004, p. 621-630.

FU, Y.; Dong, Z.; HE, X. Modeling, validating and automating composition of web services. In: ICWE '06: Proceedings of the 6th international conference on Web engineering, New York, NY, USA: ACM Press, 2006, p. 217-224.

García-FAnJul, J.; Riva, C.; TUYA, J. Generation of conformance test suites for compositions of web services using model checking. In: Testing: Academic \& Industrial Conference Practice And Research Techniques (TAIC PART'06), 2006, p. 127-130.

GenRICH, H. J. Predicate/transition nets. In: Advances in Petri Nets, Springer-Verlag, 1987, p. 207-247 (Lecture Notes in Computer Science, v.254).

Goldberg, A.; WAng, T. C.; Zimmerman, D. Applications of feasible path analysis to program testing. In: ISSTA '94: Proceedings of the 1994 ACM SIGSOFT international symposium on Software testing and analysis, New York, NY, USA: ACM, 1994, p. 80-94. 
Gottschalk, K.; Graham, S.; Kreger, H.; Shell, J. Introduction to web services architecture. IBM Systems journal, v. 41, p. 170-177, 2002.

Hamadi, R.; Benatallah, B. A petri net-based model for web service composition. In: ADC '03: Proceedings of the 14th Australasian database conference, Darlinghurst, Australia, Australia: Australian Computer Society, Inc., 2003, p. 191-200.

Hausen, A. C. Valimpi: Uma ferramenta de teste estrutural para programas paralelos no ambiente de passagem de mensagem mpi. Dissertação de Mestrado, INF/UFPR, Curitiba, PR, 2005.

Henzinger, T. A.; Jhala, R.; Majumdar, R.; Sutre, G. Lazy abstraction. In: POPL '02: Proceedings of the 29th ACM SIGPLAN-SIGACT symposium on Principles of programming languages, New York, NY, USA: ACM Press, 2002, p. 58-70.

Holzmann, G. J. The spin model checker: Primer and reference manual. Addison-Wesley, Boston, Massachusetts, 2003.

Horgan, J. R.; London, S. A. Data flow coverage and the C language. In: Symposium Software Testing, Analysis, and Verification, 1991, p. 87-97.

HuAng, H.; TsaI, W.-T.; PAUl, R. Proof slicing with application to model checking web services. In: the Eighth IEEE International Symposium on Object-Oriented Real-Time Distributed Computing (ISORC'05), 2005a, p. 292-299.

Huang, H.; Tsai, W.-T.; PAul, R.; Chen, Y. Automated model checking and testing for composite web services. In: 8th International Symposium on Object-Oriented Real-Time Distributed Computing (ISORC'05), 2005b, p. 300-307.

IEEE IEEE standard glossary of Software Engineering terminology. Padrão 620.12, IEEE, 1990.

Jensen, K. Coloured petri nets: Practical use. 2nd ed. Berlin: Springer, 1997.

JOPERA Jopera project: Process support for more than web services. Disponível em: http: //www.iks. ethz. ch/ jopera. Último acesso: 15/03/2008, 2004.

Jordan, D.; Evdemon, J.; Alves, A.; Arkin, A.; Askary, S.; Barreto, C.; Bloch, B.; Curbera, F.; Ford, M.; Goland, Y.; Guízar, A.; Kartha, N.; LiU, C. K.; Khalaf, R.; Konig, D.; Marin, M.; Mehta, V.; Thatte, S.; Rijn, D.; Yendluri, P.; Yiu, A. Oasis web services business process execution language (wsbpel) v2.0. Disponível em: http: //docs.oasis-open.org/wsbpel/2 . 0/. Último acesso: 15/03/2008, 2007.

JURIC, M. B. Bpel and java. Disponível em: http://www.theserverside.com/tt/ articles/article.tss? l=BPELJava. Último acesso: 15/03/2008, 2005. 
KARP, R. M.; Miller, R. E. Parallel program schemata. Journal of Computer and System Sciences, v. 3, n. 2, p. 147-195, 1969.

Katayama, T.; Furukawa, Z.; Ushijima, K. Design and implementation of test-case generation for concurrent programs. In: Asia Pacific Software Engineering Conference (APSEC), Los Alamitos, CA, USA: IEEE Computer Society, 1998.

Katayama, T.; Itoh, E.; Ushijima, K.; Furukawa, Z. Test-case generation for concurrent programs with the testing criteria using interaction sequences. In: Asia Pacific Software Engineering Conference (APSEC), Los Alamitos, CA, USA: IEEE Computer Society, 1999.

Kavantzas, N.; Burdett, D.; Ritzinger, G.; Fletcher, T.; Lafon, Y.; Barreto, C. Web services choreography description language version 1.0. Disponível em: http: //www . w3 . org/TR/ws-cdl-10/. Último acesso: 15/03/2008, 2005.

Kazhamiakin, R.; Pistore, M.; Santuari, L. Analysis of communication models in web service compositions. In: $W W W$ '06: Proceedings of the 15th international conference on World Wide Web, New York, NY, USA: ACM Press, 2006, p. 267-276.

Keen, M.; Cavell, J.; Hill, S.; Kee, C. K.; Neave, W.; Rumph, B.; Tran, H. Bpel4ws business processes with websphere business integration: Understanding, modeling, migrating. 1st ed. IBM, 2004.

KRAWCZYK, H.; WISZNIEWSKI, B. Classification of software defects in parallel programs. Relatório Técnico 2, Faculty of Electronics, Technical University of Gdansk, Poland, 1994.

KREGER, H. Web services conceptual architecture (wsca 1.0). IBM, disponível em: http: //www-306.ibm.com/software/solutions/webservices/pdf / WSCA. pdf. Último acesso: 15/03/2008, 2001.

Kumar, D.; Harous, S. Distributed simulation of timed petri nets: Basic problems and their resolution. In: IEEE Systems, Man and Cybernetics, 1994, p. 1498-1510.

LARMAN, C. Utilizando uml e padrões : uma introdução à análise e ao projeto orientados a objetos e ao desenvolvimento iterativo. 3 ed. Bookman, 695 p., 2007.

Lemos, O. A. L. Teste de programas orientado a aspectos: uma abordagem estrutural para aspectj. Dissertação de Mestrado, ICMC/USP, São Carlos, SP, 2005.

Leung, H.; White, L. Insights into regression testing. Proceedings of Conference on Software Maintenance, p. 60-69, 1989.

LI, Z.; SUN, W.; JiAng, Z. B.; ZHANG, X. Bpel4ws unit testing: Framework and implementation. In: IEEE International Conference on Web Services (ICWS'05), 2005, p. 103-110. 
Linkman, S.; VincenZI, A. M. R.; Maldonado, J. An evaluation of systematic functional testing using mutation testing. In: 7th International Conference on Empirical Assessment in Software Engineering - EASE, Keele, UK, 2003, p. 1-15.

LIPTON, R. The reachability problem and the boundedness problem for petri nets are exponentialspace hard. In: Conference on Petri Nets and Related Methods, MIT, 1975.

Maldonado, J. C. Critérios potenciais usos: Uma contribuição ao teste estrutural de software. Tese de doutoramento, DCA/FEE/UNICAMP, Campinas, SP, 1991.

Maldonado, J. C.; Auri, E. F. B.; Vincenzi, M. R.; Delamaro, M. E.; Souza, S.; Jino, M. Introdução ao teste de software. Instituto de Ciências Matemáticas e de Computação ICMC-USP, nota Didática n. 65, 2004.

Martins, E.; Toyota, C. M. Construção de classes autotestáveis. In: VIII SCTF - Simpósio de Computação Tolerante a Falhas, Campinas, SP, 1999, p. 196-209.

Masiero, P. C.; Lemos, O. A. L.; Ferrari, F. C.; Maldonado, J. C. Teste de software orientado a objetos e a aspectos: Teoria e prática. In: Breitman, K.; Anido, R., eds. Atualizações em Informática, cáp. 1, Rio de Janeiro/RJ - Brasil: Editora PUC-Rio, p. 13-71, 2006.

Mathur, A. P. On the relative strengths of data flow and mutation testing. In: Ninth Annual Pacific Northwest Software Quality Conference, Portland, OR, 1991, p. 165-181.

Mathur, A. P.; Wong, W. E. An empirical comparison of data flow and mutation based test adequacy criteria. The Journal of Software Testing, Verification, and Reliability, v. 4, n. 1, p. 9-31, 1994.

MAYER, P.; LÜBKE, D. Towards a bpel unit testing framework. In: TAV-WEB '06: Proceedings of the 2006 workshop on Testing, analysis, and verification of web services and applications, New York, NY, USA: ACM Press, 2006, p. 33-42.

McGuinness, D. L.; Harmelen, F. Owl web ontology language overview. Disponível em: http: / /www.w3.org/TR/owl-features/. Último acesso: 15/03/2008, 2004.

MEI, H.; ZhANG, L. A framework for testing web services and its supporting tool. In: IEEE International Workshop on Service-Oriented System Engineering, 2005, p. 207-214.

Milanovic, N.; MaleK, M. Current solutions for web service composition. IEEE Internet Computing, v. 8, n. 6, p. 51-59, 2004.

Milner, R. Communicating and mobile systems: the pi-calculus. 1st ed. Cambridge University Press, 1999. 
Murata, T. Petri nets: Properties, analysis and applications. Proceedings of the IEEE, v. 77, n. 4, p. 541-580, 1989.

Murata, T.; Shenker, B.; Shatz, S. Detection of ada static deadlocks using petri net invariants. IEEE Transactions on Software Engineering, v. 15, n. 3, p. 314-326, 1989.

Myers, G. J.; SAndler, C.; BAdgett, T.; Thomas, T. M. The art of software testing. John Wiley \& Sons, Inc., Hoboken, New Jersey, 2004.

NARAyanan, S.; McIlraith, S. A. Simulation, verification and automated composition of web services. In: $W W W$ '02: Proceedings of the 11th international conference on World Wide Web, New York, NY, USA: ACM Press, 2002, p. 77-88.

NeWCOMER, E. Understanding web services: XML, WSDL, SOAP and UDDI. 1st ed. Addison Wesley, 2002.

Newcomer, E.; Lomow, G. Uunderstanding soa with web services. 1st ed. Addison-Wesley Professional, 2004.

NTAFos, S. C. A comparison of some structural testing strategies. IEEE Transactions on Software Engineering, v. 14, n. 6, p. 868-873, 1988.

OASIS Uddi specifications tc. Disponível em: http://www.oasis-open.org/ committees/uddi-spec/doc/tcspecs . htm. Último acesso: 15/03/2008, 2005.

OfFUtT, A. J.; IRVINE, A. Testing object-oriented software using the category-partition method. In: 17th International Conference on Technology of Object-Oriented Languages and Systems, Santa Barbara, CA: Prentice-Hall, 1995, p. 293-304.

Offutt, A. J.; Lee, A.; Rothermel, G.; Untch, R. H.; ZAPF, C. An experimental determination of sufficient mutant operators. ACM Transactions on Software Engineering Methodology, v. 5, n. 2, p. 99-118, 1996.

Offutt, A. J.; PAn, J. Automatically detecting equivalent mutants and infeasible paths. Software Testing, Verification and Reliability, v. 7, n. 3, p. 165-192, 1997.

Offutt, J.; Liu, S.; Abdurazik, A.; Ammann, P. Generating test data from state-based specifications. The Journal of Software Testing, Verification, and Reliability, v. 13, n. 1, p. 25$53,2003$.

OfFutT, J.; XU, W. Generating test cases for web services using data perturbation. SIGSOFT Softw. Eng. Notes, v. 29, n. 5, p. 1-10, 2004.

ORACLE Oracle bpel process manager 2.0 - quick start tutorial. Disponível em: http://www.oracle.com/technology/products/ias/bpel/pdf/ orabpel-Quickstart.pdf. Último acesso: 22/06/2007, 2004. 
OSTRAND, T. J.; BALCER, M. J. The category-partition method for specifying and generating fuctional tests. Commun. ACM, v. 31, n. 6, p. 676-686, 1988.

OStRAnd, T. J.; WeYUKER, E. J. Data flow based test adequacy analysis for languages with pointers. In: Symposium on Software Testing, 1996, p. 74-86.

Papazoglou, M. P.; Georgakopoulos, D. Service-oriented computing. Commun. ACM, v. 46, n. 10, p. 24-28, 2003.

PAutAsso, C. Jopera: an agile environment for web service composition with visual unit testing and refactoring. In: IEEE Symposium on Visual Languages and Human-Centric Computing (VL/HCC'05), 2005, p. 311-313.

Peltz, C. Web services orchestration and choreography. Computer, v. 36, p. 46 - 52, 2003.

Perry, D. E.; KAISER, G. E. Adequate testing and object-oriented programming. J. Object Oriented Program., v. 2, n. 5, p. 13-19, 1990.

Peterson, J. L. Petri net theory and the modeling of systems. New Jersey: Prentice-Hall, Englewood Cliffs, 1981.

PInto, I. Um sistema de apoio ao teste de aplicações smalltalk. Dissertação de Mestrado, CPGCC/UFRGS, Porto Alegre, RS, 1998.

Pressman, R. S. Software engineering: A practitioner's approach. 6th ed. McGraw-Hill, 2005.

RAmalingam, G. Context-sensitive synchronization-sensitive analysis is undecidable. ACM Transactions on Programming Languages and Systems, v. 22, n. 2, p. 416-430, 2000.

RAmamoorthy, C.; BAstani, F. Software reliability - status and perspectives. IEEE Transactions on Software Engineering, v. 8, n. 4, p. 354-371, 1982.

RAPPS, S.; WeyUKer, E. J. Selecting software test data using data flow information. IEEE Transactions on Software Engineering, v. 11, n. 4, p. 367-375, 1985.

Rocha, A. D.; Silva Simão, A.; Maldonado, J. C.; Masiero, P. C. Uma ferramenta baseada em aspectos para o teste funcional de programas java. In: XIX SBES - Simpósio Brasileiro de Engenharia de Software, Uberlândia, MG, Brasil, 2005, p. 263-278.

Roy, J.; Ramanujan, A. Understanding web services. IT Professional, v. 3, n. 6, p. 69-73, 2001.

Siblini, R.; MAnsour, N. Testing web services. In: The 3rd ACS/IEEE International Conference on Computer Systems and Applications, 2005. 
SILVEIRA, F. Ferramenta de apoio ao teste de aplicações java baseada em reflexão computacional. Dissertação de Mestrado, CPGCC/UFRGS, Porto Alegre, RS, 2001.

SimÃo, A. S. Proteum-RS/PN: Uma ferramenta para a validação de redes de Petri baseada na análise de mutantes. Dissertação de Mestrado, ICMC/USP, São Carlos, SP, 2000.

Simão, A. S. Aplicação da análise de mutantes no contexto do teste e validação de redes de petri coloridas. Tese de Doutoramento, ICMC/USP, São Carlos, SP, 2004.

Simão, A. S.; Maldonado, J. C. Mutation based test sequence generation for Petri nets. In: Proceedings of III Workshop of Formal Methods, João Pessoa, PB, 2000, p. 68-79.

Simão, A. S.; Maldonado, J. C.; Fabbri, S. C. P. F. Proteum-RS/PN: A tool to support edition, simulation and validation of Petri nets based on mutation testing. In: Anais do XIV Simpósio Brasileiro de Engenharia de Software, João Pessoa, PB, 2000, p. 227-242.

SOAP Soap specifications. Disponível em: http://www.w3.org/TR/soap/. Último acesso: 15/03/2008, 2003.

SOAPUI the web service, soa and soap testing tool - soapUI. Disponível em: http: / / www . soapui .org/. Último acesso: 15/03/2008, 2008.

Sommerville, I. Engenharia de software. 6 ed. Addison Wesley, 2003.

Souza, S.; S.R., V.; Souza, P.; Simão, A.; Bliscosque, T.; Lima, A.; Hausen, A. Valipar: A testing tool for message-passing parallel programs. In: International Conference on Software knowledge and Software Engineering - SEKE05), Taipei-Taiwan, 2005, p. 386-391.

SouzA, S. R. S. Avaliação do custo e eficácia do critério análise de mutantes na atividade de teste de software. Dissertação de Mestrado, Instituto de Ciências Matemáticas e de Computação da Universidade de São Paulo (ICMC/USP), São Carlos, SP, 1996.

SugetA, T. Proteum-RS/ST: Uma ferramenta para apoiar a validação de especificações statecharts baseada na análise de mutantes. Dissertação de Mestrado, ICMC/USP, São Carlos, SP, 1999.

Sun The source for java developers. Disponível em: http:// java.sun.com/. Último acesso: 22/06/2007, 2007.

Sun Microsystems Model-view-controller. Disponível em: http://java.sun.com/ blueprints/patterns/MVC . html. Último acesso: 22/03/2008, 2002.

TAYLOR, R. N. Complexity of analyzing the synchronization structure of concurrent programs. Acta Informatica, v. 19, n. 1, p. 57-84, 1983. 
Tsai, W. T.; Chen, Y.; Paul, R.; LiaO, N.; Huang, H. Cooperative and group testing in verification of dynamic composite web services. In: the 28th Annual International Computer Software and Applications Conference (COMPSAC'04), 2004, p. 170-173.

Tsai, W. T.; PAul, R.; Song, W.; CAO, Z. Coyote: an xml-based framework for web services testing. In: 7th IEEE International Symposium on High Assurance Systems Engineering, 2002a, p. 173-174.

Tsai, W. T.; PAul, R.; WAng, Y.; FAn, C.; WAnG, D. Extending wsdl to facilitate web services testing. In: Proceedings of the 7th IEEE International Symposium on High Assurance Systems Engineering (HASE'02), 2002b, p. 171-172.

VAsconcelos, D. R. Análise de estratégias utilizando verificação formal de modelos. Dissertação de mestrado, PUC/RIO, Rio de Janeiro, RJ, 2003.

Vergilio, S. R.; SouzA, S. R. S.; SouzA, P. S. L. Coverage testing criteria for messagepassing parallel programs. In: LATW2005 - 6th IEEE Latin-AmericanTestWorkshop, Salvador, Ba, 2005, p. 161-166.

Vilela, P. R.; Maldonado, J. C.; Jino, M. Program graph visualization. Software-Practice \& Experience, v. 27, n. 11, p. 1245-1262, 1997.

Vincenzi, A. M. R. Orientação a objeto: Definição e análise de recursos de teste e validação. Tese de Doutoramento, ICMC/USP, São Carlos, SP, 2004.

Vincenzi, A. M. R.; Wong, W. E.; Delamaro, M. E.; Maldonado, J. C. JaBUTi: A coverage analysis tool for Java programs. In: XVII SBES - Simpósio Brasileiro de Engenharia de Software, Manaus, AM, Brasil, 2003, p. 79-84.

W3C Web services description language (wsdl). Disponível em: http://www.w3.org/ TR/wsdl. Último acesso: 15/03/2008, 2001.

W3C Web services activity. Disponível em: http://www.w3.org/2002/ws/. Último acesso: 15/03/2008, 2002.

W3C Extensible markup language (xml). Disponível em: http://www.w3.org/XML/. Último acesso: 15/03/2008, 2003.

W3C Document object model (dom). Disponível em: http: / /www . w3 . org/DOM/. Último acesso: 15/03/2008, 2005.

Weyuker, E. J. The complexity of data flow citeria for test data selection. Information Processing Letters, v. 19, n. 2, p. 103-109, 1984. 
WeyUKer, E. J. The cost of data flow testing: an empirical study. IEEE Transactions on Software Engineering, v. 16, n. 2, p. 121-128, 1990.

Weyuker, E. J.; Weiss, S. N.; HAMlet, R. G. Comparison of program testing strategies. In: 4th Symposium on Software Testing, Analysis and Verification, Victoria, British Columbia, Canada, 1991, p. 1-10.

WONG, W. E.; LEI, Y.; MA, X. Effective generation of test sequences for structural testing of concurrent programs. In: 10th IEEE International Conference on Engineering of Complex Computer Systems (ICECCS'05), Los Alamitos, CA, USA: IEEE Computer Society, 2005, p. 539-548.

Wong, W. E.; Mathur, A. P. Fault detection effectiveness of mutation and data flow testing. Software Quality Journal, v. 4, n. 1, p. 69-83, 1995.

Wong, W. E.; Mathur, A. P.; Maldonado, J. C. Mutation versus all-uses: An empirical evaluation of cost, strength and effectiveness, cáp. 40 London: Chapmann \& Hall, p. 258-265, 1995.

YAn, J.; LI, Z.; YuAn, Y.; Sun, W.; ZHANG, J. Bpel4ws unit testing: Test case generation using a concurrent path analysis approach. 17th International Symposium on Software Reliability Engineering (ISSRE'06), v. 0, p. 75-84, 2006.

YAnG, C.-S. D.; Pollock, L. All-uses testing of shared memory parallel programs. Software Testing, Verification and Reliability (STVR), v. 13, n. 1, p. 3-24, 2003.

YANG, C.-S. D.; Souter, A. L.; POLlOCK, L. L. All-du-path coverage for parallel programs. In: ISSTA '98: Proceedings of the 1998 ACM SIGSOFT international symposium on Software testing and analysis, New York, NY, USA: ACM Press, 1998, p. 153-162.

YANG, Y.; TAN, Q.; XIAO, Y.; YU, J.; LIU, F. Verifying web services composition: A transformation-based approach. In: PDCAT '05: Proceedings of the Sixth International Conference on Parallel and Distributed Computing Applications and Technologies, Washington, DC, USA: IEEE Computer Society, 2005a, p. 546-548.

YAnG, Y.; TAN, Q.; XIAO, Y.; YU, J.; LIU, F. Exploiting hierarchical cp-nets to increase the reliability of web services workflow. In: SAINT '06: Proceedings of the International Symposium on Applications on Internet, Washington, DC, USA: IEEE Computer Society, 2006, p. 116-122.

YAnG, Y.; TAN, Q.; YU, J.; LIU, F. Transformation bpel to cp-nets for verifying web services composition. In: International Conference on Next Generation Web Services Practices (NWeSP'05), 2005b. 
YUAN, Y.; LI, Z.; SUN, W. A graph-search based approach to bpel4ws test generation. In: International Conference on Software Engineering Advances (ICSEA'06), Los Alamitos, CA, USA: IEEE Computer Society, 2006.

Zeng, L.; Benatallah, B.; Dumas, M.; Kalagnanam, J.; Sheng, Q. Z. Quality driven web services composition. In: $W W W$ '03: Proceedings of the 12th international conference on World Wide Web, New York, NY, USA: ACM Press, 2003, p. 411-421.

ZHU, H. A formal analysis of the subsume relation between software test adequacy criteria. IEEE Transactions on Software Engineering, v. 22, n. 4, p. 248-255, 1996.

Zhu, H.; Hall, P. A. V.; MAY, J. H. R. Software unit test coverage and adequacy. ACM Computing Surveys (CSUR), v. 29, n. 4, p. 366-427, 1997. 
APÊNDICE

\section{$A$}

Códigos BPEL

Listagem A.1: Código BPEL para o problema NiceJourney.

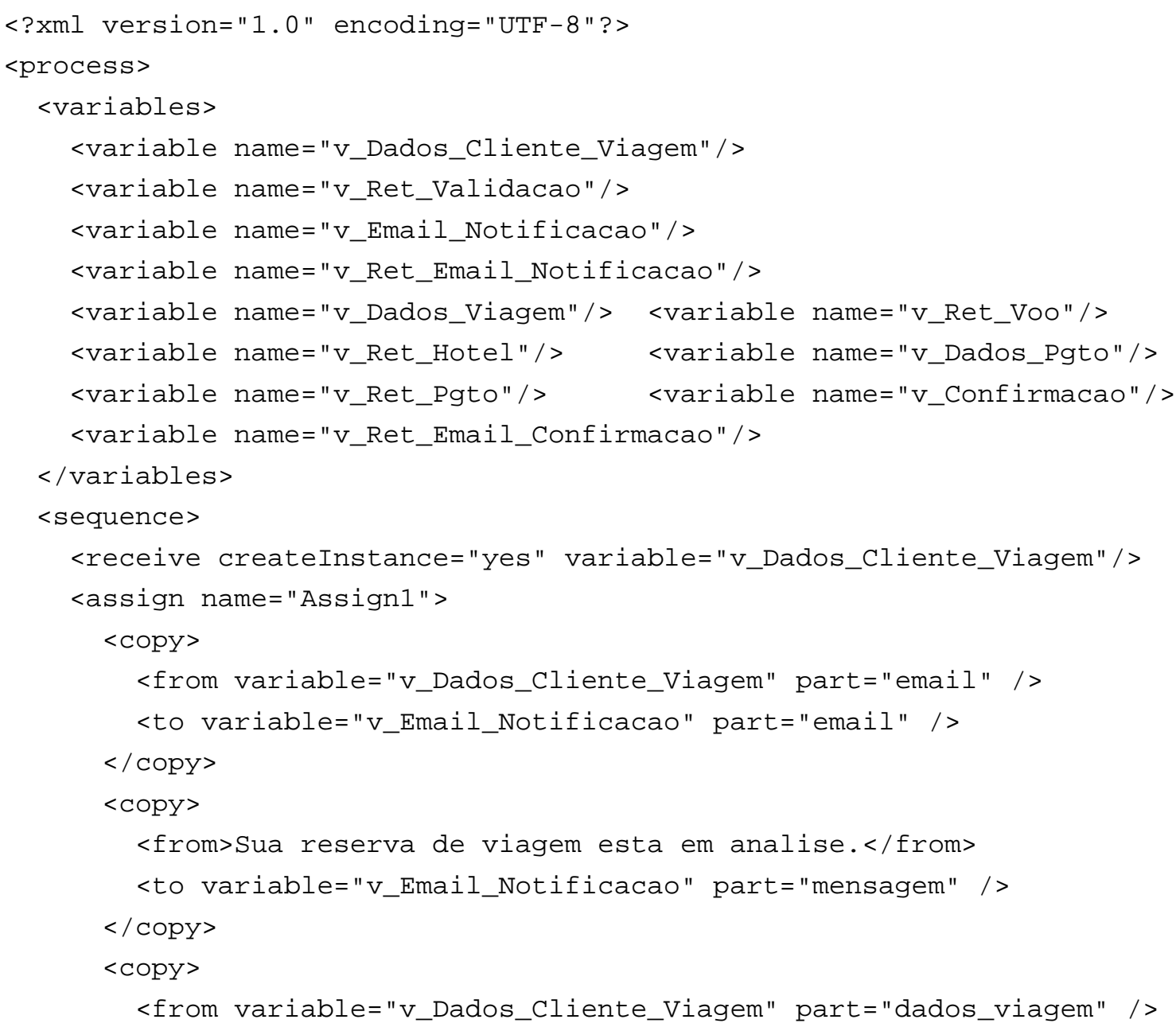




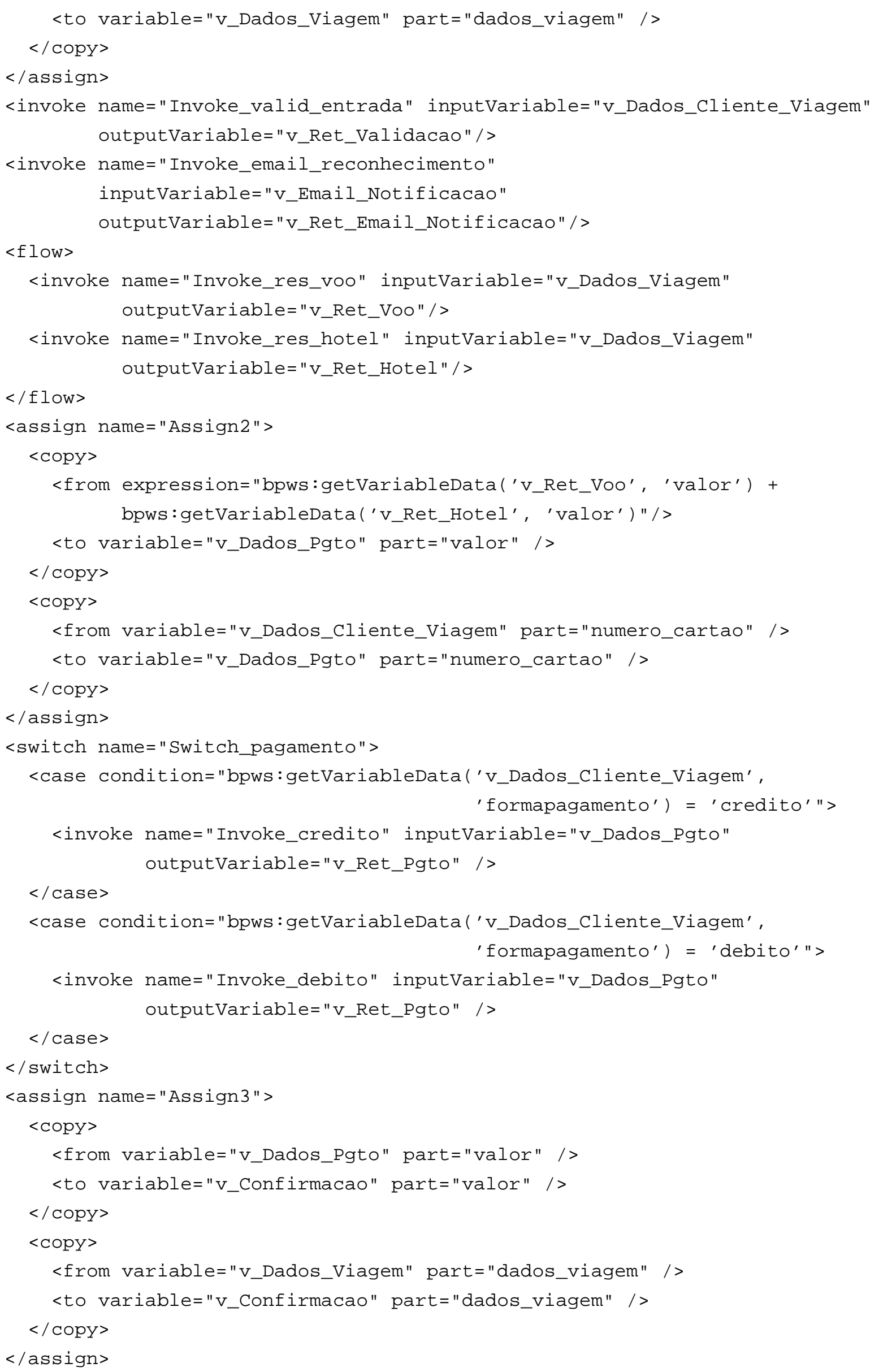


<invoke name="Invoke_email_confirmacao" inputVariable="v_Confirmacao" outputVariable="v_Ret_Email_Confirmacao" />

$<$ reply variable="v_Confirmacao"/>

$</$ sequence $>$

$</$ process $>$ 